NBSIR 85-3143

\title{
Influence of Block and Mortar Strength on Shear Resistance of Concrete Block Masonry Walls
}

Kyle Woodward

Frank Rankin

U.S. DEPARTMENT OF COMMERCE

National Bureau of Standards

National Engineering Laboratory

Center for Building Technology

Gaithersburg, MD 20899

April 1985

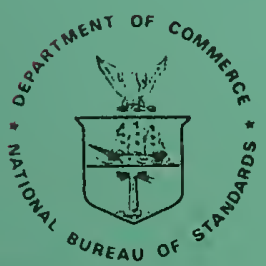

S. DEPARTMENT OF COMMERCE

100 TIONAL BUREAU OF STANDARDS

.456

$85-3143$

1985 

NBSIR $85-3143$

...

INFLUENCE OF BLOCK AND MORTAR

STRENGTH ON SHEAR RESISTANCE OF CONCRETE BLOCK MASONRY WALLS

Kyle Woodward

Frank Rankin

U.S. DEPARTMENT OF COMMERCE

National Bureau of Standards

National Engineering Laboratory

Center for Building Technology

Gaithersburg, MD 20899

April 1985

U.S. DEPARTMENT OF COMMERCE, Malcolm Baldrige, Secretary NATIONAL BUREAU OF STANDARDS. Emest Ambler, Director 



\begin{abstract}
Data from seventeen masonry wall panel tests are presented. All of the walls are ungrouted, unreinforced, and constructed with hollow concrete block. The primary variables in the test series are block and mortar strength, but the applied vertical compressive stress and wall aspect ratio are also varied. The walls are built with either a "high" strength block or a "low" strength block having gross area unit strengths of approximately 1800 psi and 1300 psi, respectively. The mortar is either a Type $\mathrm{S}$ or a Type $\mathrm{N}$ mortar and, for convenience, is identified as high and low strength mortar, respectively. Thirteen of the wall panels have nominal dimensions of $64 \mathrm{in}$. long $\mathrm{x} 64 \mathrm{in}$. high $\times 8$ in. thick, but two of the walls are 96 in. long and the remaining two walls are $48 \mathrm{in}$. long. The applied net area vertical compressive stress is constant for a given test, but varies between $100 \mathrm{psi}$ and $400 \mathrm{psi}$ for tests in the series reported herein. The walls are tested in the NBS Tri-directional Test Facility using fixed-ended boundary conditions at the top and bottom of the walls. A vertical compressive stress is applied and maintained while in-plane lateral displacements are imposed at the top of the wall. The test results indicate that for the lower levels of vertical compressive stress the effect of block and mortar strength on maximum in-plane shear resistance is relatively small, while with increased vertical compressive stress the effect of increasing material strength becomes significant and results in increased shear resistance. There is an interaction between the block and mortar strength such that the wall behavior may not be adequately predicted by considering the two strengths independently.
\end{abstract}




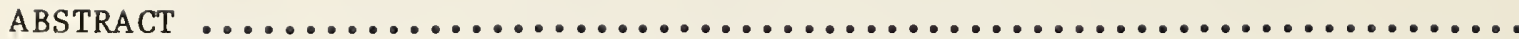

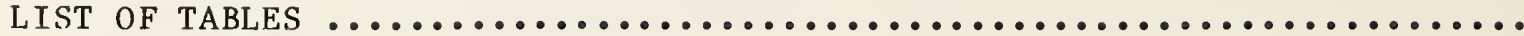

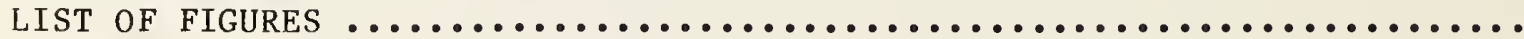

1. INTRODUCTION $\ldots \ldots \ldots \ldots \ldots \ldots \ldots \ldots \ldots \ldots \ldots \ldots \ldots \ldots \ldots \ldots \ldots \ldots \ldots \ldots \ldots \ldots \ldots \ldots$

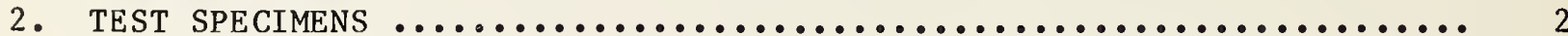

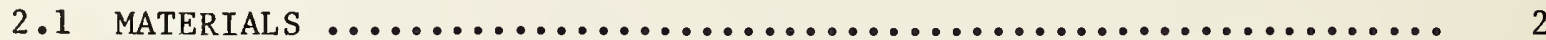

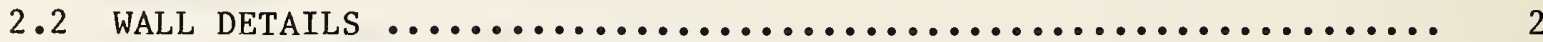

2.3 TEST SETUP AND INSTRUMENTATION $\ldots \ldots \ldots \ldots \ldots \ldots \ldots \ldots \ldots \ldots \ldots \ldots \ldots \ldots \ldots$

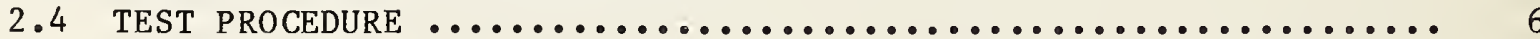

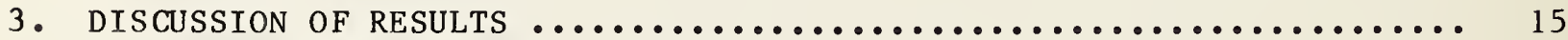

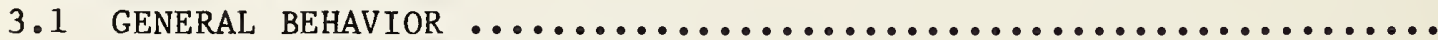

3.2 MAXIMUM IN-PLANE RESISTANCE $\ldots \ldots \ldots \ldots \ldots \ldots \ldots \ldots \ldots \ldots \ldots \ldots \ldots \ldots \ldots$

3.3 SHEAR STRESS-DISPLACEMENT RELATIONSHIP $\ldots \ldots \ldots \ldots \ldots \ldots \ldots \ldots \ldots \ldots$

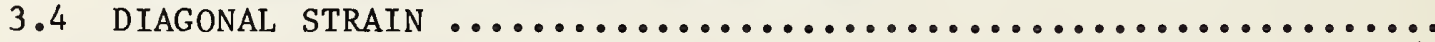

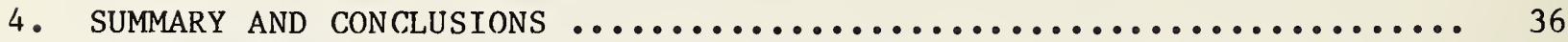

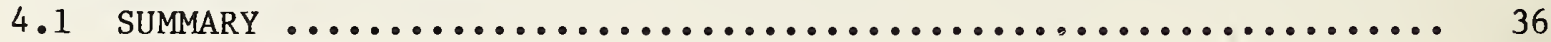

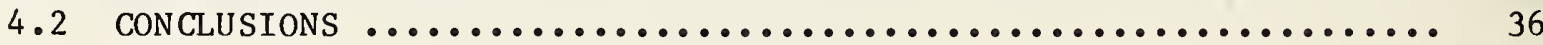

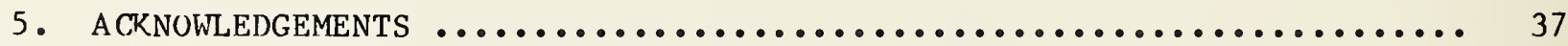

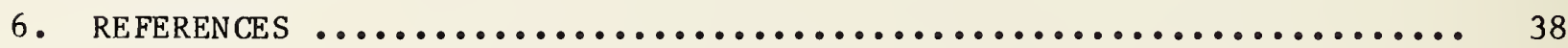

APPENDICES $\ldots \ldots \ldots \ldots \ldots \ldots \ldots \ldots \ldots \ldots \ldots \ldots \ldots \ldots \ldots \ldots \ldots \ldots \ldots \ldots \ldots \ldots \ldots \ldots \ldots \ldots$

A. OVERVIEW OF MASONRY RESEARCH PROGRAM $\ldots \ldots \ldots \ldots \ldots \ldots \ldots \ldots \ldots \ldots \ldots \ldots \ldots \ldots$ A 1

B. MATERIALS ......................................... B-1

B.1 CONCRETE MASONRY UNITS $\ldots \ldots \ldots \ldots \ldots \ldots \ldots \ldots \ldots \ldots \ldots \ldots \ldots \ldots \ldots \ldots \ldots \ldots$

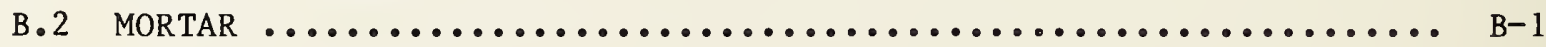

C. WALL PANEL DESCRIPTION $\ldots \ldots \ldots \ldots \ldots \ldots \ldots \ldots \ldots \ldots \ldots \ldots \ldots \ldots \ldots \ldots \ldots \ldots \ldots \ldots . \ldots \ldots$

C.1 WALL PANEL FABRICATION $\ldots \ldots \ldots \ldots \ldots \ldots \ldots \ldots \ldots \ldots \ldots \ldots \ldots \ldots \ldots \ldots \ldots . . \ldots \ldots$

C. 2 PRISM FABRICATION $\ldots \ldots \ldots \ldots \ldots \ldots \ldots \ldots \ldots \ldots \ldots \ldots \ldots \ldots \ldots \ldots \ldots \ldots \ldots \ldots . \ldots \ldots$

D. WALl PANEL TESTS: SETUP AND PlACEMENT $\ldots \ldots \ldots \ldots \ldots \ldots \ldots \ldots \ldots \ldots \ldots \ldots \ldots$ D 1

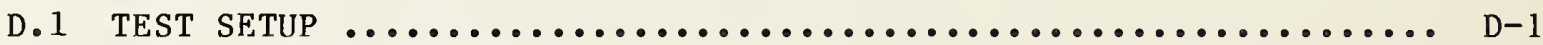

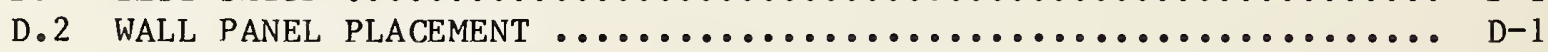

E. WALL PANEL LOAD-DISPLACEMENT CIRVES $\ldots \ldots \ldots \ldots \ldots \ldots \ldots \ldots \ldots \ldots \ldots \ldots \ldots$ 


\begin{abstract}
Data from seventeen masonry wall panel tests are presented. All of the walls are ungrouted, unreinforced, and constructed with hollow concrete block. The primary variables in the test series are block and mortar strength, but the applied vertical compressive stress and wall aspect ratio are also varied. The walls are built with either a "high" strength block or a "low" strength block having gross area unit strengths of approximately 1800 psi and 1300 psi, respectively. The mortar is either a Type $\mathrm{S}$ or a Type $\mathrm{N}$ mortar and, for convenience, is identified as high and low strength mortar, respectively. Thirteen of the wall panels have nominal dimensions of $64 \mathrm{in.}$ long x 64 in. high $x 8$ in. thick, but two of the walls are $96 \mathrm{in.}$ long and the remaining two walls are $48 \mathrm{in}$. long. The applied net area vertical compressive stress is constant for a given test, but varies between 100 psi and 400 psi for tests in the series reported herein. The walls are tested in the NBS Tri-directional Test Facility using fixed-ended boundary conditions at the top and bottom of the walls. A vertical compressive stress is applied and maintained while in-plane lateral displacements are imposed at the top of the wall. The test results indicate that for the lower levels of vertical compressive stress the effect of block and mortar strength on maximum in-plane shear resistance is relatively small, while with increased vertical compressive stress the effect of increasing material strength becomes significant and results in increased shear resistance. There is an interaction between the block and mortar strength such that the wall behavior may not be adequately predicted by considering the two strengths independent ly.
\end{abstract}




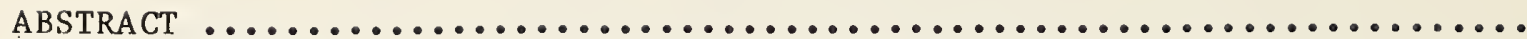
iii

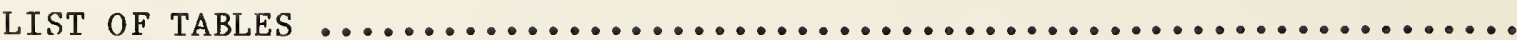

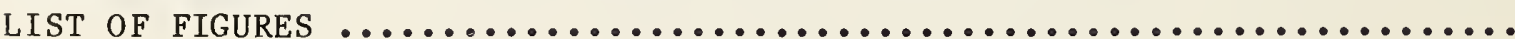

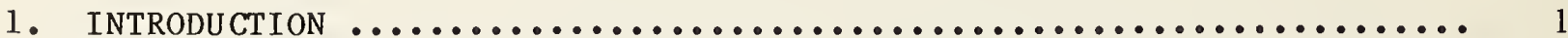

2. TEST SPECIMENS $\ldots \ldots \ldots \ldots \ldots \ldots \ldots \ldots \ldots \ldots \ldots \ldots \ldots \ldots \ldots \ldots \ldots \ldots \ldots \ldots \ldots \ldots \ldots . \ldots \ldots \ldots$

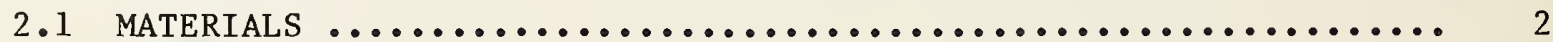

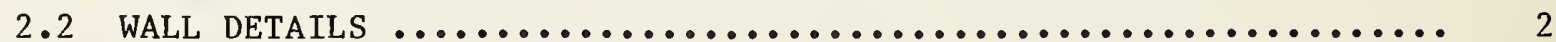

2.3 TEST SETUP AND INSTRUMENTATION $\ldots \ldots \ldots \ldots \ldots \ldots \ldots \ldots \ldots \ldots \ldots \ldots \ldots \ldots \ldots . \ldots \ldots$

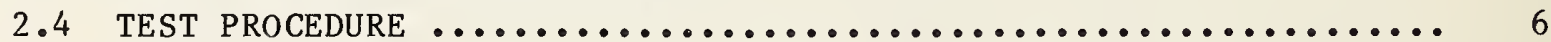

3. DISCUSSION OF RESULTS $\ldots \ldots \ldots \ldots \ldots \ldots \ldots \ldots \ldots \ldots \ldots \ldots \ldots \ldots \ldots \ldots \ldots \ldots \ldots \ldots \ldots$

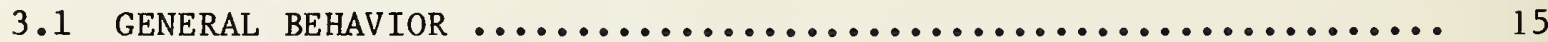

3.2 MAXIMUM IN-PLANE RESISTANCE ......................... 15

3.3 SHEAR STRESS-DISPLACEMENT RELATIONSHIP $\ldots \ldots \ldots \ldots \ldots \ldots \ldots \ldots \ldots \ldots \ldots$

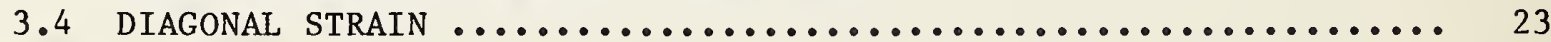

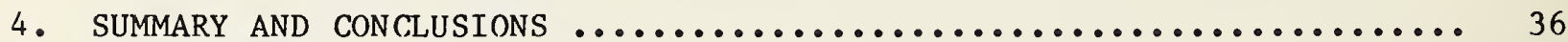

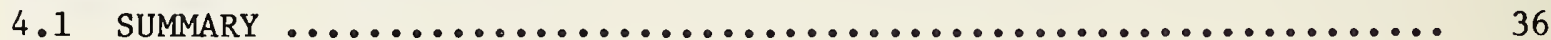

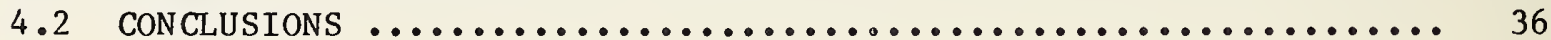

5. ACKNOWLEDGEMENTS $\ldots \ldots \ldots \ldots \ldots \ldots \ldots \ldots \ldots \ldots \ldots \ldots \ldots \ldots \ldots \ldots \ldots \ldots \ldots$

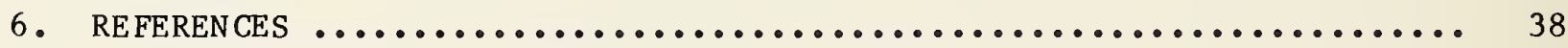

APPENDICES $\ldots \ldots \ldots \ldots \ldots \ldots \ldots \ldots \ldots \ldots \ldots \ldots \ldots \ldots \ldots \ldots \ldots \ldots \ldots \ldots \ldots \ldots \ldots$

A. OVERVIEW OF MASONRY RESEARCH PROGRAM $\ldots \ldots \ldots \ldots \ldots \ldots \ldots \ldots \ldots \ldots \ldots \ldots \ldots$ A

B. MATERIALS ........................................ B-1

B.1 CONCRETE MASONRY UNITS $\ldots \ldots \ldots \ldots \ldots \ldots \ldots \ldots \ldots \ldots \ldots \ldots \ldots \ldots \ldots \ldots \ldots \ldots \ldots \ldots$

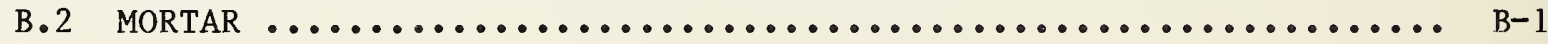

C. WALL PANEL DESCRIPTION $\ldots \ldots \ldots \ldots \ldots \ldots \ldots \ldots \ldots \ldots \ldots \ldots \ldots \ldots \ldots \ldots \ldots \ldots . \ldots \ldots$

C.1 WALL PANEL FABRICATION $\ldots \ldots \ldots \ldots \ldots \ldots \ldots \ldots \ldots \ldots \ldots \ldots \ldots \ldots \ldots \ldots \ldots$.

C.2 PRISM FABRICATION $\ldots \ldots \ldots \ldots \ldots \ldots \ldots \ldots \ldots \ldots \ldots \ldots \ldots \ldots \ldots \ldots \ldots \ldots \ldots \ldots \ldots$

D. WALL PANEL TESTS: SETUP AND PLACEMENT $\ldots \ldots \ldots \ldots \ldots \ldots \ldots \ldots \ldots \ldots \ldots \ldots$

D.1 TEST SETUP .................................. D-1

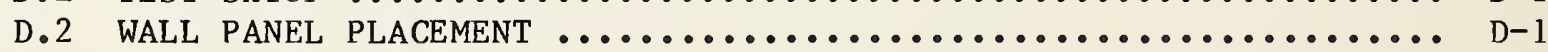

E. WALL PANEL LOAD-DISPLACEMENT CURVES $\ldots \ldots \ldots \ldots \ldots \ldots \ldots \ldots \ldots \ldots \ldots \ldots \ldots$ 
Table 2.1 Wall Panel Details .............................. 4

Table 2.2 Wall Panel Horizontal LVDT Location Dimensions ......... 8

Table 3.1 Wall Panel Maximum In-plane Resistance ............... 20

Table B.1 Dimensions and Properties of Concrete Masonry Units ...... B-3

Table B.2 Masonry Sand Sieve Analysis ........................ B-5 
Figure 2.1

Figure 2.2

Figure 2.3

Figure 2.4

Figuer 2.5

Figure 2.6

Figure 2.7

Figure 2.8

Figure 2.9

Figure 3.1

Figure 3.2

Figure 3.3

Figure 3.4

Figure 3.5

Figure 3.6

Figure 3.7

Figure 3.8

Figure 3.9

Figure 3.10

Figure 3.11

Figure 3.12

Figure 3.13

Figure 3.14

Figure 3.15

Figure 3.16

Figure 3.17

Figure 3.18

Figure 3.19

Figure 3.20

Figure B.1

Figure D.1

Figure D. 2

Figure E.1

Figure E.2

Figure E. 3

Figure E.4

Figure E. 5

Figure E.6

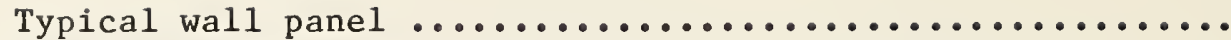

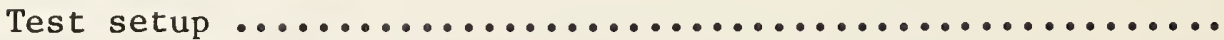

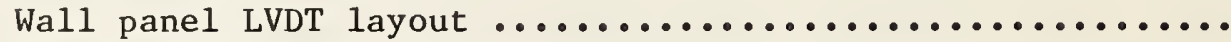

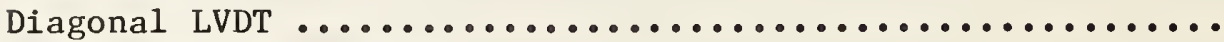

Leaf spring transducer $\ldots \ldots \ldots \ldots \ldots \ldots \ldots \ldots \ldots \ldots \ldots \ldots \ldots \ldots \ldots$

Wall panel instrumentation ( 48 in.) $\ldots \ldots \ldots \ldots \ldots \ldots \ldots \ldots$

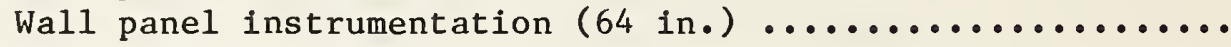

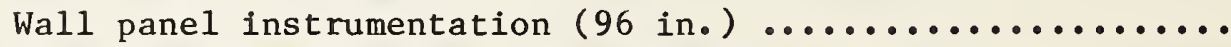

Simplified description of test method $\ldots \ldots \ldots \ldots \ldots \ldots \ldots \ldots$

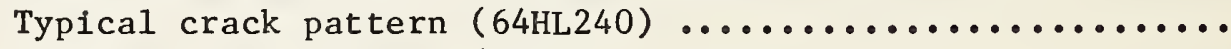

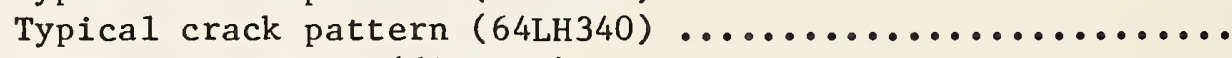

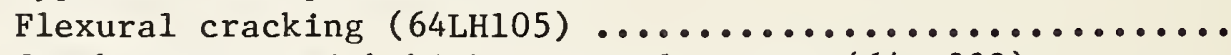

Crack pattern with high vertical stress (64HL320) ........

Crack pattern in low strength wall (64LL250) ............ Maximum shear stress versus vertical stress for

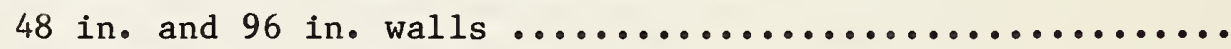
Maximum shear stress versus vertical stress for

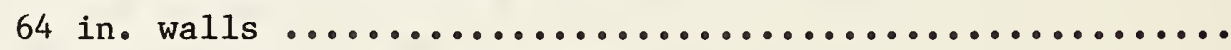

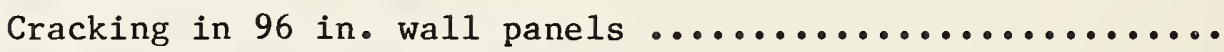

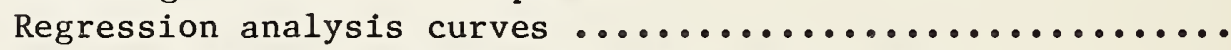

Shear stress-displacement curves (64HH \& 64LH) ...........

Shear stress-displacement curves (64HL \& 64LL) ...........

Shear stress-displacement curves $(64 \mathrm{HH} \& 64 \mathrm{HL}) \ldots . . \ldots \ldots \ldots$

Shear stress-displacement curves (64LH \& 64LL) ...........

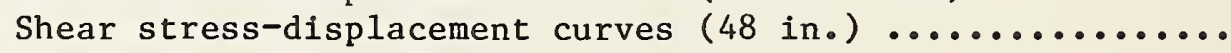

Shear stress-displacement curves (96 in.) ..............

Combined shear stress-diagonal strain curves ............

Shear stress-diagonal strain curves $(64 \mathrm{HH} \& 64 \mathrm{LH}) \ldots . . . .$.

Shear stress-diagonal strain curves (64HL \& 64LL) ........

Shear stress-diagonal strain curves $(64 \mathrm{HH} \& 64 \mathrm{HL}) \ldots \ldots \ldots$

Shear stress-diagonal strain curves $(64 \mathrm{LH} \& 64 \mathrm{LL}) \ldots \ldots \ldots$

Concrete Masonry Units .........................

Wall panel transport harness .......................

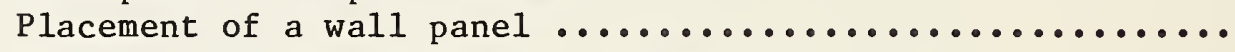

Crack pattern and load-displacement curve for

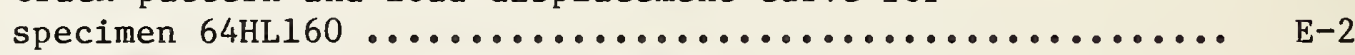

Crack pattern and load-displacement curve for

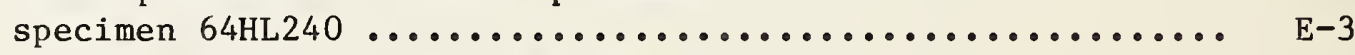

Crack pattern and load-displacement curve for

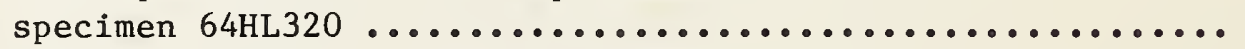

Crack pattern and load-displacement curve for

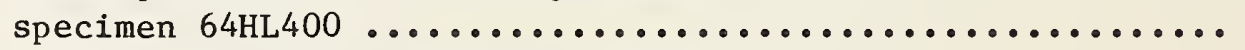

Crack pattern and load-displacement curve for

specimen $64 L L 170 \ldots \ldots \ldots \ldots \ldots \ldots \ldots \ldots \ldots \ldots \ldots \ldots \ldots \ldots \ldots$

Crack pattern and load-displacement curve for

specimen $64 \mathrm{LL} 250$ 
Figure E.7 Crack pattern and load-displacement curve for

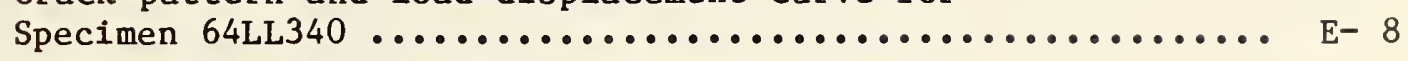

Figure E. 8 Crack pattern and load-displacement curve for specimen $64 L L 420$................................. E- 9

Figure E.9 Crack pattern and load-displacement curve for

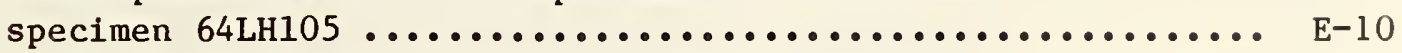

Figure E.10 Crack pattern and load-displacement curve for

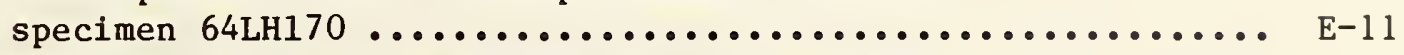

Figure E.11 Crack pattern and load-displacement curve for

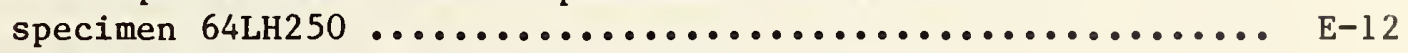

Figure E.12 Crack pattern and load-displacement curve for

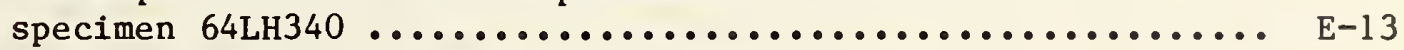

Figure E.13 Crack pattern and load-displacement curve for specimen $64 \mathrm{LH} 420$................................. E-14

Figure E.14 Crack pattern and load-displacement curve for

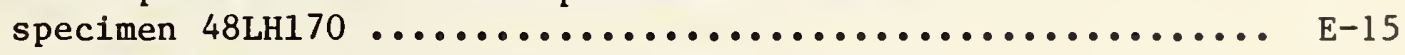

Figure E.15 Crack pattern and load-displacement curve for

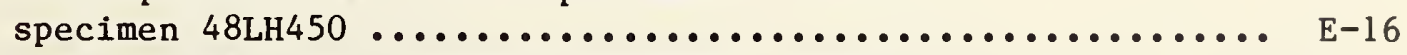

Figure E.16 Crack pattern and load-displacement curve for

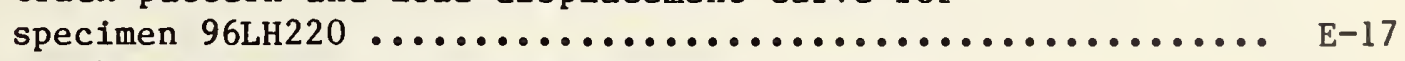

Figure E.17 Crack pattern and load-displacement curve for specimen 96LH320 



\section{INTRODUCTION}

This report describes an experimental test series investigating the shear behavior of unreinforced, hollow concrete block masonry walls. The test series reported herein is part of a larger experimental research program which has as its main objective the determination of the in-plane shear (lateral load) resistance of shear dominated masonry walls. The primary parameters discussed in this report are block and mortar strength. The vertical (axial) compressive stress and wall aspect ratio are also parameters in this test series, but only secondarily, in order to observe the interaction of parameters.

Data from seventeen wall tests are presented in this report. The walls have nominal heights and thicknesses of $64 \mathrm{in.}$ and $8 \mathrm{in.,}$ respectively. Thirteen of the seventeen walls are $64 \mathrm{in.}$ long, two of the walls are $48 \mathrm{in}$. and the remaining two walls are 96 in. long. The vertical compressive stress varies in the test series from a low of about 100 psi to a high of approximately 400 psi. These stresses are based on the net cross-sectional area of the walls. The concrete block has a gross area unit strength of either 1300 psi or 1800 psi (approximate) and the mortar is proportioned either as a Type $S$ or a Type N.

This report is the third in a series of reports documenting the overall research program. Since the report is but one in a series, certain information common to all of the reports has been placed in appendices. The intent of this organization is to reduce redundancy in the main body of the report without omitting information necessary to the report's understanding if read independently of the other reports in the series. The purpose of this report is to present in a timely manner a general description of the tests and a limited presentation of key data. Detailed data analysis is left to summary reports which are issued periodically and combine sufficient test information to fully address a particular topic.

A brief background description of the overall research program is in appendix A. The materials and wall panel descriptions are discussed in chapter 2 along with instrumentation and general test procedure. Further descriptions of materials, fabrication techniques, and test setup may be found in appendices $B, C$, and D. A brief, general discussion of the more obvious test results is presented in chapter 3. The individual wall panel load-displacement curves and crack pattern maps are in appendix $E$. The summary and conclusions are presented in chapter 4. 


\section{TEST SPECIMENS}

This chapter presents a brief description of the materials used in constructing the walls, the details of each wall (e.g., length, block strength), instrument dtion, and general test procedures. More complete descriptions may be found in appendices B, C, and D.

\subsection{MATERIALS}

All materials used in the wall panels and companion prisms were commercially available and were representative of those commonly used in building construction. The concrete block was hollow, two-core block and was from two lots. One lot contained block having a gross area unit compressive strength of 1813 psi while the other lot had block whose gross area unit compressive strength was 1304 psi. For the purposes of this report the block having the strength of 1813 psi was identified as "high" strength, while the other block was termed "low" strength. These terms were relative indices and not a classification of their absolute strengths. The mortar used in constructing the walls was proportioned as either a Type S and termed "high" strength or as a Type $\mathrm{N}$ and designated "low" strength.

\subsection{WALL DETAILS}

A typical wall panel is illustrated in fig. 2.1. The details of each wall are listed in table 2.1. The wall panel identifier is a two part label with the two parts separated by a hyphen. That part of the identifier preceeding the hyphen is the descriptive label and has the form $\mathrm{mABn}$. In place of $\mathrm{m}$ there is a number representing the nominal length of the wall panel expressed in inches. The $\mathrm{n}$ term is the approximate applied vertical compressive stress on the wall panel. The stress is based on the net cross-sectional area of the wall and is in units of psi. The positions represented by $A$ and $B$ designate the strength of block and mortar, respectively. The letter H signifies "high" while the letter L denotes "low". An example of the descriptive label is $64 \mathrm{HL} 240$ which is read to mean a $64 \mathrm{in}$. long wall constructed with "high" strength block and "low" strength mortar which is tested with an applied vertical compressive stress of about 240 psi.

\subsection{TEST SETUP AND INSTRUMENTATION}

The walls are tested in the NBS Tri-directional Test Facility (fig. 2.2). The facility is a structural test rig which can apply forces and/or displacements in any or all of the six degrees of freedom at the top of the wall. The bottom of the wall is held stationary by a restraining crosshead.

The instrumentation used to monitor the behavior of a wall panel during a test can be divided into two main categories. The first category includes the load and displacement transducers mounted on the hydraulic actuators which are part of the test facility. The information from these transducers is used both for the control system of the test facility and for measuring specimen response. The global forces and displacements imposed on a test specimen are computed from these data. The second category of instrumentation includes the 


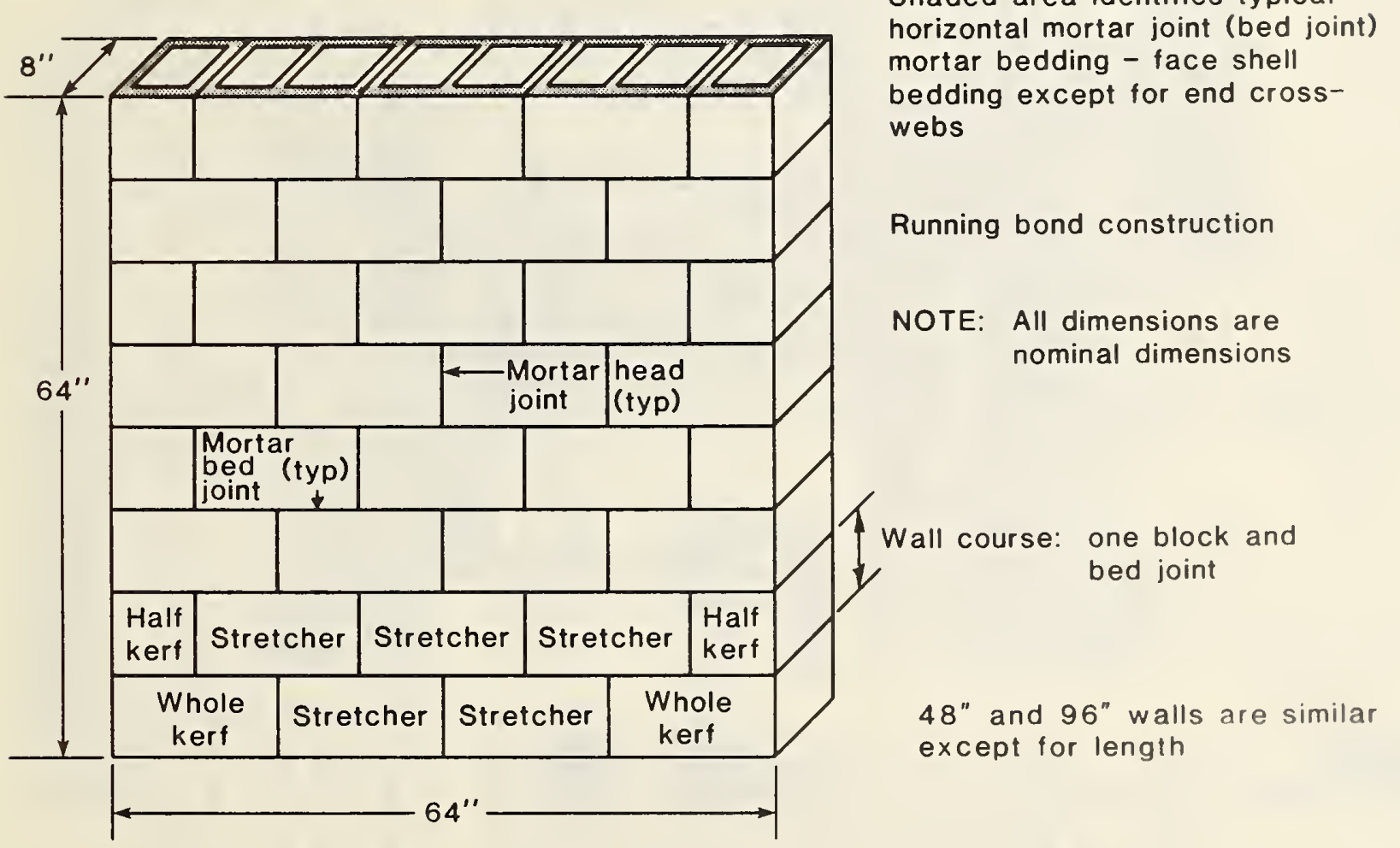

Figure 2.1 Typical wall panel 


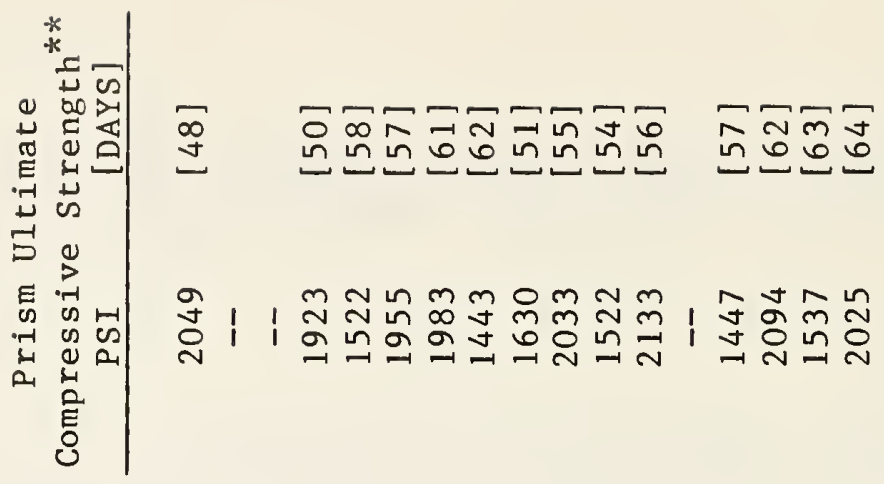

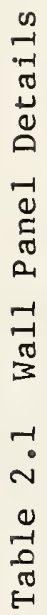

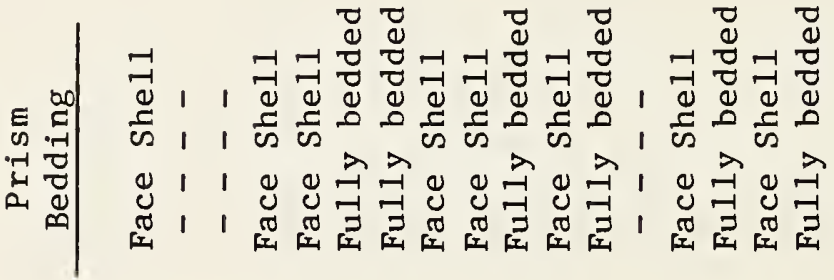

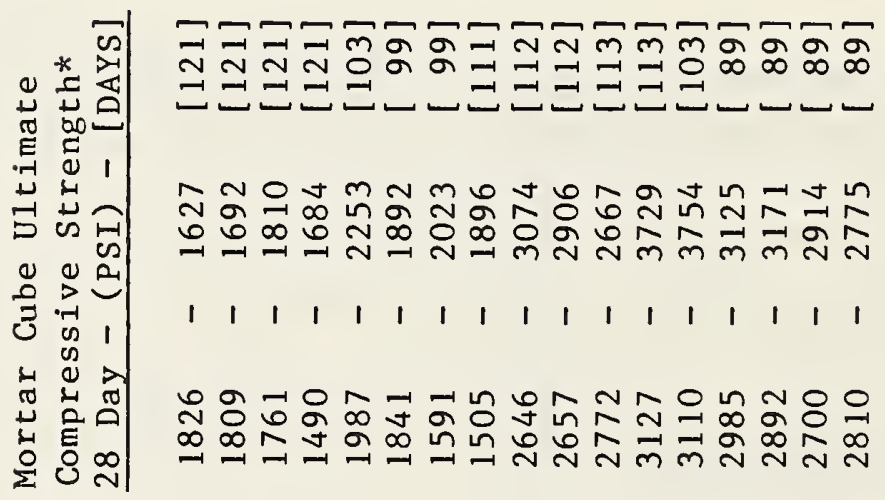

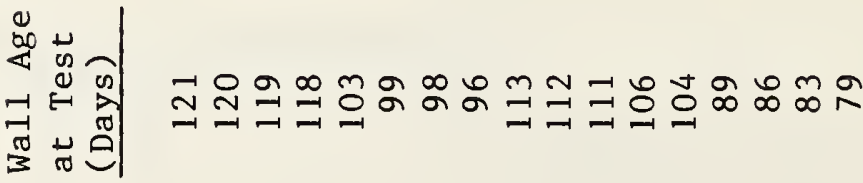

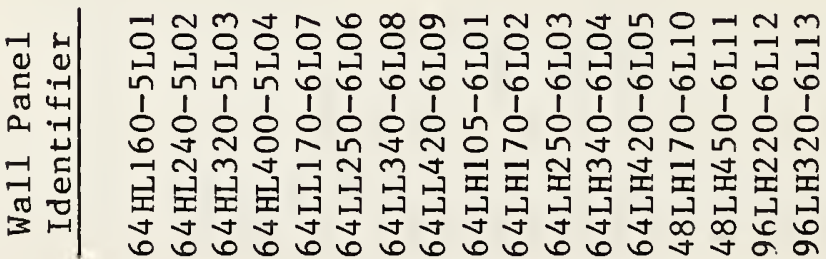

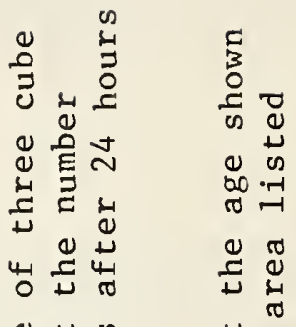

茂告䒕

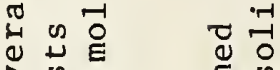

$>$ ह

थ 㟔

ป气

$\rightarrow-1$

\&

$>$ प

प्山० 吾 हू

क व 0 क 站

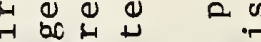

4

ह ग 0

o

$\therefore \frac{\pi}{\nu}$

$\rightarrow-0$

유

ब०

$\exists \sum \prod_{\pi}$ का

$\overbrace{}^{\pi}$

จ

๘

(1)

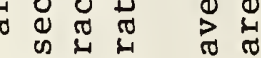

है की

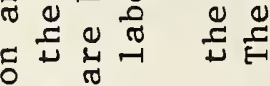

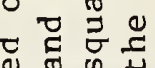

ब

๙

की

$\rightarrow$ 艺

क $\stackrel{\infty}{\sim} \frac{2}{\infty}$

(1)

正 क ल

ए

क

$\stackrel{0}{\stackrel{0}{0}}$

$>0$

क

( )

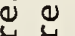

㫕

()

บ

$\Xi 5$

$*$ 


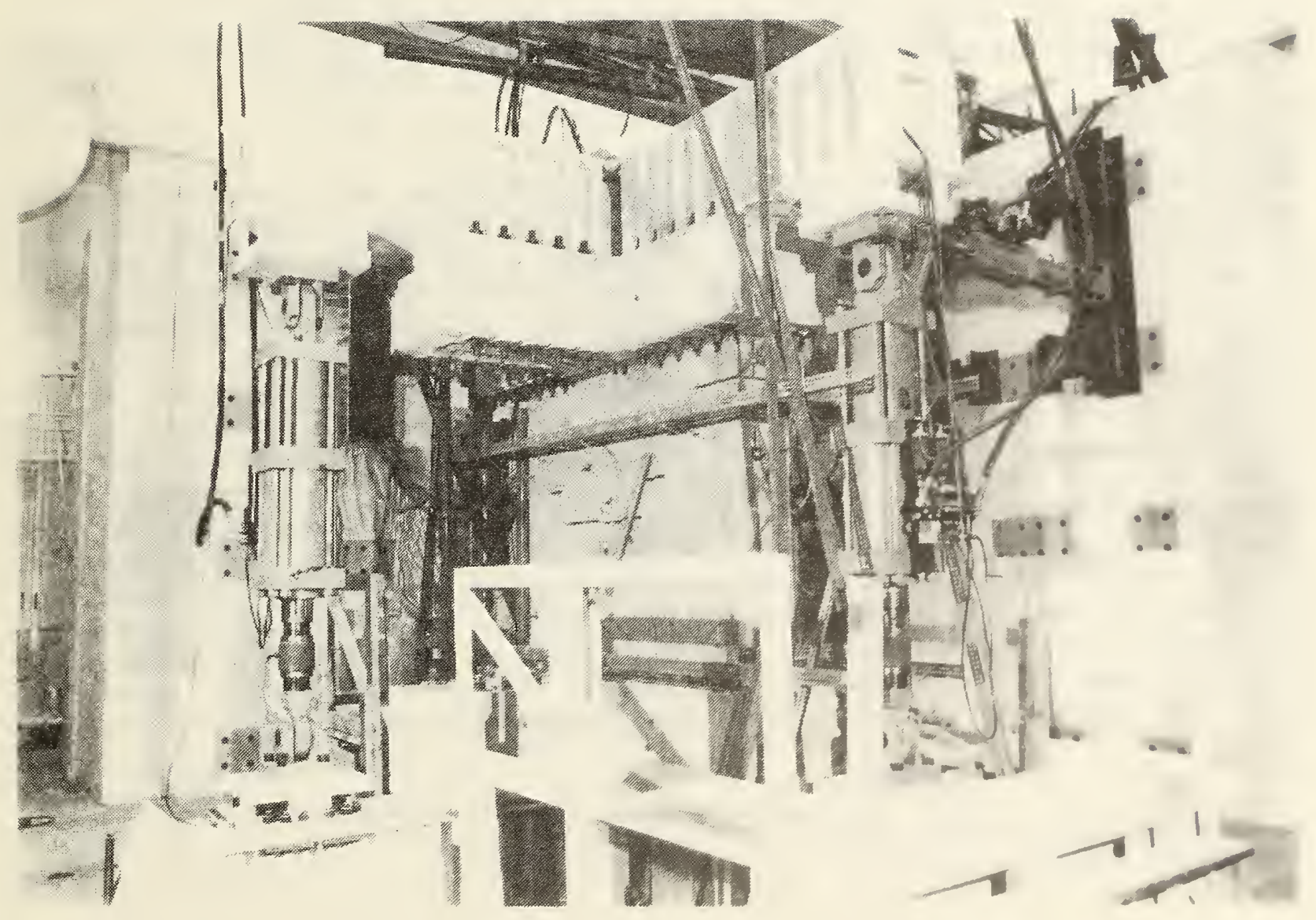

Figure 2.2 Test setup 
transducers physically attached to the wall specimens. These include horizontally mounted linear variable differential transformers (LVDTs) which are mounted to measure the in-plane displacement of the wall along the wall height. The displacements are measured relative to a fixed reference. The positions of the LVDTs are shown in fig. 2.3 and 1 isted in table 2.2. The other instrumentation attached to the test specimen measure displacements of one part of the wall relative to another part of the wall. These data are then used to compute wall strains by dividing the measured displacement by the gage length of the transducers. Two general types of transducers are used, the first being LVDTs mounted between swiveling posts attached to the wall surface (fig. 2.4). These devices are used only for measuring displacement along the wall diagonals, one on each side of the wall. The other type of transducer is a leaf spring transducer also mounted on posts attached to the wall surface (fig. 2.5). The general locations of the transducers mounted on the wall panels are shown in figures $2.6,2.7$, and 2.8 for the 48 in., 64 in., and 96 in. long walls, respectively.

All of the analog instrumentation is connected to a high speed analog-todigital converter which is part of a general computer-based data acquisition and load control system.

\subsection{TEST PROCEDURE}

The first step in a typical wall test was to check the data channels for unusual variations in output and obtain a measure of the ambient voltage oscillation. With the data channels in proper working order a set of data was acquired which served as the "zero" condition of the test. The hydraulic actuators of the test facility were then pressurized and another set of data readings were obtained. Compressive vertical (axial) load was applied to the wall until the desired value was achieved. After stabilizing the vertical load, in-plane lateral displacement was applied at the top of the wall panel. The lateral displacement was applied with the upper crosshead of the facility maintaining a "zero" rotation condition (fig. 2.9). The vertical load was automatically maintained at the preset level by the facility's control system. The initial direction of lateral displacement was always to the west, but the displacement pattern varied slightly between tests. The lateral displacement was generally increased in the initial direction until a diagonal crack was fully formed. Afterwards, the displacement was either reversed or increased until the wall could not support the imposed vertical load. Data were acquired at regular intervals during the test at lateral displacement intervals of about 0.005 in. 


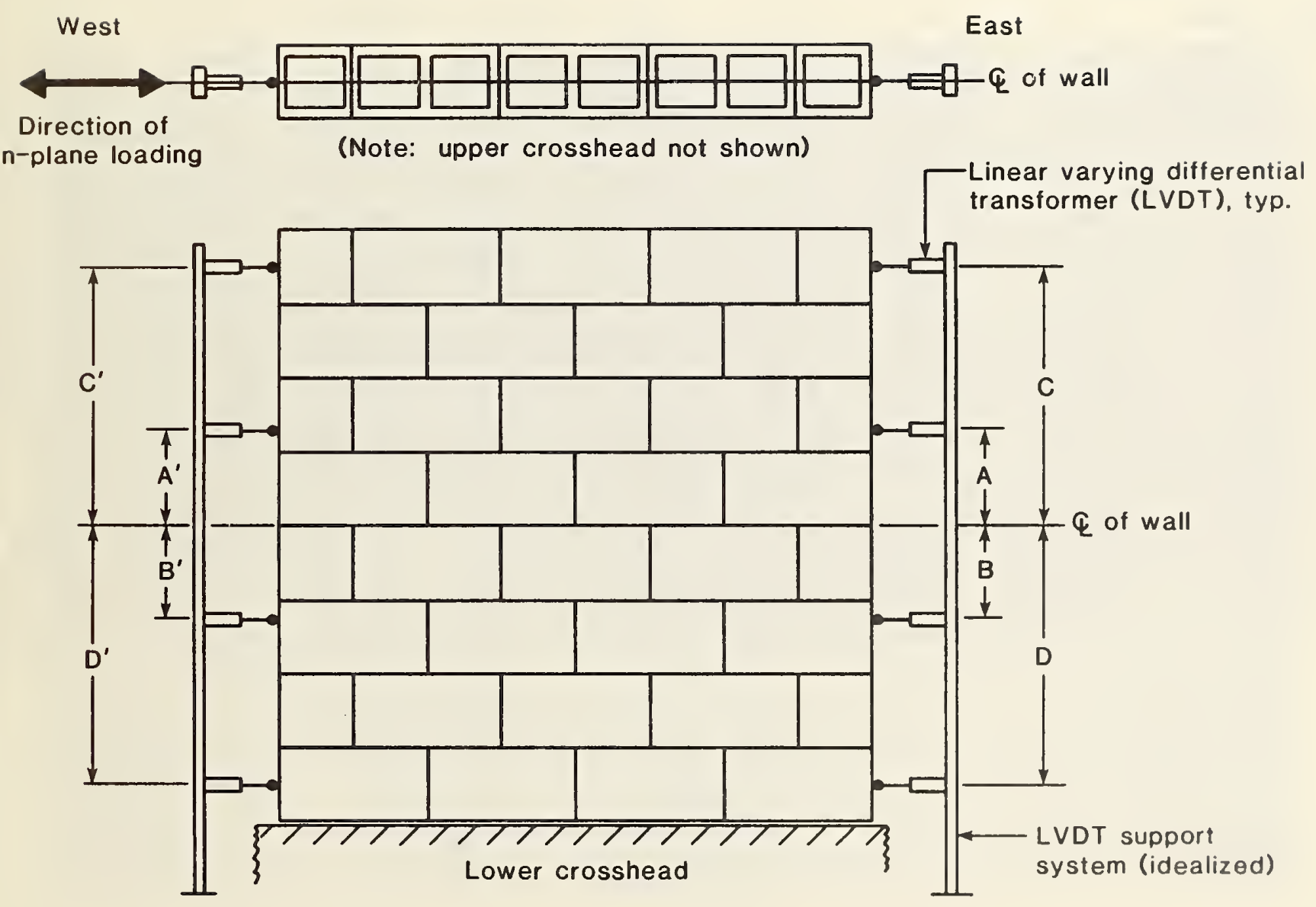

Figure 2.3 Wall panel LVDT layout 
Table 2.2 Wall Panel Horizontal LVDT Location Dimensions

(Refer to fig. 2.3 for identification of dimension locations $A, B, C, D, A^{\prime}, B^{\prime}, C^{\prime}$, and $D^{\prime}$ )

\begin{tabular}{|c|c|c|c|c|c|c|c|c|}
\hline $\begin{array}{l}\text { Wall Panel } \\
\text { Identifier }\end{array}$ & $\begin{array}{c}A \\
\left(i_{\bullet}\right)\end{array}$ & $\begin{array}{c}B \\
\text { (in.) }\end{array}$ & $\begin{array}{c}\mathrm{C} \\
(\mathrm{in} .)\end{array}$ & $\begin{array}{c}D \\
\text { (in.) }\end{array}$ & $\begin{array}{l}A^{\prime} \\
(\text { in. })\end{array}$ & $\begin{array}{c}B^{\prime} \\
\text { (in.) }\end{array}$ & $\begin{array}{c}C^{\prime} \\
(\text { in. })\end{array}$ & $\begin{array}{c}D^{\prime} \\
\text { (in.) }\end{array}$ \\
\hline 64 HL 160 & 10.25 & 9.50 & 27.13 & 29.25 & 9.88 & 10.88 & 27.25 & 28.25 \\
\hline 64 HL 240 & 9.88 & 9.88 & 26.75 & 29.50 & 10.0 & 10.38 & 27.50 & 27.75 \\
\hline 64 HL 320 & 10.38 & 9.50 & 27.13 & 29.25 & 7.38 & 10.38 & 27.63 & 27.38 \\
\hline 64 HL400 & 10.25 & 9.38 & 27.0 & 29.13 & 7.38 & 10.38 & 27.75 & 27.38 \\
\hline 64LL170 & 10.25 & 9.13 & 27.50 & 28.50 & 9.50 & 10.0 & 27.88 & 27.13 \\
\hline 64LL250 & 10.38 & 9.13 & 27.38 & 28.63 & 9.25 & 10.0 & 27.63 & 27.38 \\
\hline 64LL340 & 10.13 & 9.25 & 27.38 & 28.75 & 9.25 & 10.25 & 27.50 & 27.38 \\
\hline 64LL4 20 & 10.13 & 9.25 & 27.38 & 28.75 & 9.25 & 10.25 & 27.50 & 27.38 \\
\hline $64 \mathrm{LH} 105$ & 10.0 & 9.75 & 26.75 & 29.38 & 7.13 & 10.75 & 27.50 & 27.75 \\
\hline $64 \mathrm{LH} 170$ & 9.75 & 9.75 & 26.88 & 29.25 & 8.75 & 10.75 & 27.0 & 27.88 \\
\hline $64 \mathrm{LH} 250$ & 9.75 & 9.63 & 26.75 & 29.50 & 8.63 & 10.63 & 27.13 & 28.0 \\
\hline $64 \mathrm{LH} 340$ & 10.0 & 9.63 & 26.75 & 29.50 & 8.63 & 10.75 & 26.88 & 28.0 \\
\hline $64 \mathrm{LH} 420$ & 10.0 & 9.63 & 26.75 & 29.50 & 8.63 & 10.75 & 26.88 & 28.0 \\
\hline 48LH170 & 10.13 & 9.25 & 27.88 & 28.50 & 9.38 & 10.0 & 27.88 & 27.38 \\
\hline $48 \mathrm{LH} 450$ & 10.63 & 9.13 & 28.25 & 28.13 & 9.38 & 10.25 & 27.75 & 27.38 \\
\hline 96LH220 & 10.50 & 9.0 & 28.50 & 27.75 & 9.38 & 10.13 & 27.75 & 27.25 \\
\hline $96 \mathrm{LH} 320$ & 10.50 & 9.0 & 28.50 & 27.75 & 9.38 & 10.13 & 27.75 & 27.25 \\
\hline
\end{tabular}




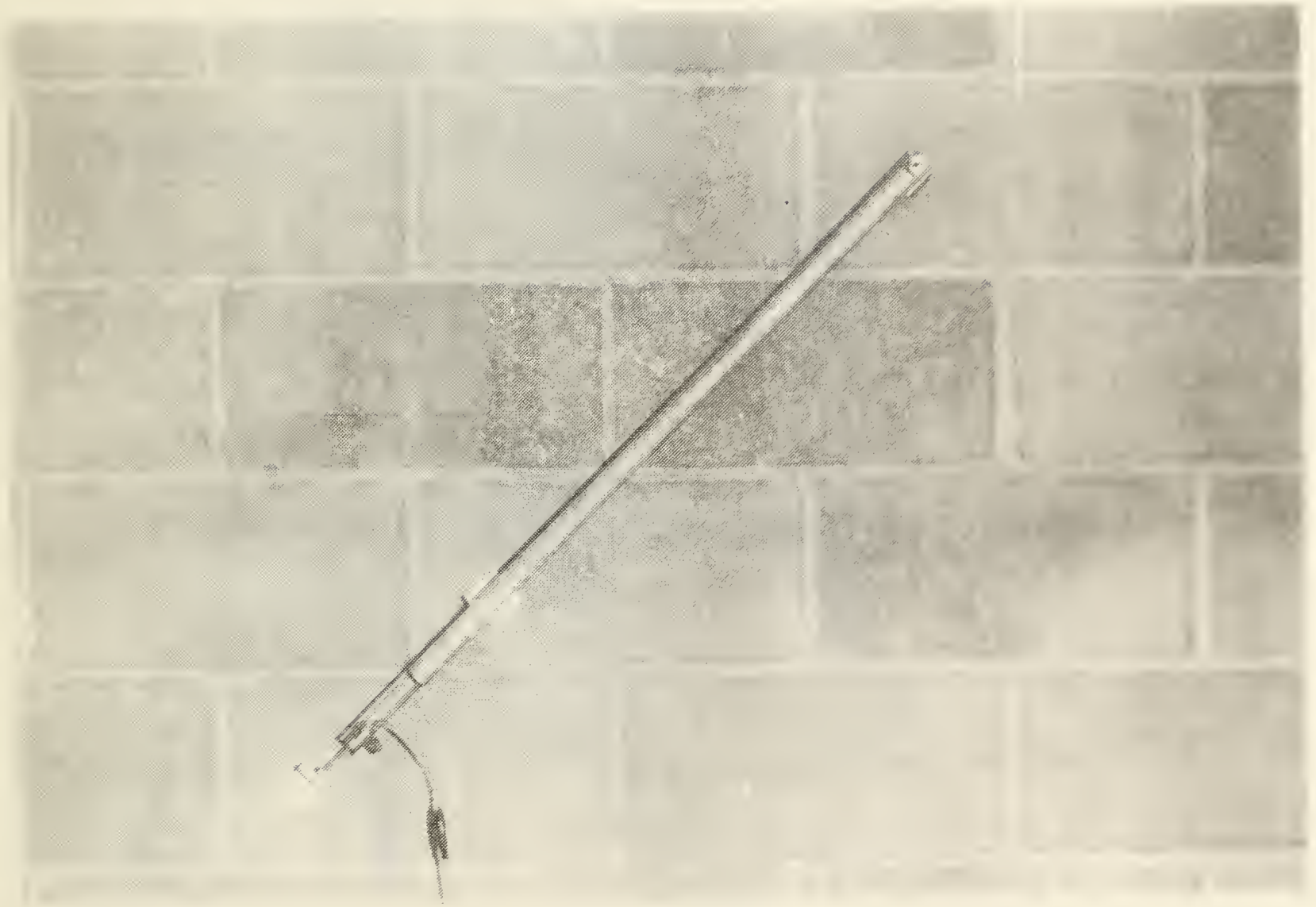

Figure 2.4 Diagonal LVDT 


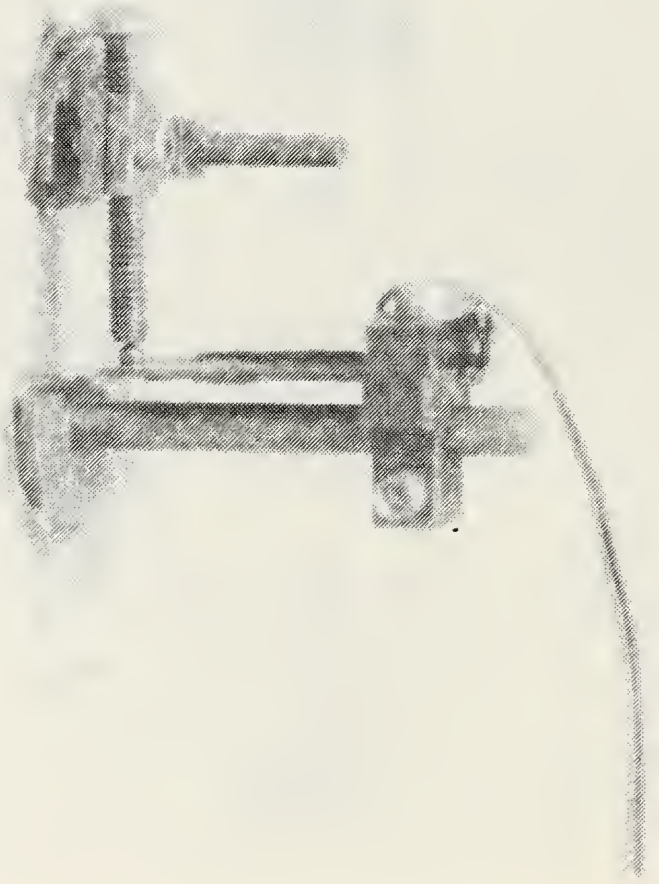

Figure 2.5 Leaf spring transducer 


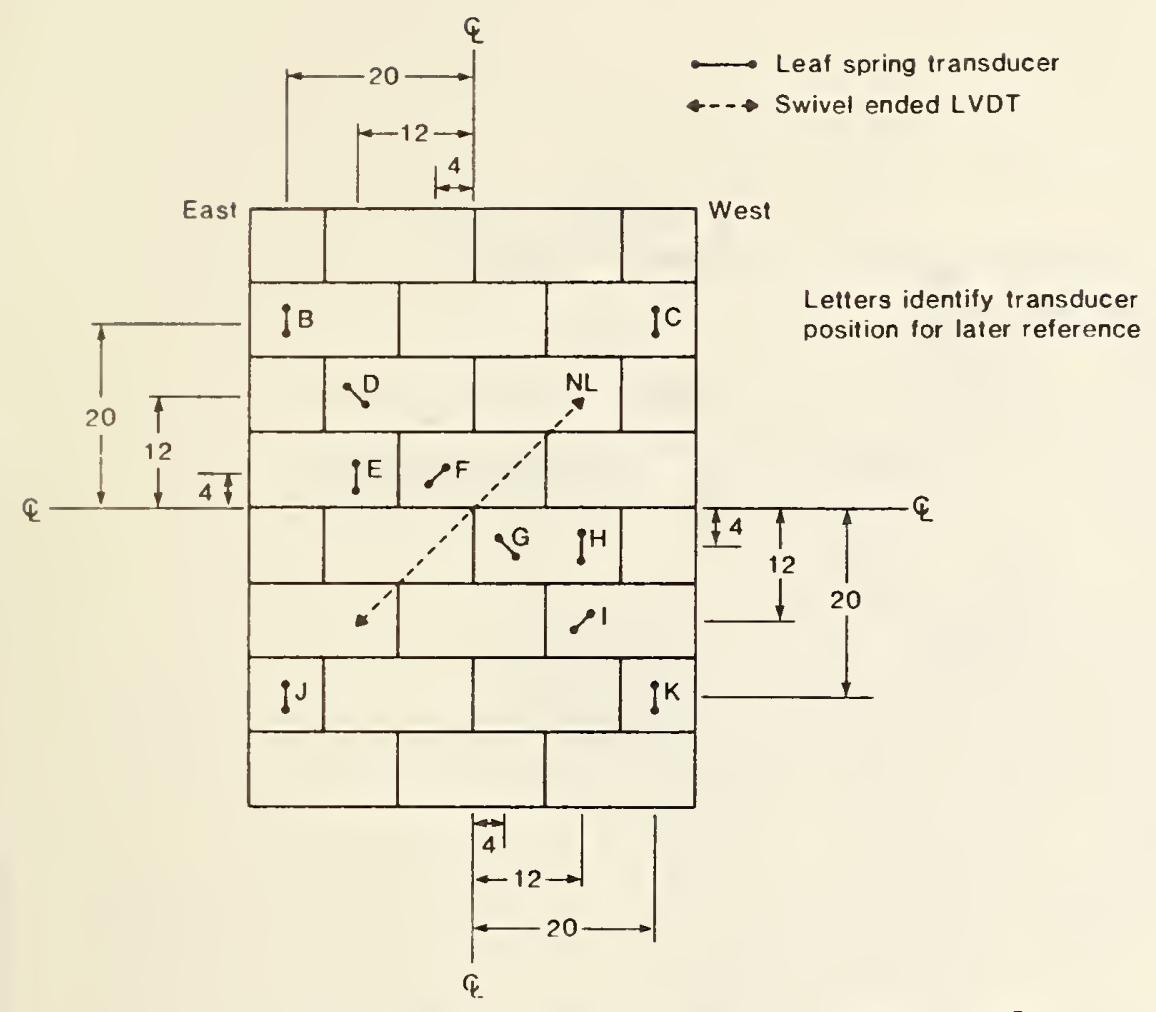

NORTH SIDE OF $48^{\prime \prime}$ WALL PANEL

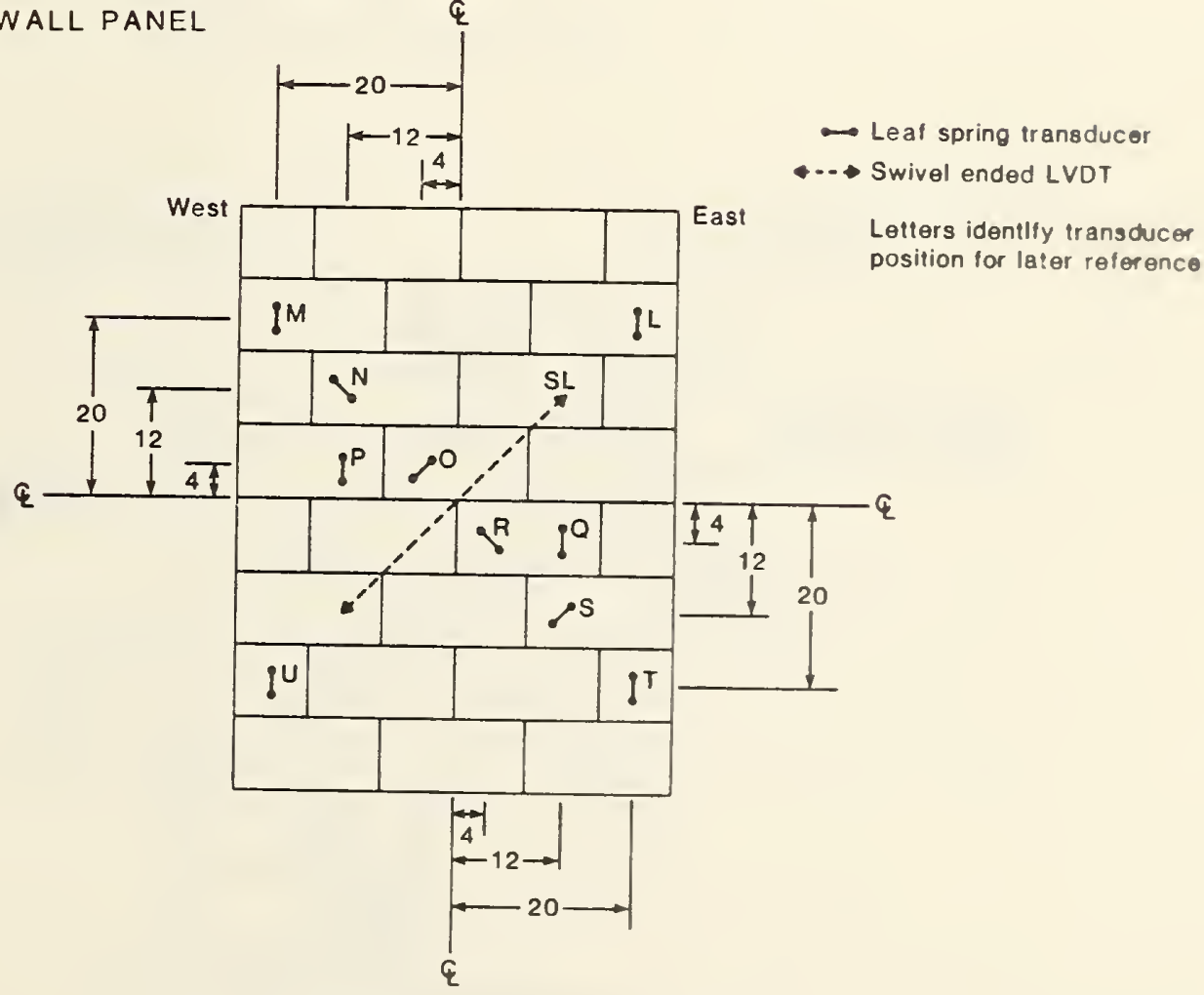

SOUTH SIDE OF 48" WALL PANEL

Figure 2.6 Wall panel instrumentation (48 in.) 


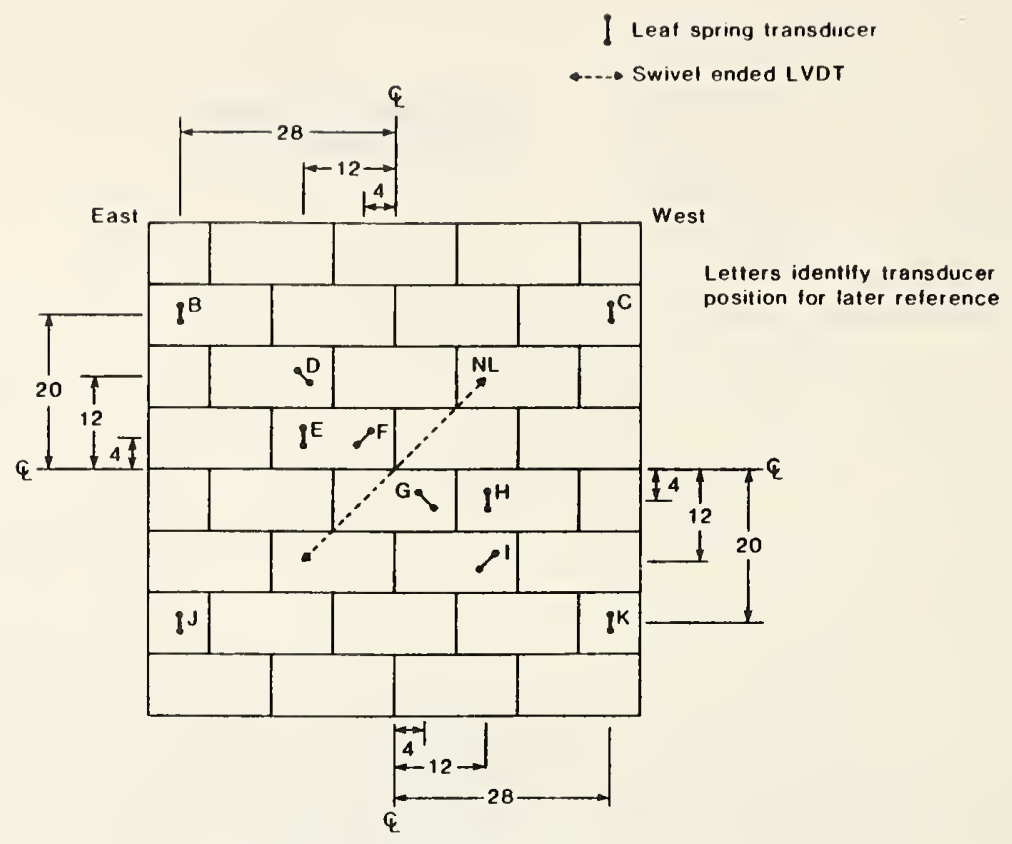

NORTH SIDE OF $64^{*}$ WALL PANEL

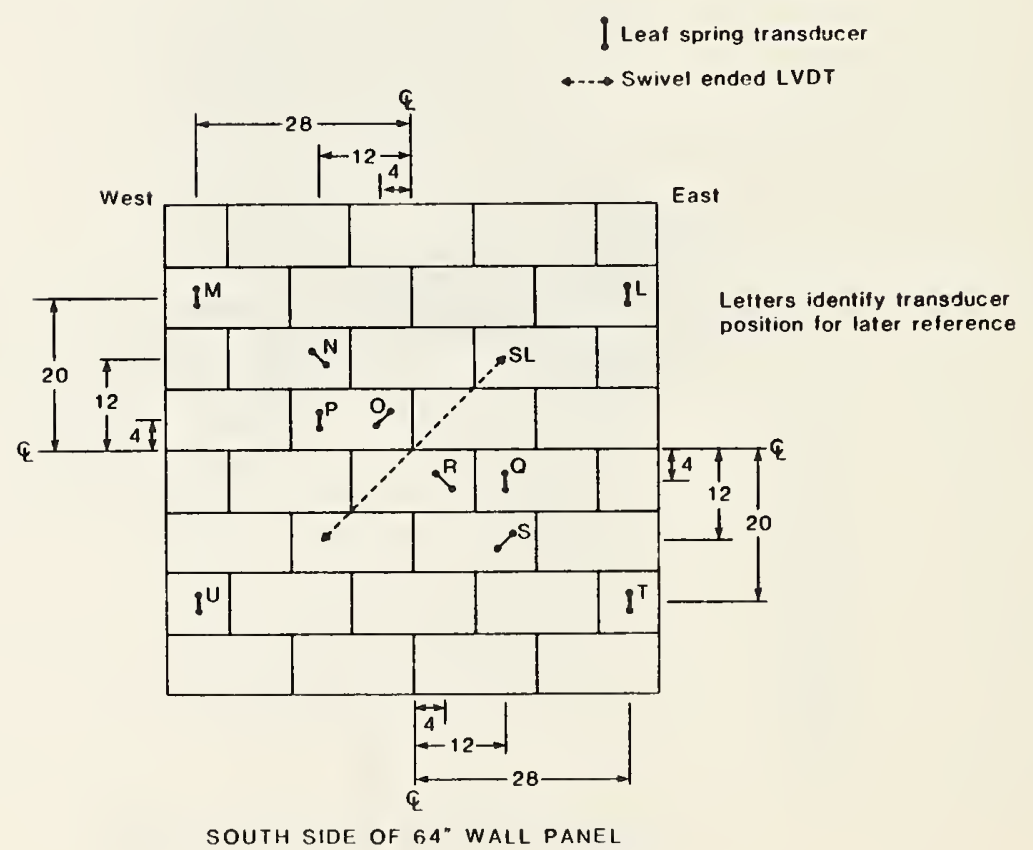

Figure 2.7 Wall panel instrumentation (64 in.) 


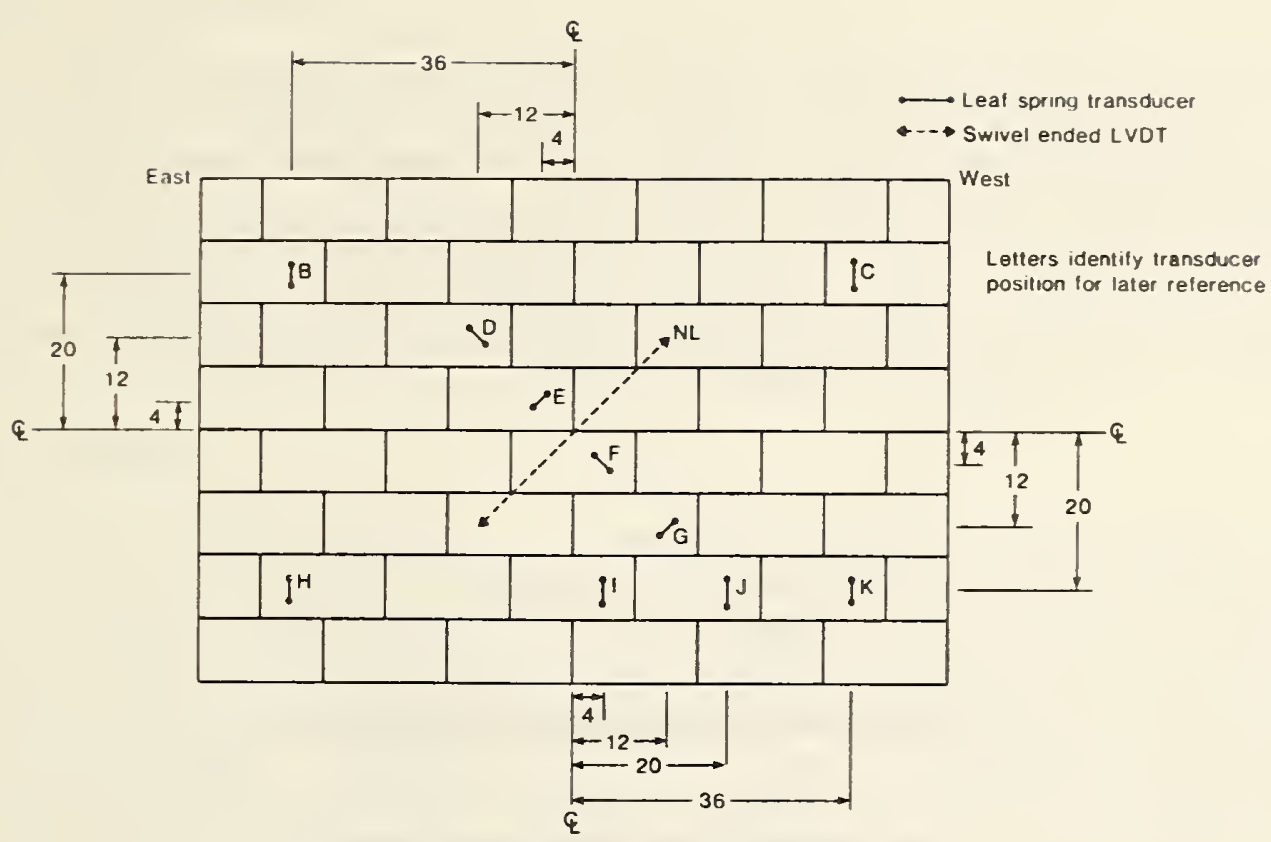

NORTH SIDE OF $96^{\circ}$ WALL PANEL

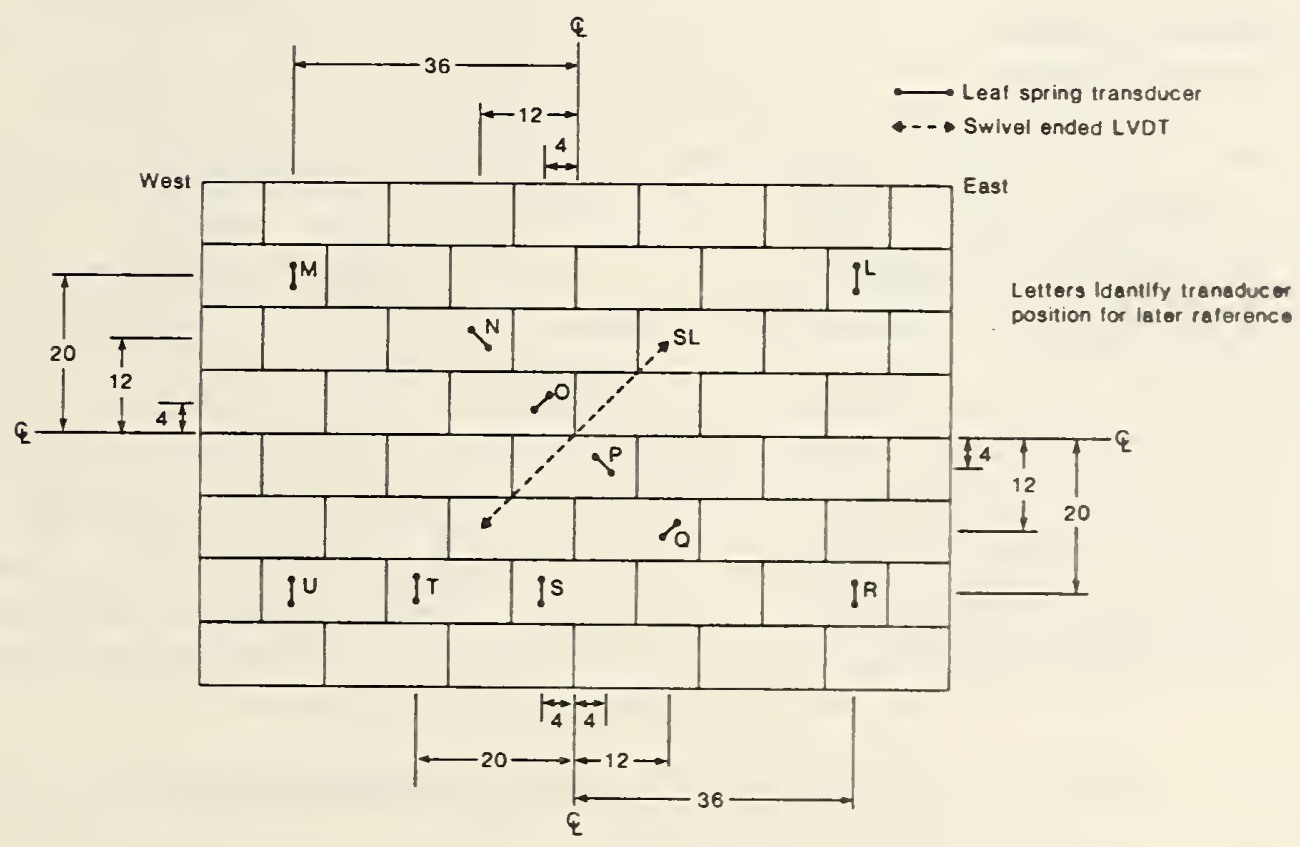

SOUTH SIDE OF 96" WALL PANEL

Figure 2.8 Wall panel instrumentation (96 in.) 
$\Delta_{D}$ is the imposed in-plane lateral displacement

$\Delta_{1}, \Delta_{2}$ are the vertical dimensions required to achieve desired vertical load. $\Delta_{1}$ need not equal $\Delta_{2}$.

q

Upper crosshead

Lower crosshead
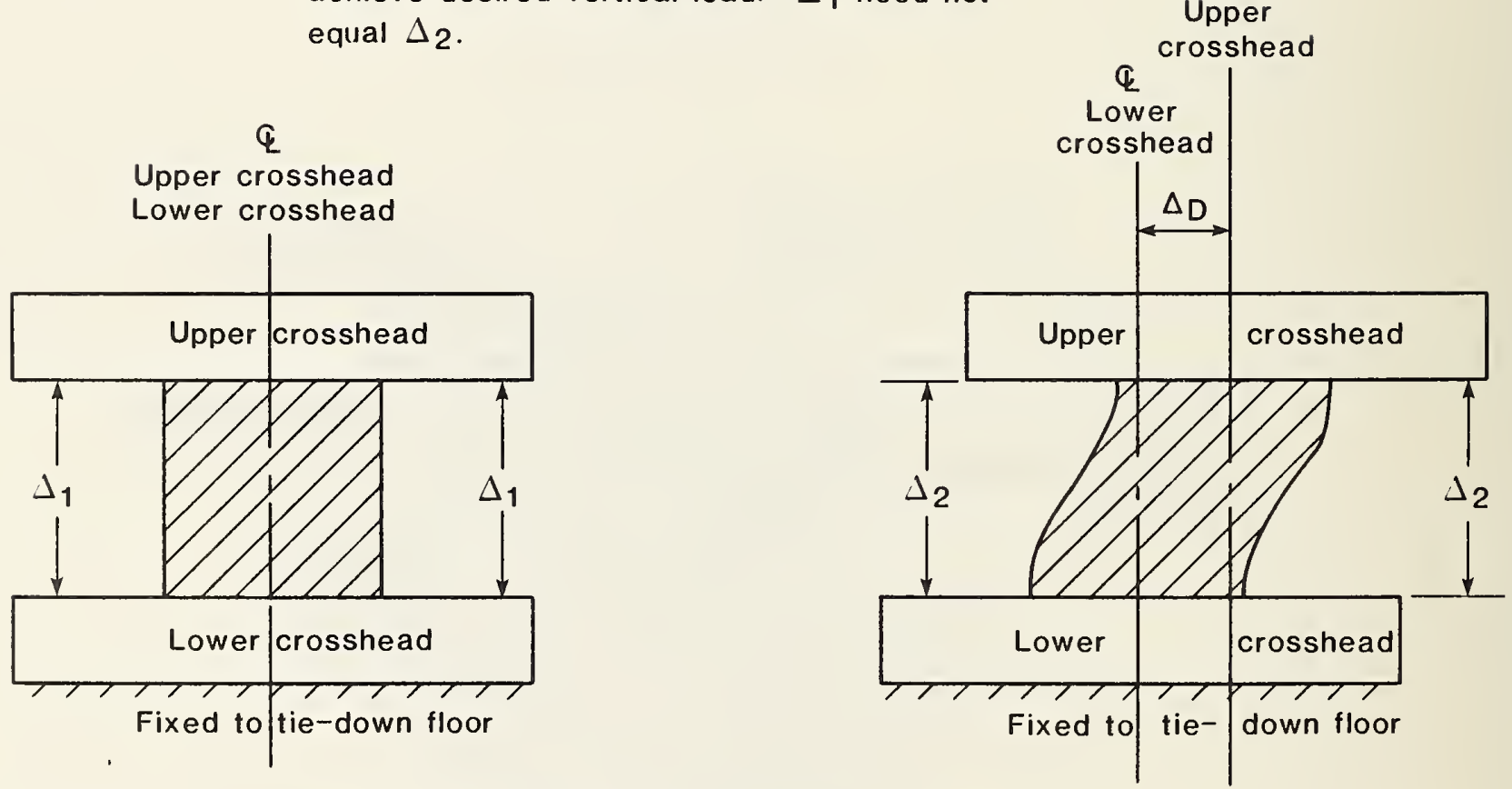

SIMPLIFIED DESCRIPTION OF IMPOSED DISPLACEMENT

Figure 2.9 Simplified description of test method 


\section{DISCUSSION OF RESULTS}

In addition to the seventeen wall panel tests reported herein, data from wall panel tests reported previously [1,2] are used in the discussion which follows. The combination of wall tests include variations in applied vertical compressive stress and wall panel aspect ratio. The focus of the discussion is on the influence of block and mortar strength, but effects of the other parameters will be discussed when it appears that there is an interaction between the parameters. The presentation is not intended to be a detailed analysis of the data as that will appear in a subsequent summary report.

\subsection{GENERAL BEHAVIOR}

The typical mode of wall distress was a diagonal tension form of shear distress as evidenced by the pronounced cracking along the diagonals of the wall panels (figures 3.1 and 3.2). The exception to this mode of distress came only when the level of vertical compressive stress was low, resulting in a flexurally dominated initial mode of distress as shown in fig. 3.3 where the horizontal flexure crack developed. However, even for the walls exhibiting flexural distress, it was possible to produce a local diagonal tension crack and, if the vertical compressive stress was increased sufficiently, a general diagonal tension mode of distress.

Given that the typical indication of distress was diagonal tension cracking, there were observed differences in the form of the crack paths. It was previously observed $[1,2]$ that both the level of vertical compressive stress and the aspect ratio influenced the orientation of the cracking. In general, the trajectory of the crack pattern was rather constant along a roughly 45 degree line, especially for the square wall panels. The path that the diagonal crack followed, however, was slightly more variable with most of the previously reported walls exhibiting block cracking rather than a simple stair-step crack along the mortar joints. The previous walls all had high strength block and mortar. The influence of block and mortar strength seemed to be consistent with the mortar strength having more effect. The degree of influence was a function of the level of vertical compressive stress and to a lesser degree aspect ratio. Walls with high strength block and low strength mortar tended to exhibit diagonal cracking of the stair-step fashion (fig. 3.1), but with high levels of vertical stress some block cracking occurred (fig. 3.4). Conversely, walls with low strength block and high strength mortar exhibited much more through block cracking (fig. 3.2). The combination of low strength block and mortar resulted in a definite combination of the two types of crack path (fig. 3.5), though it appeared that the cracking began along the mortar joints and then, shortly afterward, initiated in the block units.

\subsection{MAXIMUM IN-PLANE RESISTANCE}

The capacity of particular interest in these tests is the maximum in-plane lateral load resistance. This load is referred to as the shear force capacity and when the shear force is divided by a nominal value for the wall's net cross-sectional area the resulting computed stress is termed the shear stress. The advantage of using shear stress rather than force is in the normalization 


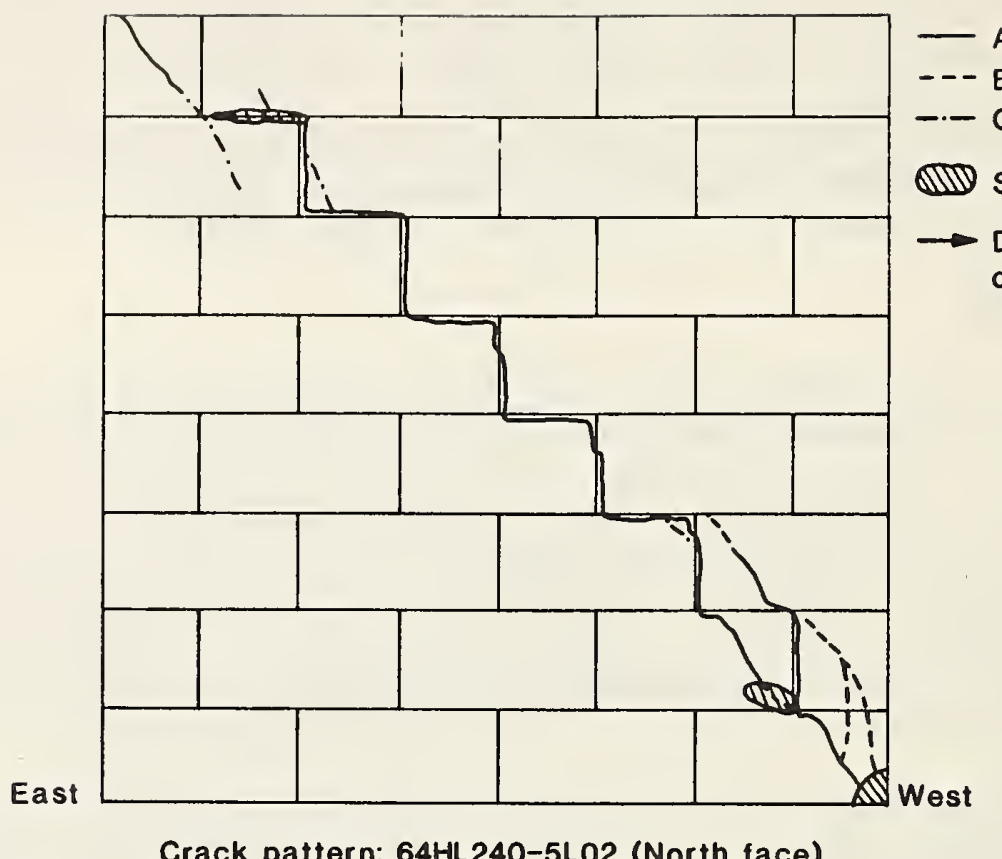

\section{B}

$-C$

(10) spalled aréa

Direction of initial displacement

Figure 3.1 Typical crack pattern (64HL240)

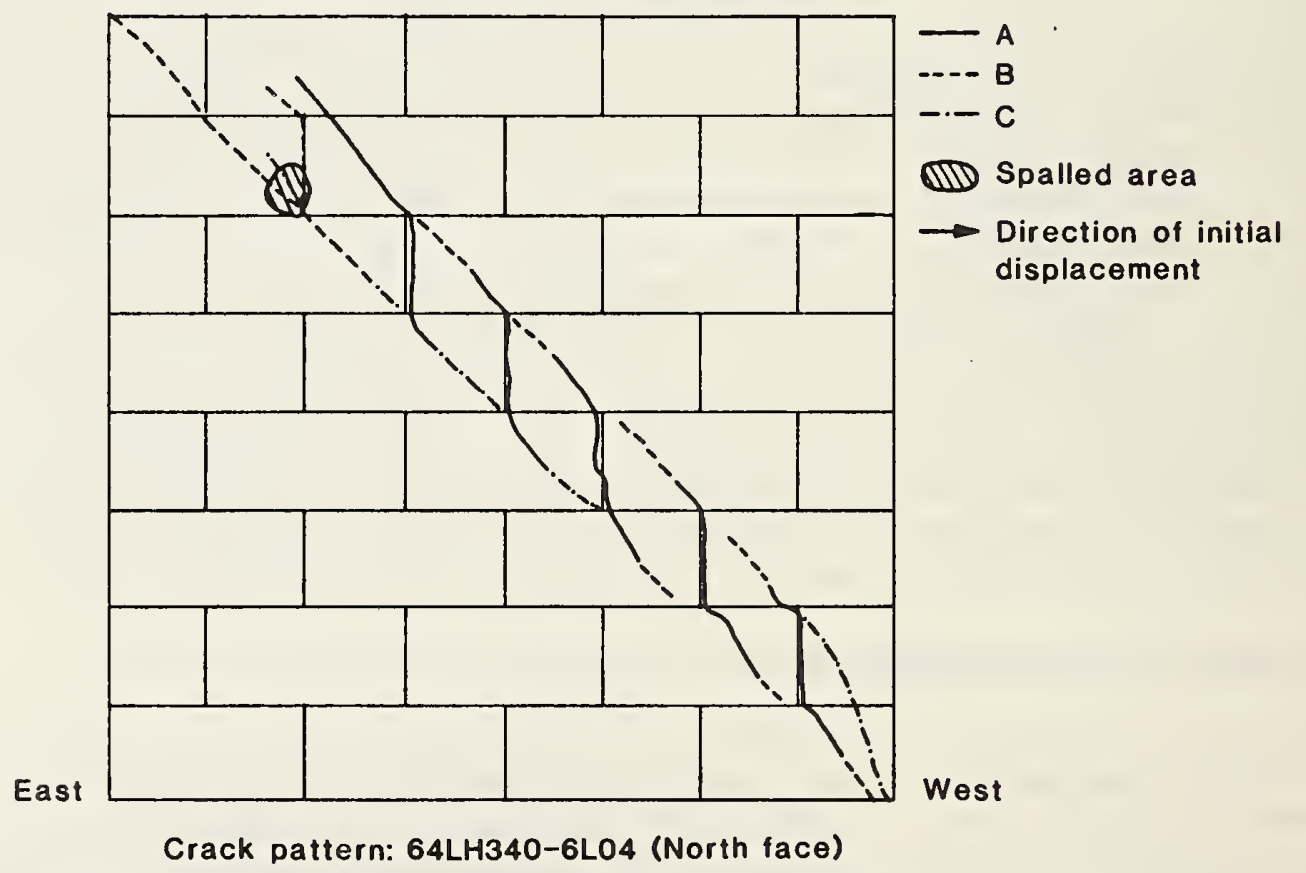

Figure 3.2 Typical crack pattern (64LH340) 


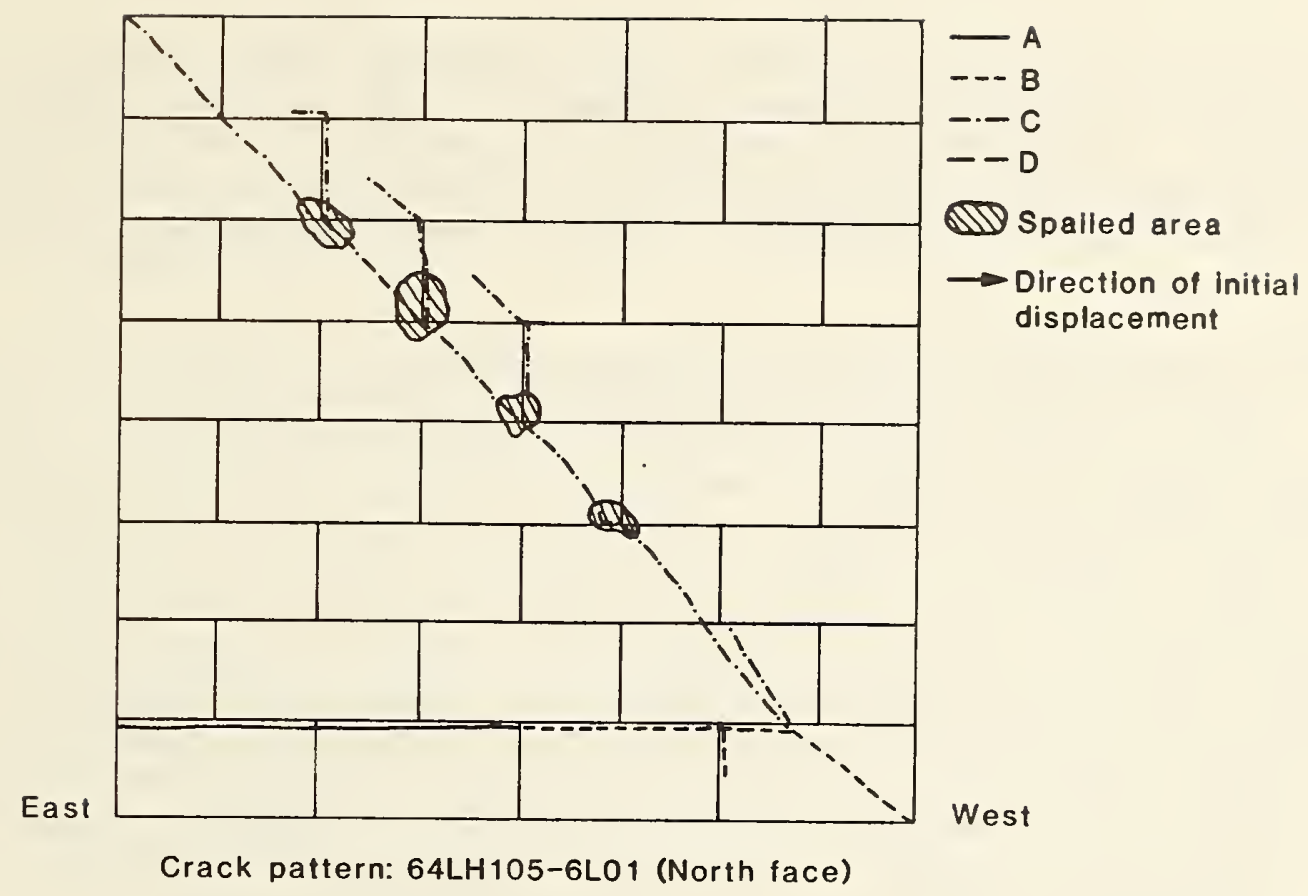

Figure 3.3 Flexural cracking (64LH105)

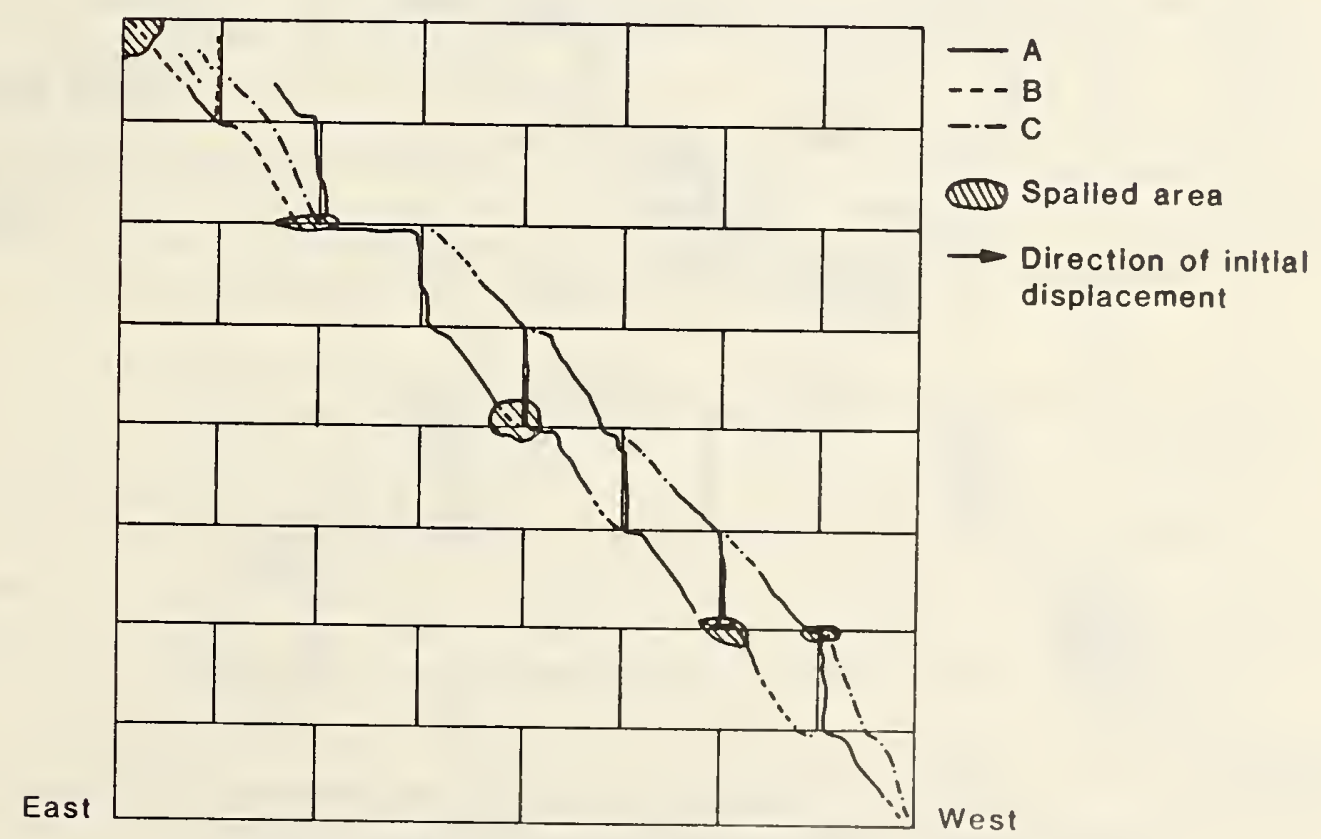

Crack pattern: 64HL320-5L03 (North face)

Figure 3.4 Crack pattern with high vertical stress (64HL320) 


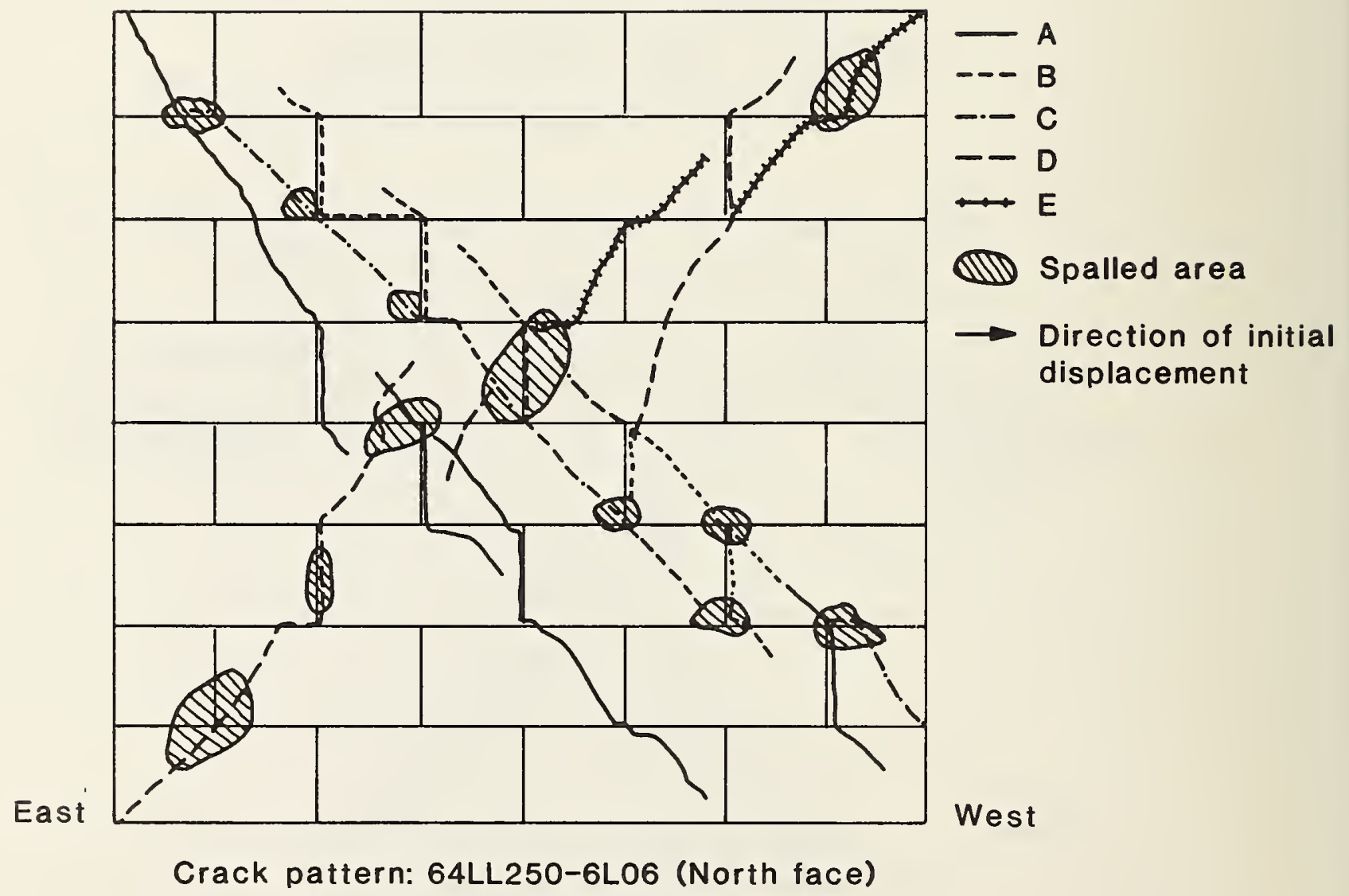

Figure 3.5 Crack pattern in low strength wall (64LL250) 
of the capacity with respect to varying wall area as between a 96 in. wall and a $64 \mathrm{in}$. wall. This may be an incomplete normalization, but for the purposes of this report it is considered an acceptable normalization. The maximum shear resistance of each wall panel is listed in table 3.1 along with the applied vertical compression stress and wall displacement coincident with the achievement of maximum shear.

The maximum shear stresses are plotted versus the vertical compressive stresses in figures 3.6 and 3.7 along with data from the previously reported tests $[1,2]$. Figure 3.6 contains the data for the $48 \mathrm{in}$. and $96 \mathrm{in}$. long wall panels. It appears that the block strength does not affect the maximum shear stress for the 96 in. walls and had only a minor impact for the 48 in. walls. In the case of the $48 \mathrm{in}$. walls the trend is, as might be expected, lower maximum shear resistance with the lower block strength. The trend, or more appropriately, the lack of a trend, for the $96 \mathrm{in.} \mathrm{walls} \mathrm{is} \mathrm{most} \mathrm{probably} \mathrm{the}$ result of the diagonal crack path. The diagonal cracking in the 96 in. walls was almost exclusively along the mortar joints (fig. 3.8) making it unlikely that the block strength would be a significant parameter for maximum shear stress. The mortar strength is not an intentional variable for the 48 in. and 96 in. long walls and no observations can be made on the effect of mortar strength.

The maximum shear stress versus vertical compressive stress comparisons for the $64 \mathrm{in.}$ long wall panels are plotted in fig. 3.7. The comparison for block strength is made between the open and closed forms of each symbol and the comparison for mortar strength is made between similar forms, open or closed, of the different symbols. The most obvious general trend is the divergence of maximum shear stresses as the vertical stress increases. The group of data points at the 160 psi vertical compressive stress level reflect four different parameters and yet there is little difference between the points. By contrast, the spread in maximum shear stresses at the 400 psi vertical compressive stress level is quite large. It is clear that the vertical compressive stress has an effect on the apparent interaction between block and mortar strength and the maximum shear stress for the 64 in. long wall panels.

The trend of the data plotted in fig. 3.7 is more easily visualized by regression analyses (fig. 3.9). Four of the lines are linear while the remaining line, labelled $64 \mathrm{LH}$, is quadratic because the regression analyes showed a significant improvement in fit for the quadratic compared to the linear representation. The line labels indicate the data used in determining each line. Label $64 \mathrm{XX}$ means that all of the data for the $64 \mathrm{in.}$ long wall panels are used in the regression analysis for that line. A certain amount of caution should be exercised in evaluating the trends especially outside the limits of the data values. The bounds are indicated by vertical lines on the plot and describe the limits of stresses generally contained in the actual data. The tendency towards dispersion as the vertical stress increases is evident. Another clear trend is that as the vertical stress increases there is a marked decrease in maximum shear stress for the low strength block walls as compared to the high strength walls. A similar trend for mortar strength exists for the high strength block walls, but the trend is not as pronounced for the low strength block walls. This observation suggests that the total wall behavior may be 


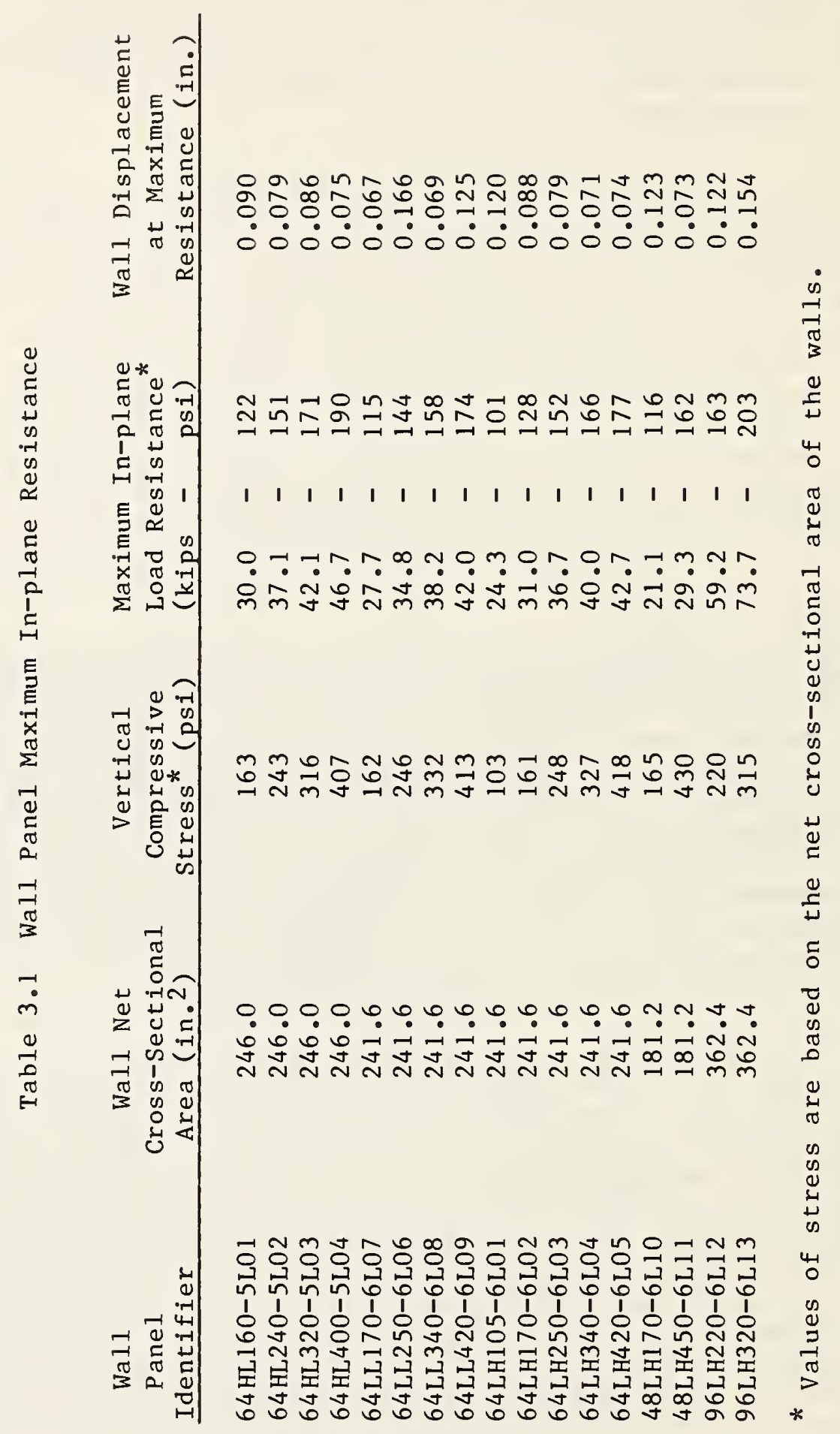




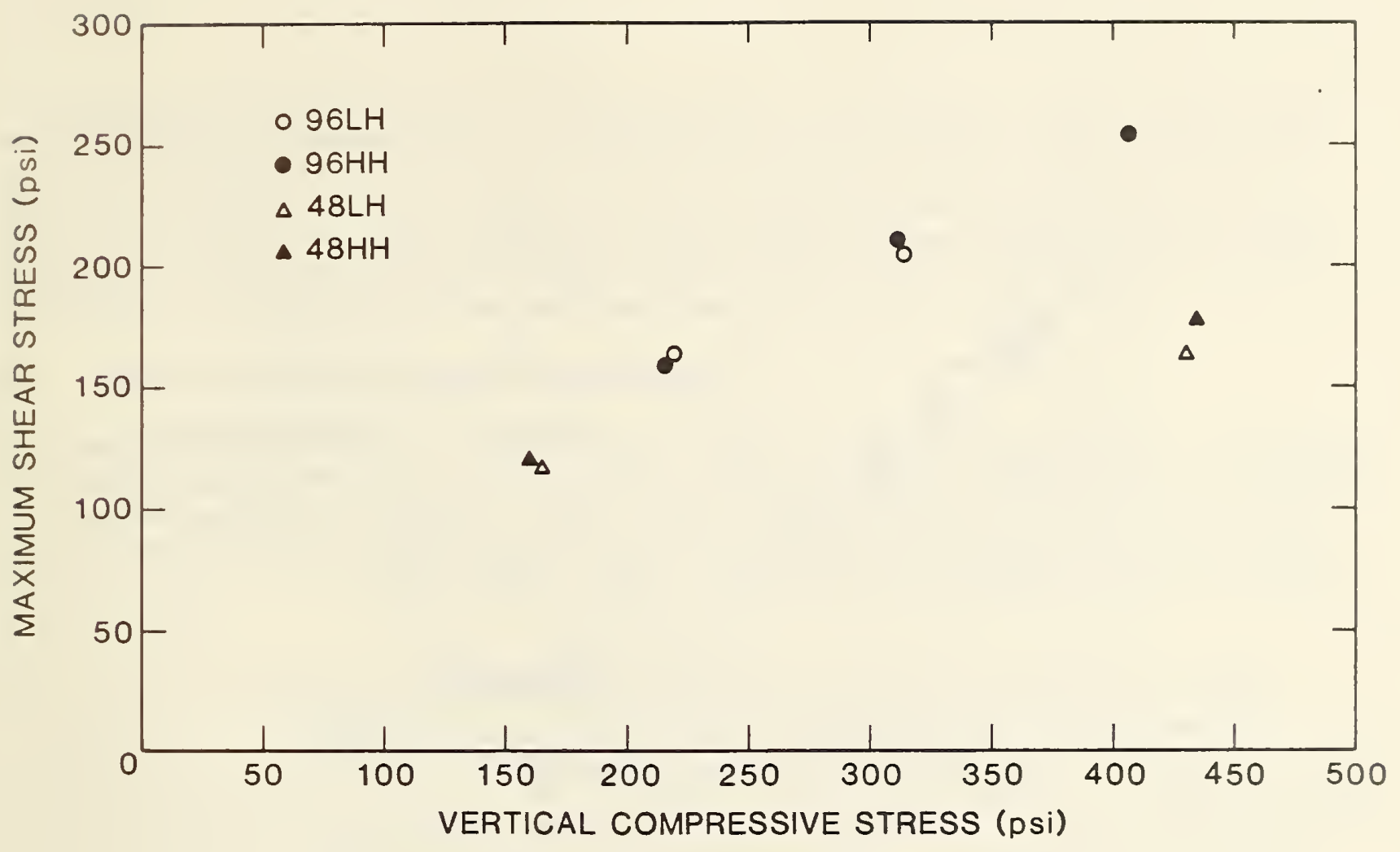

Figure 3.6 Maximum shear stress versus vertical stress for 48 in. and 96 in. walls

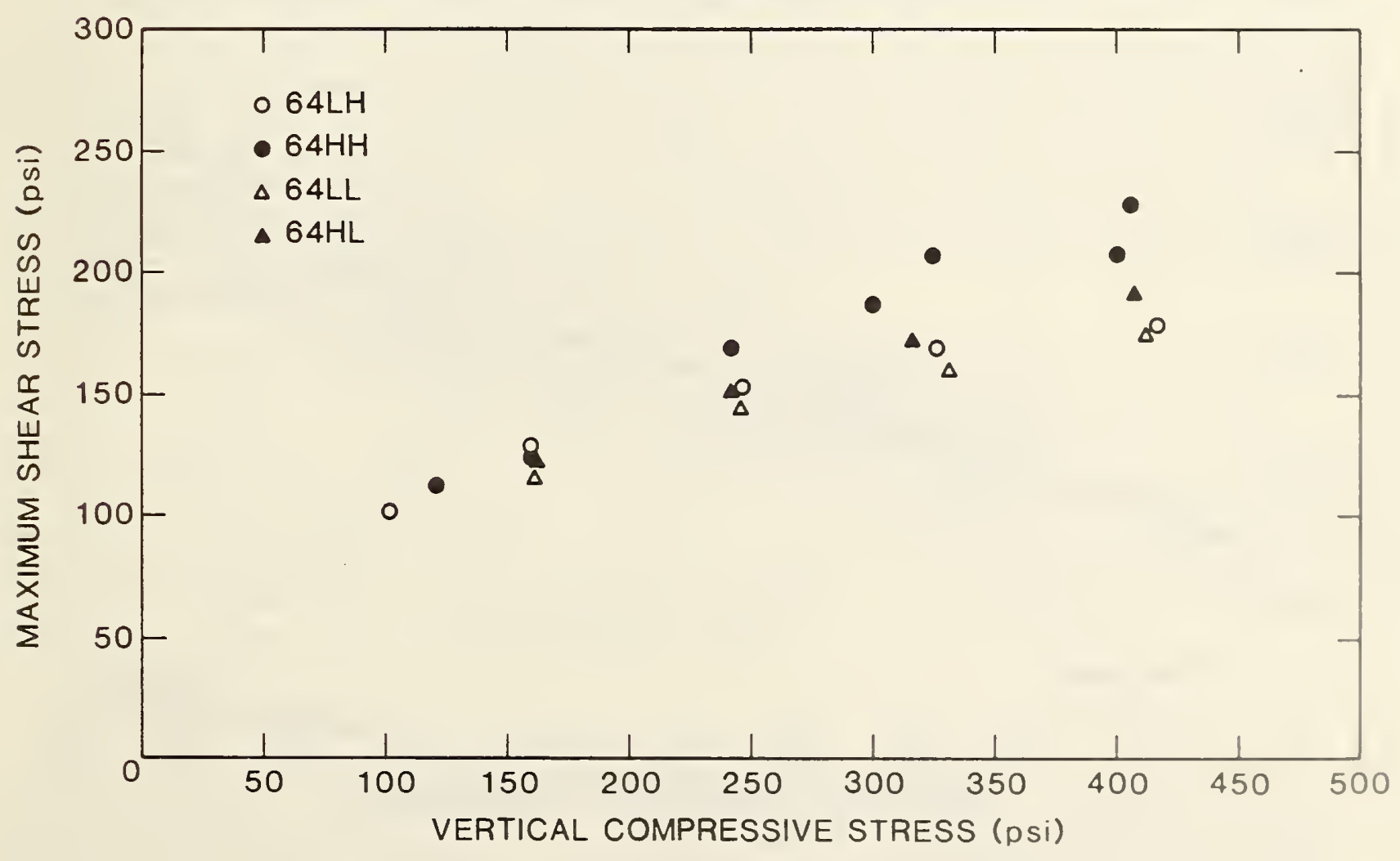

Figure 3.7 Maximum shear stress versus vertical stress for 64 in. walls 


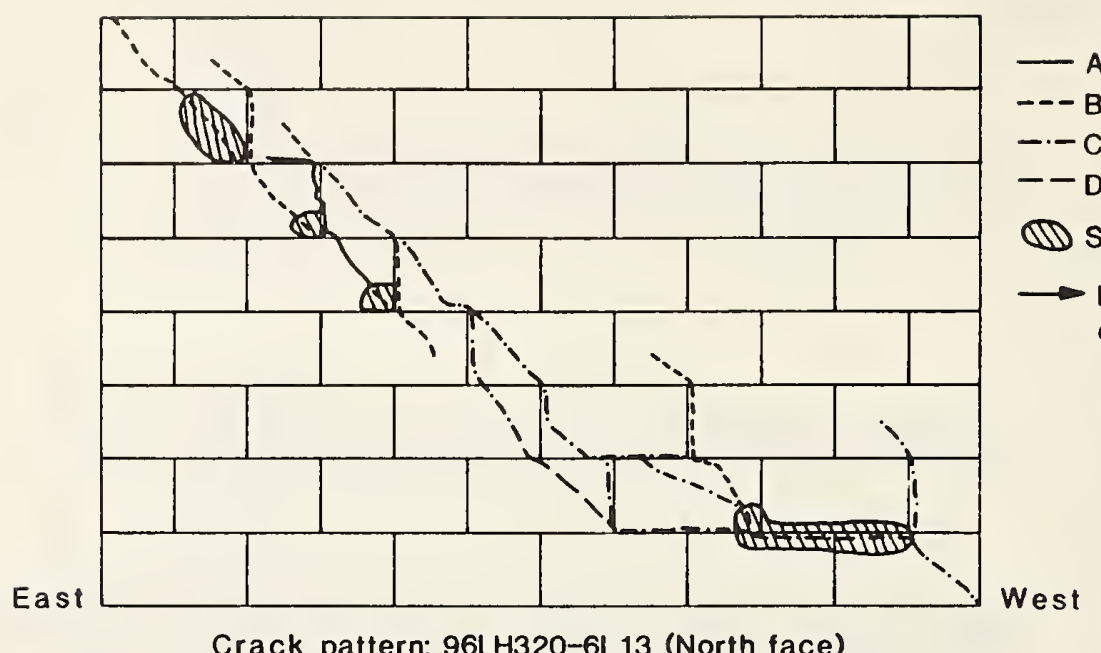

A
$--B$
$--C$
$--D$

(1) Spalled area

Direction of initial displacement

Figure 3.8 Cracking in 96 in. wall panels

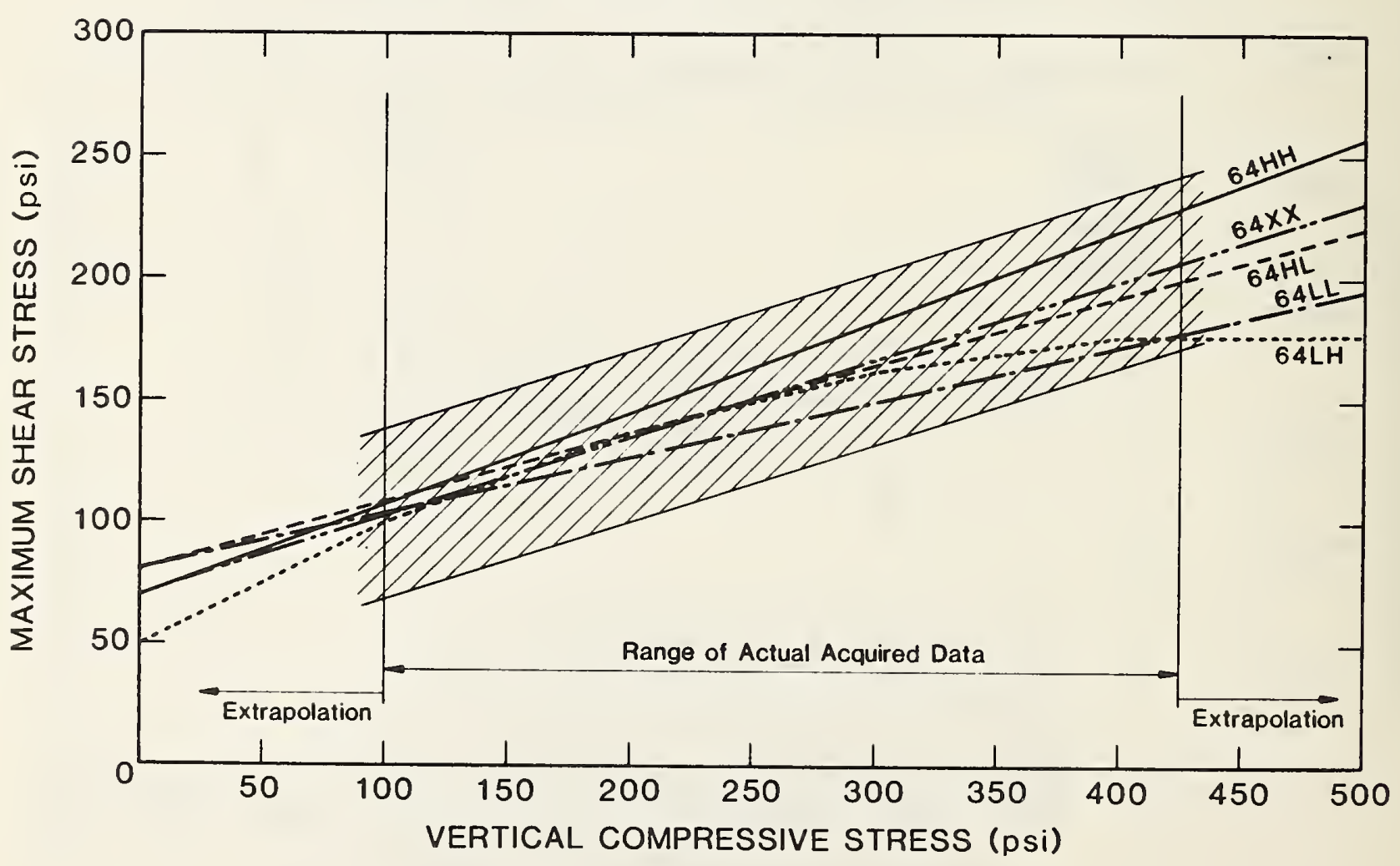

Figure 3.9 Regression analysis curves 
affected by the interaction of block and mortar strengths rather than simply by each strength independently. The regression line for all of the 64 in. long walls is plotted in fig. 3.9 and it is labelled $64 \mathrm{xx}$. The equation of the line is $\mathrm{v}=(70.8+0.321 \mathrm{a})$ where $\mathrm{v}$ is the maximum shear stress and $\mathrm{a}$ is the vertical compressive stress, both in units of psi. The standard error of the regression analysis (e) is $17.4 \mathrm{psi}$ and parallel lines $2 \mathrm{e}$ above and below the regression line are also shown on the plot.

\subsection{SHEAR STRESS-DISPLACEMENT RELATIONSHIP}

The measured shear stress-displacement curves are shown in figures 3.10 through 3.15. The shear stress is the measured global in-plane lateral load divided by the wall's net cross-sectional area and the displacement is the in-plane wall displacement as measured by the top west LVDT (fig. 2.3). The curves include only the data up to a displacement just past that corresponding to the maximum shear stress.

The curves in figures 3.10 and 3.11 illustrate the effect of block strength variation for the 64 in. long walls built with high and low strength mortar, respectively. As the relationships in fig. 3.10 indicate, there is a noticeable decrease in stiffness for the low strength block walls compared to high strength block walls built with high strength mortar. However, the same trend is not observed for the walls built with low strength mortar. There does not appear to be any indication that the variation in block strength significantly affects the wall displacement at which the maximum shear is achieved.

The curves in figures 3.12 and 3.13 show the effect of mortar strength variation for the $64 \mathrm{in}$. long walls built with high and low strength block, respectively. Based on the information presented in fig. 3.12, it appears that for the walls built with high strength block a decrease in mortar strength causes a decrease in wall stiffness. A similar trend is not apparent in the data for walls built with low strength block. These relationships also do not exhibit a tendency for the mortar strength to affect the wall displacement at which the maximum shear stress occurs.

Shear stress-displacement curves are shown in figures 3.14 and 3.15 for 48 in. and 96 in. long walls, respectively. All of the wall panels whose data are shown in these two figures have high strength mortar, but have either low or high strength block. Based on the trends observed in the $64 \mathrm{in}$. wall panels, it is expected that the low strength block walls will exhibit a marked lower stiffness, but the wall displacement coincident with the maximum shear stress will be relatively unchanged. As the curves in figures 3.14 and 3.15 illustrate, the trends observed for 64 in. walls do, in fact, exist for the 48 in. and $961 \mathrm{n}$. long walls.

\subsection{DIAGONAL STRAIN}

The primary mode of distress in the walls is diagonal tension cracking. It seems reasonable that cracking is a function of the tensile component of the diagonal stresses or strains. It is suggested by the previous reports [1, 2] that diagonal tension strain is a reliable indicator of the onset of diagonal 


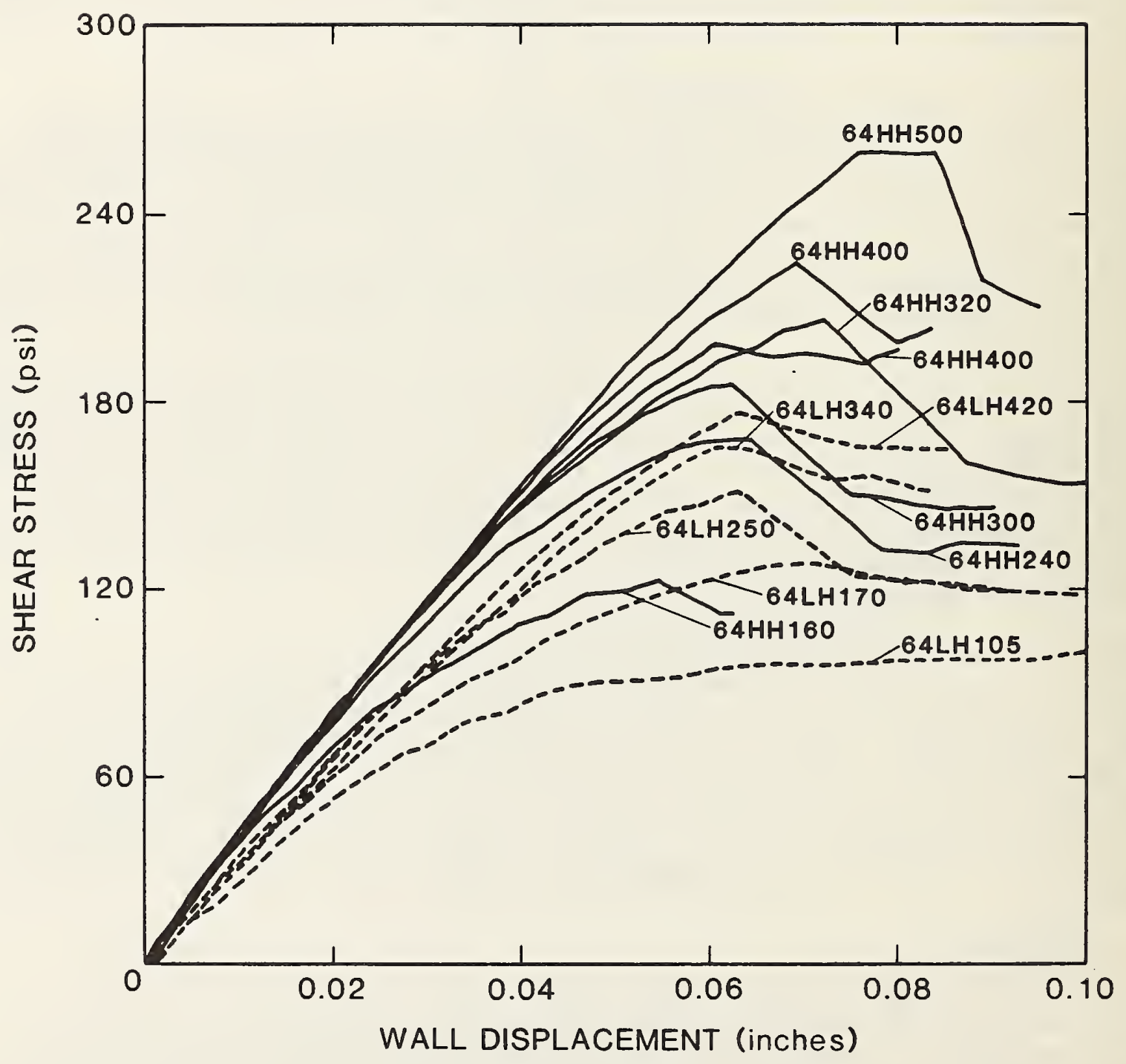

Figure 3.10 Shear stress-displacement curves ( $64 \mathrm{HH} \& 64 \mathrm{LH}$ ) 


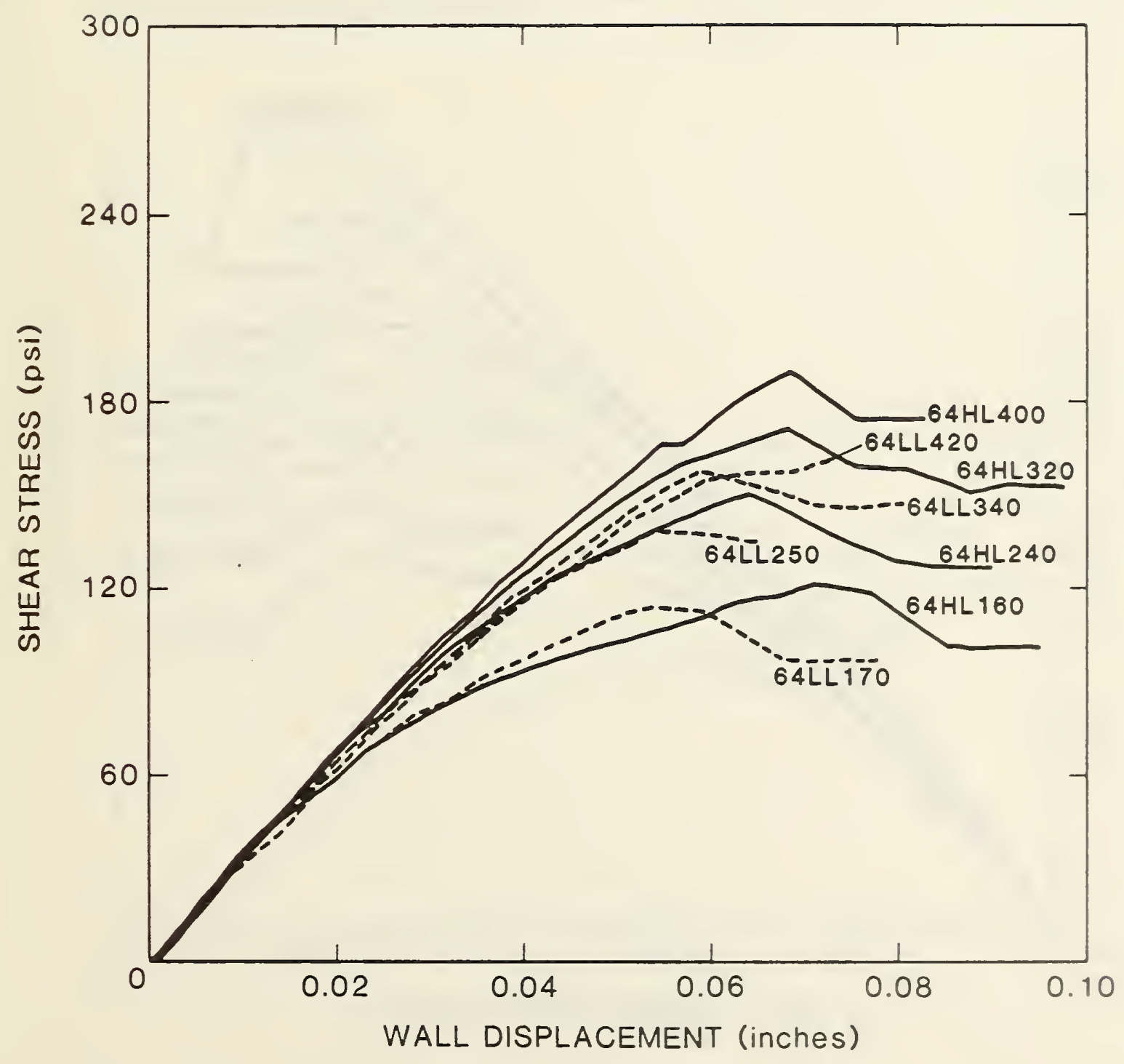

Figure 3.11 Shear stress-displacement curves (64HL \& 64LL) 


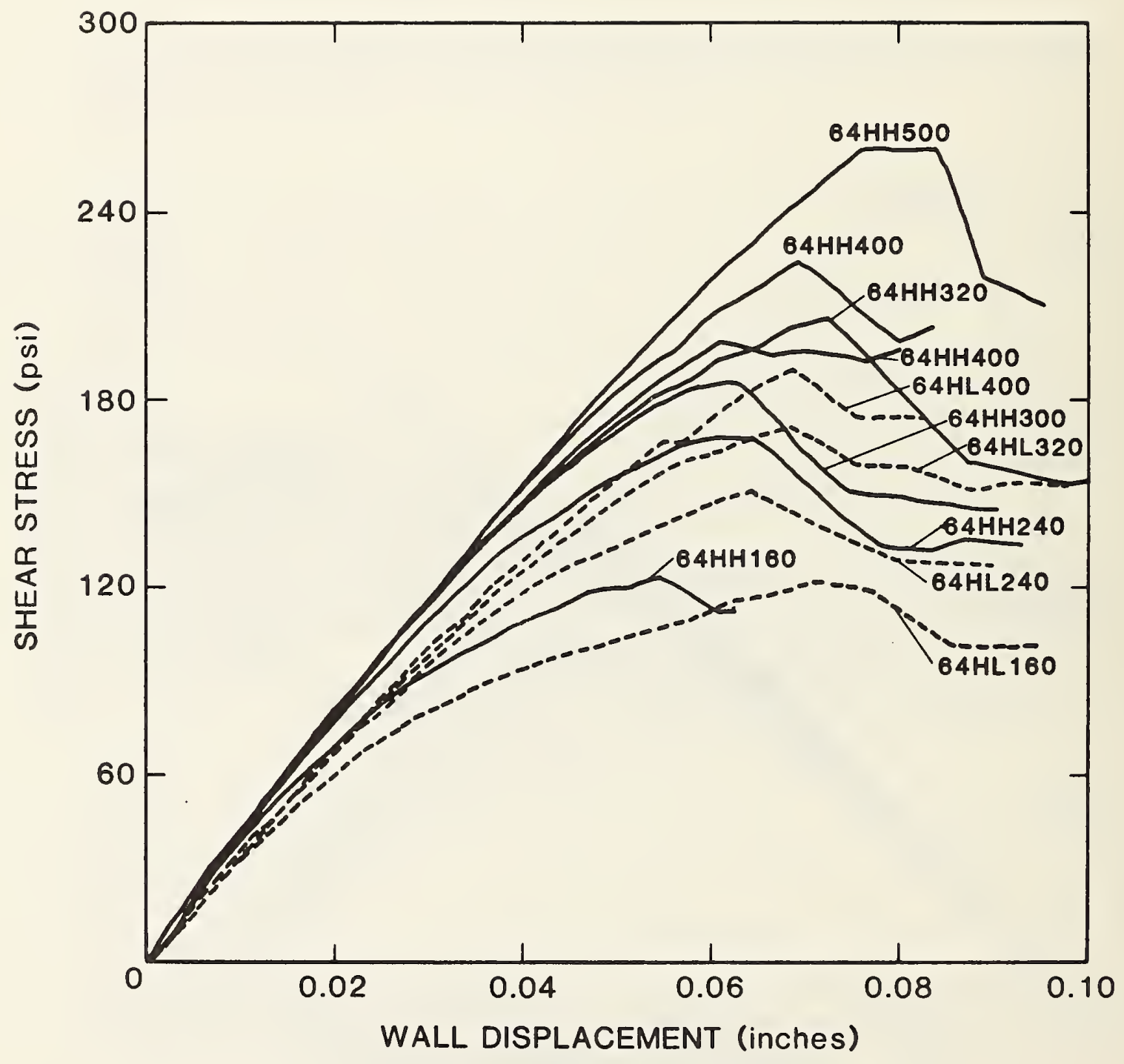

Figure 3.12 Shear stress-displacement curves ( $64 \mathrm{HH} \& 64 \mathrm{HL}$ ) 


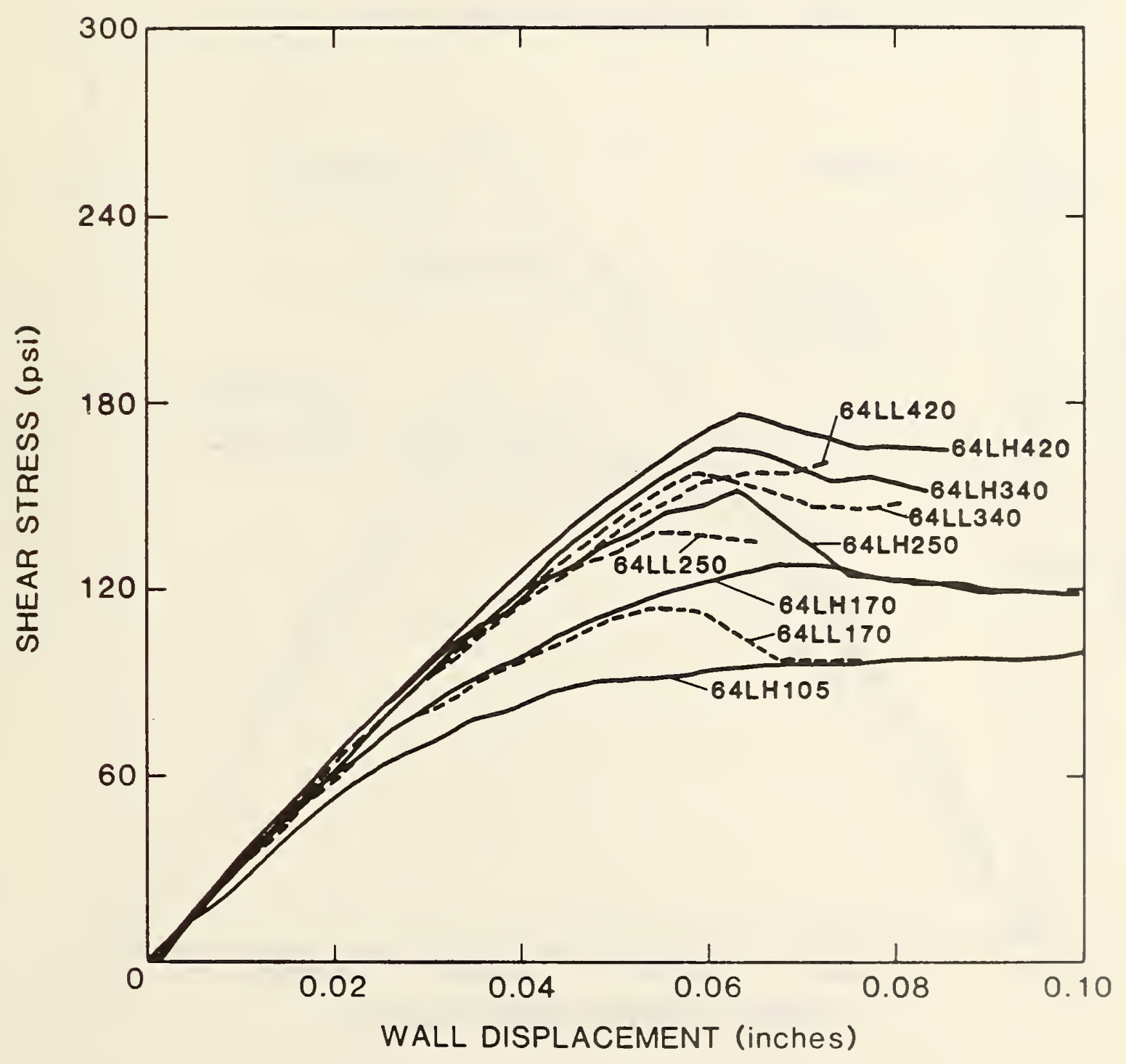

Figure 3.13 Shear stress-displacement curves (64LH \& 64LI) 


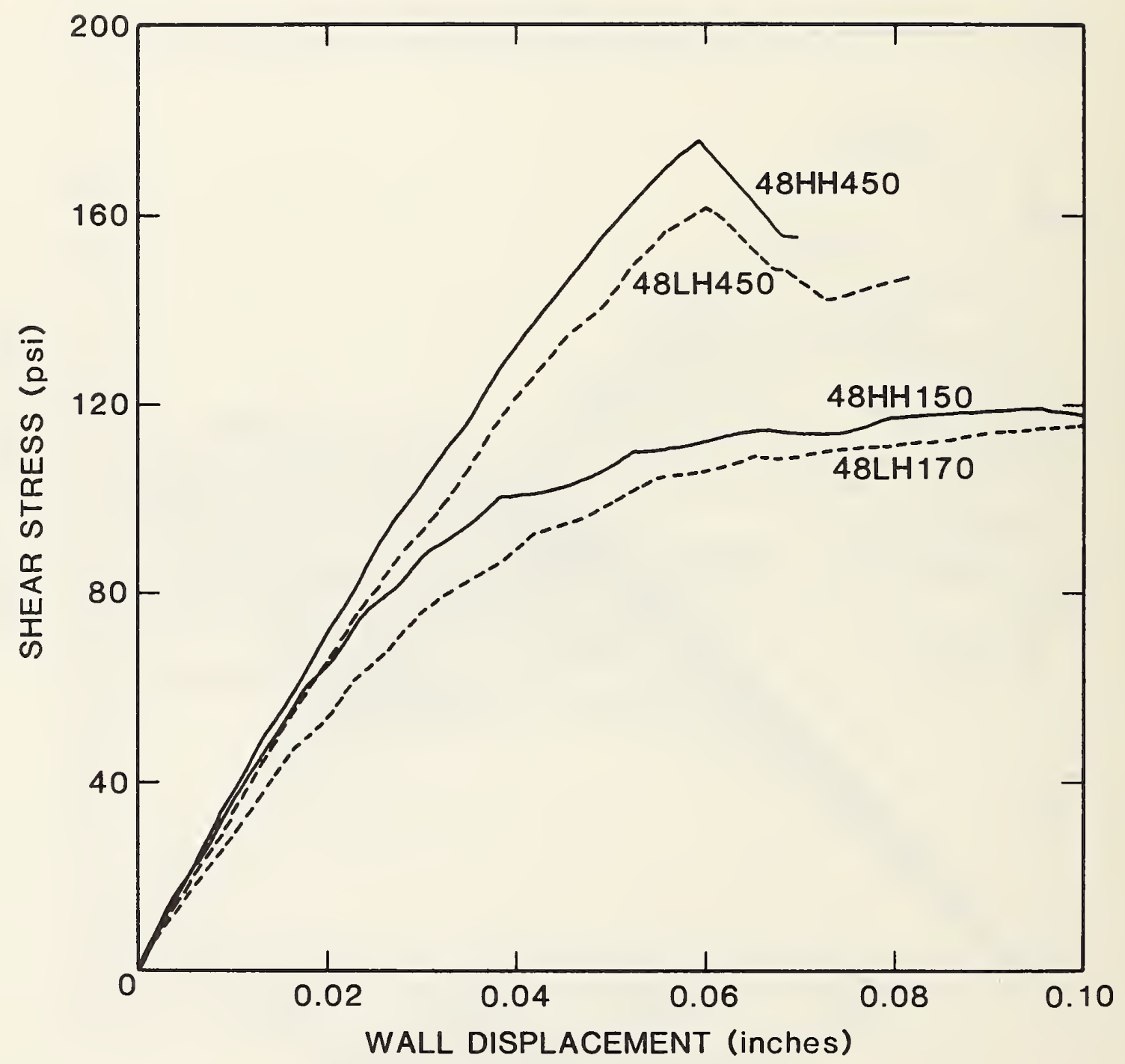

Figure 3.14 Shear stress-displacement curves (48 in.) 


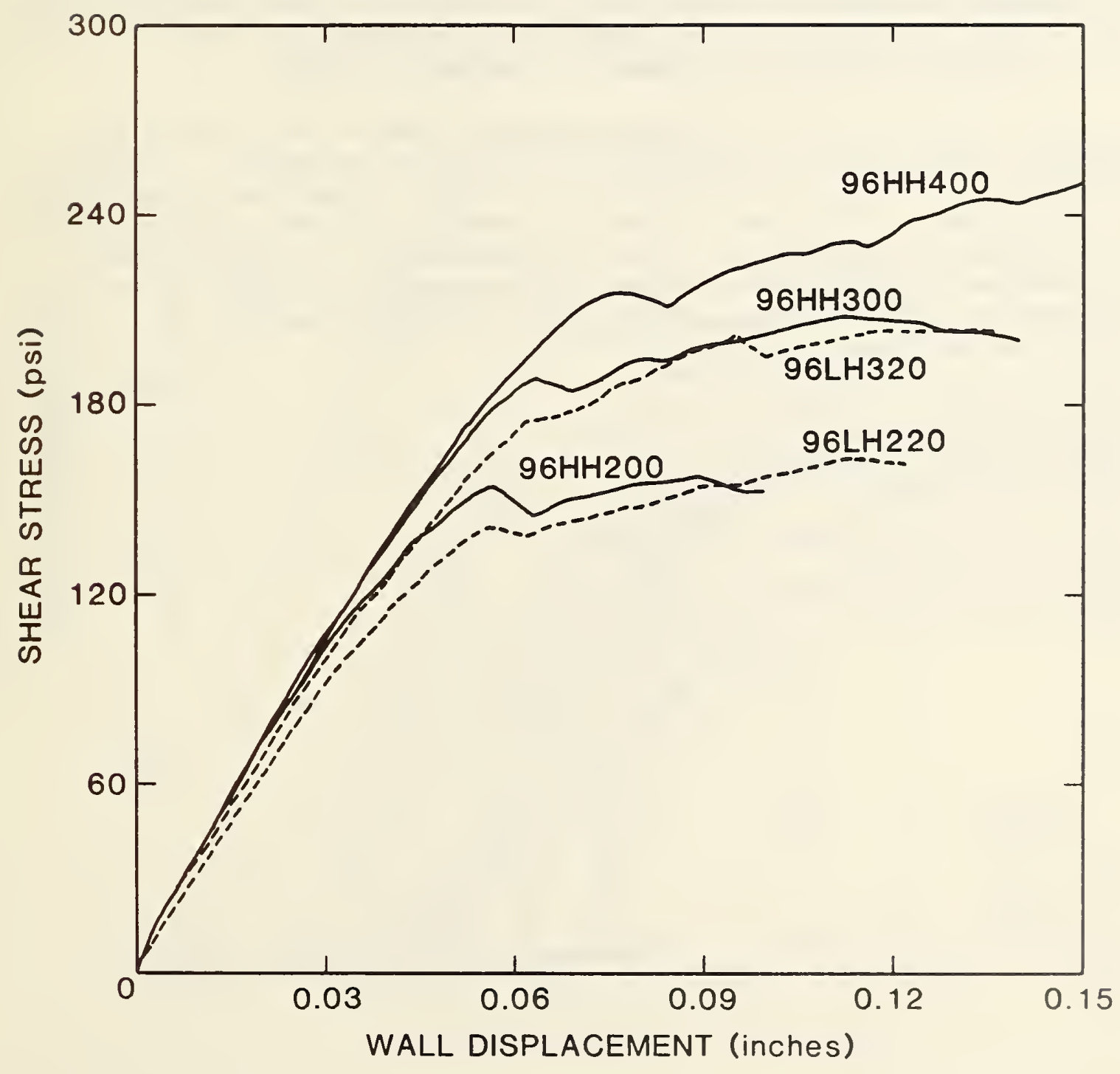

Figure 3.15 Shear stress-displacement curves (96 in.) 
tension cracking and that the threshold strain at cracking is relatively unaffected by variations in vertical compressive stress and wall aspect ratio. The data from the tests reported herein also tend to suggest that the threshold strain is unaffected by variations of block and mortar strength.

The relationships between shear stress and the diagonal strain for all of the $64 \mathrm{in.} \mathrm{wall} \mathrm{panels} \mathrm{are} \mathrm{shown} \mathrm{in} \mathrm{fig.} \mathrm{3.16.} \mathrm{These} \mathrm{include} \mathrm{data} \mathrm{from} \mathrm{wall} \mathrm{panels}$ reported previously. The diagonal strain is that computed from the displacements measured by the NL diagonal LVDT shown in fig. 2.7. With four noticeable exceptions, the curves show a definite tendency to exhibit unstable strain growth, indicative of cracking, at a common threshold strain. The exceptions are all from tests with relatively high vertical stress levels ( $>300$ psi), but not all wall panels subjected to such vertical stresses exhibited this atypical behavior. Within the scope of this report, the exceptions will remain anomalies and possible explanations for their behavior are not discussed.

The data shown in fig. 3.16 is divided into other figures (fig. 3.17-3.20) which highlight the trends for changing block or mortar strength. The effect of block strength is shown in figures 3.17 and 3.18 for high and low strength mortar, respectively. The effect of mortar strength is shown in figures 3.19 and 3.20 for high and low strength block, respectively. The data in these figures emphasize that within the variation of parameters actually tested the threshold diagonal strain is independent of the varied parameters. 


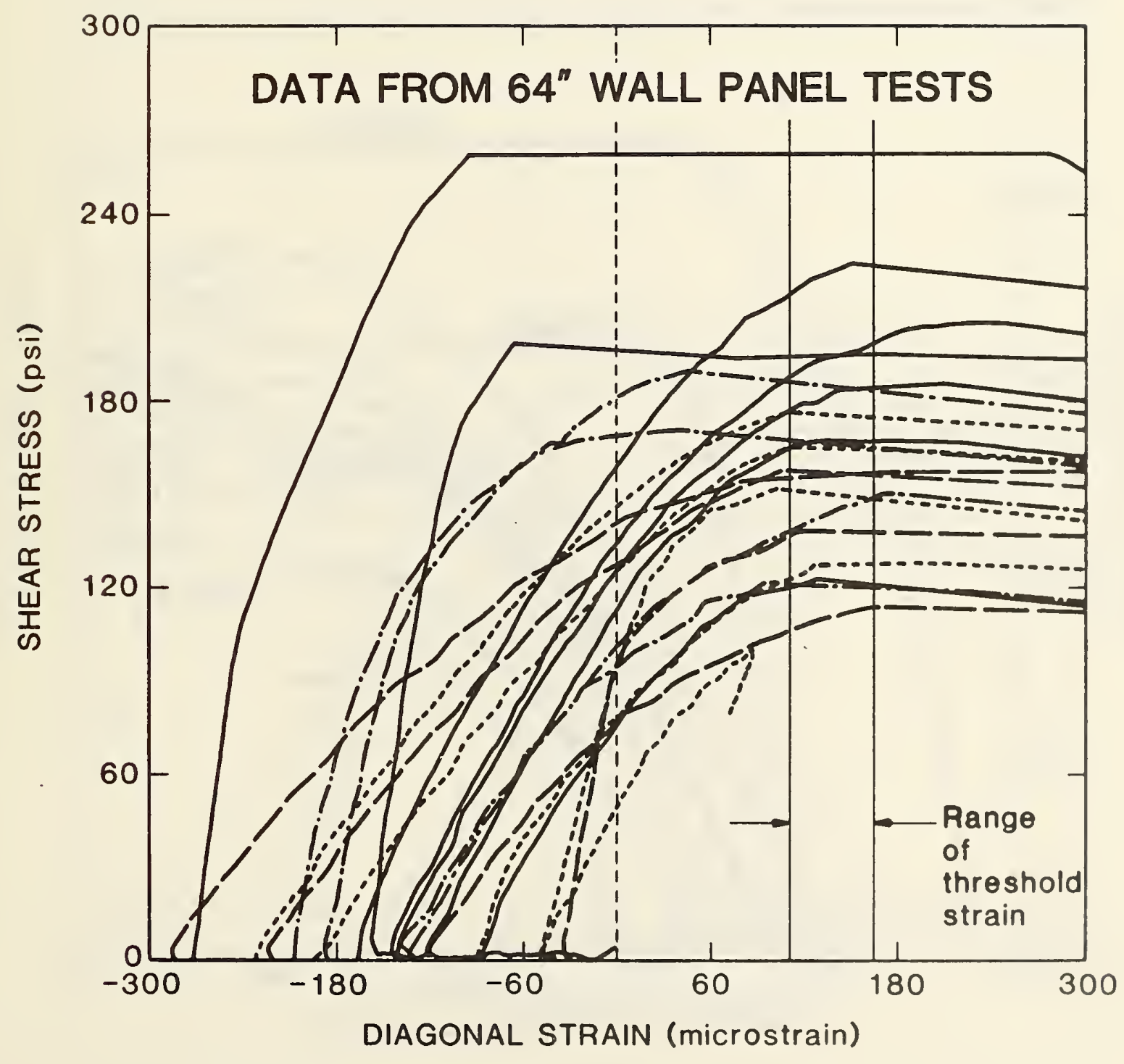

Figure 3.16 Combined shear stress-diagonal stress curves 


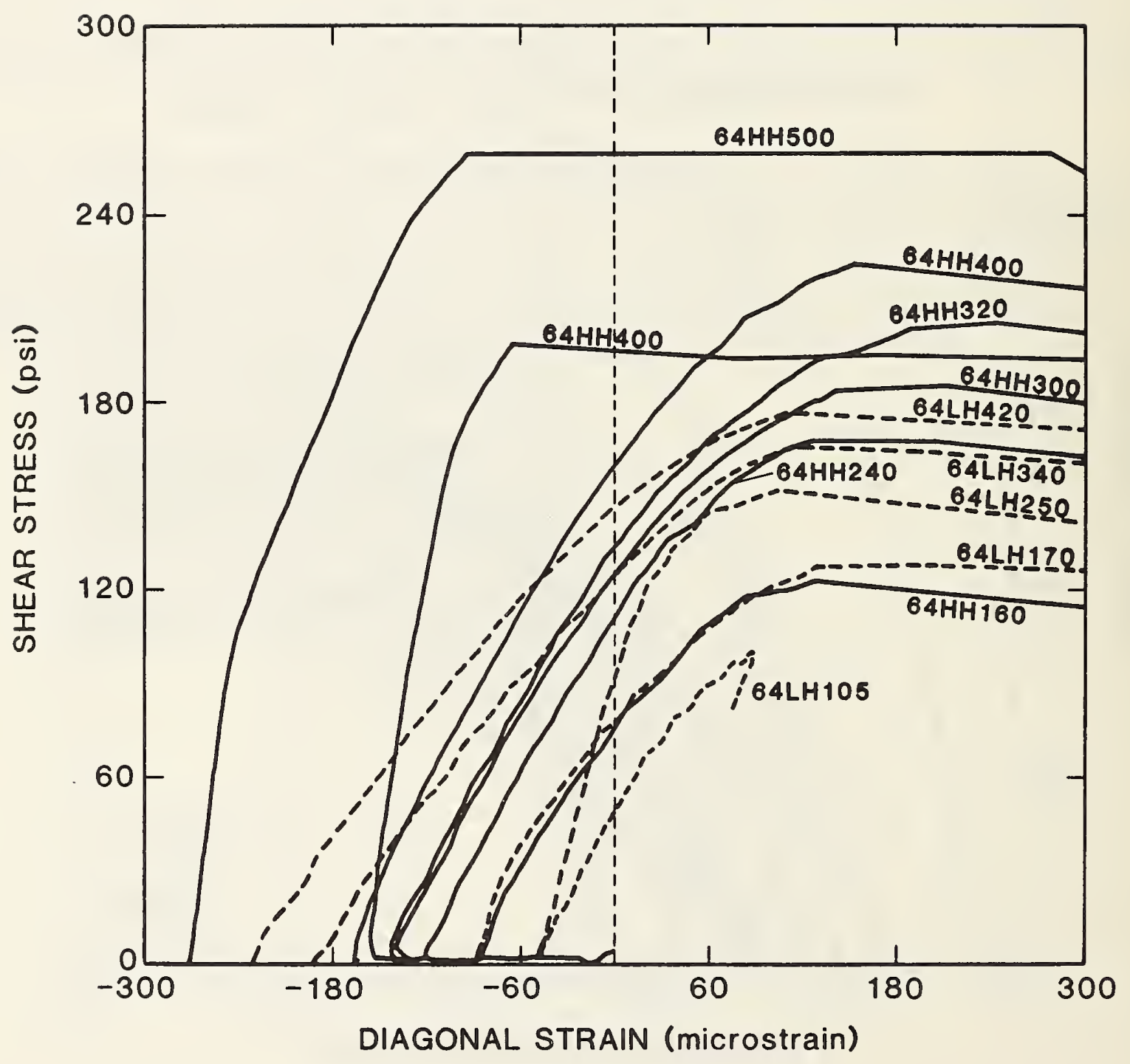

Figure 3.17 Shear stress-diagonal strain curves ( $64 \mathrm{HH} \& 64 \mathrm{LH}$ ) 


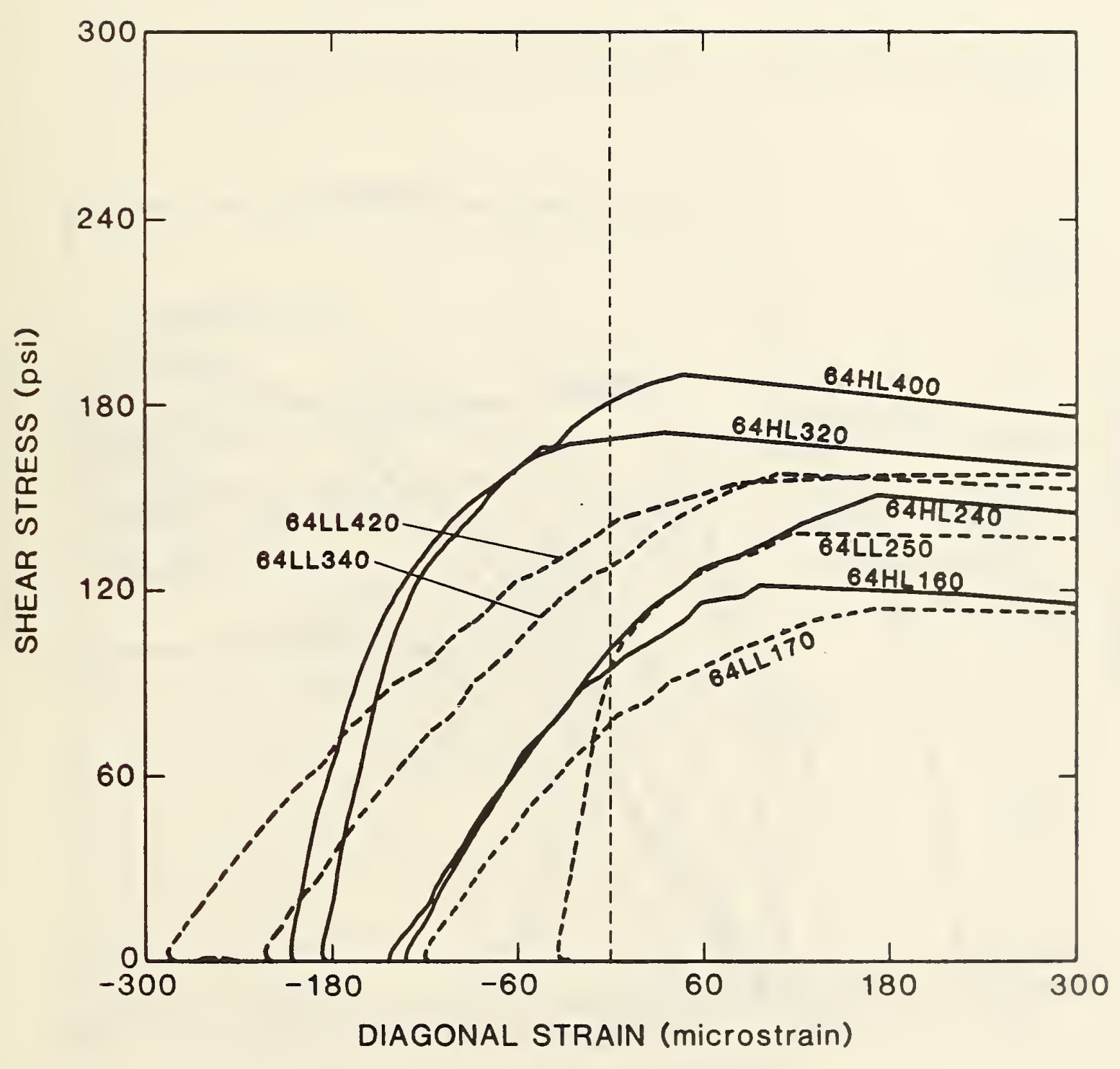

Figure 3.18 Shear stress-diagonal strain curves (64HL \& 64LL) 


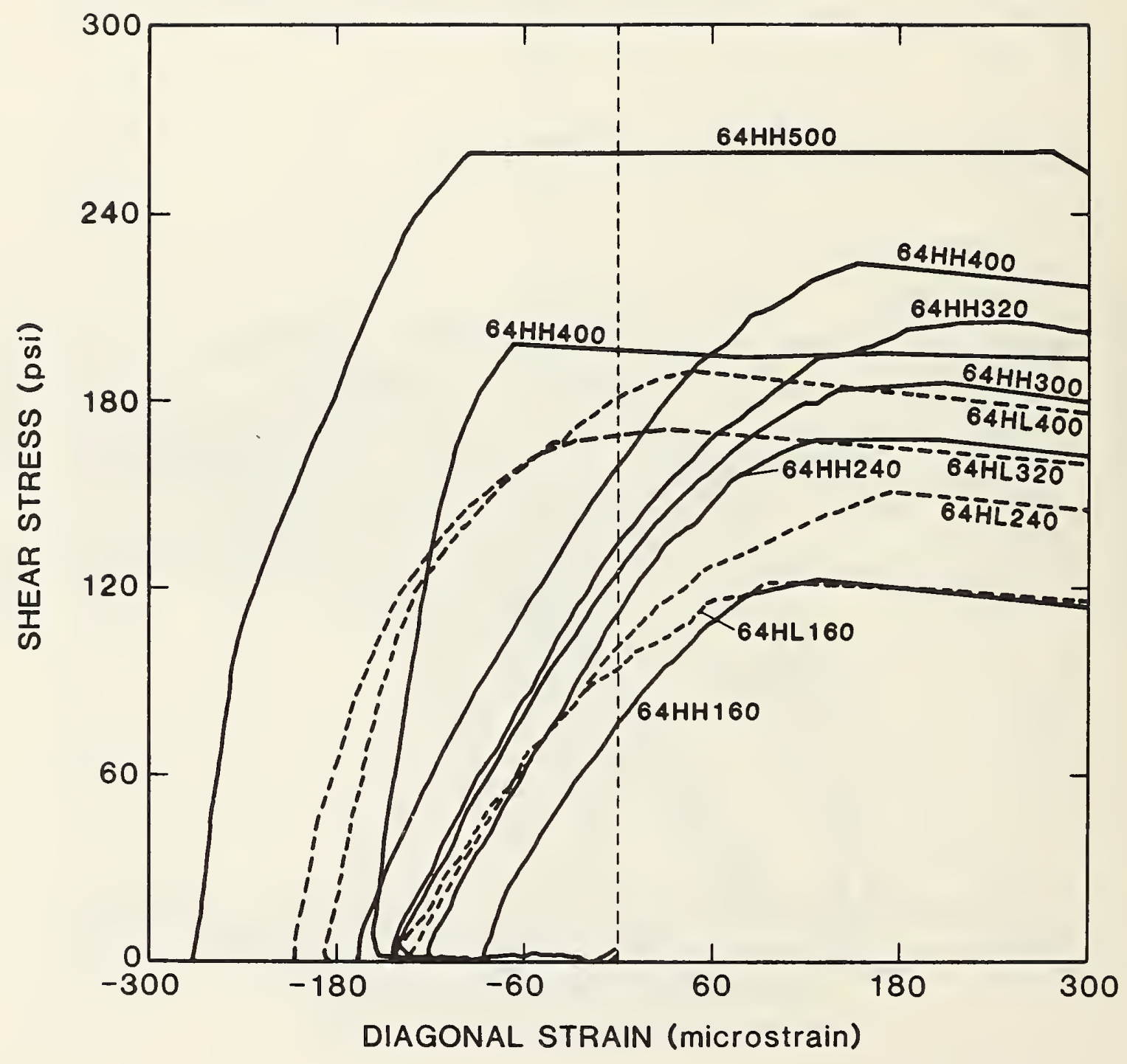

Figure 3.19 Shear stress-diagonal strain curves ( $64 \mathrm{HH} \& 64 \mathrm{HL}$ ) 


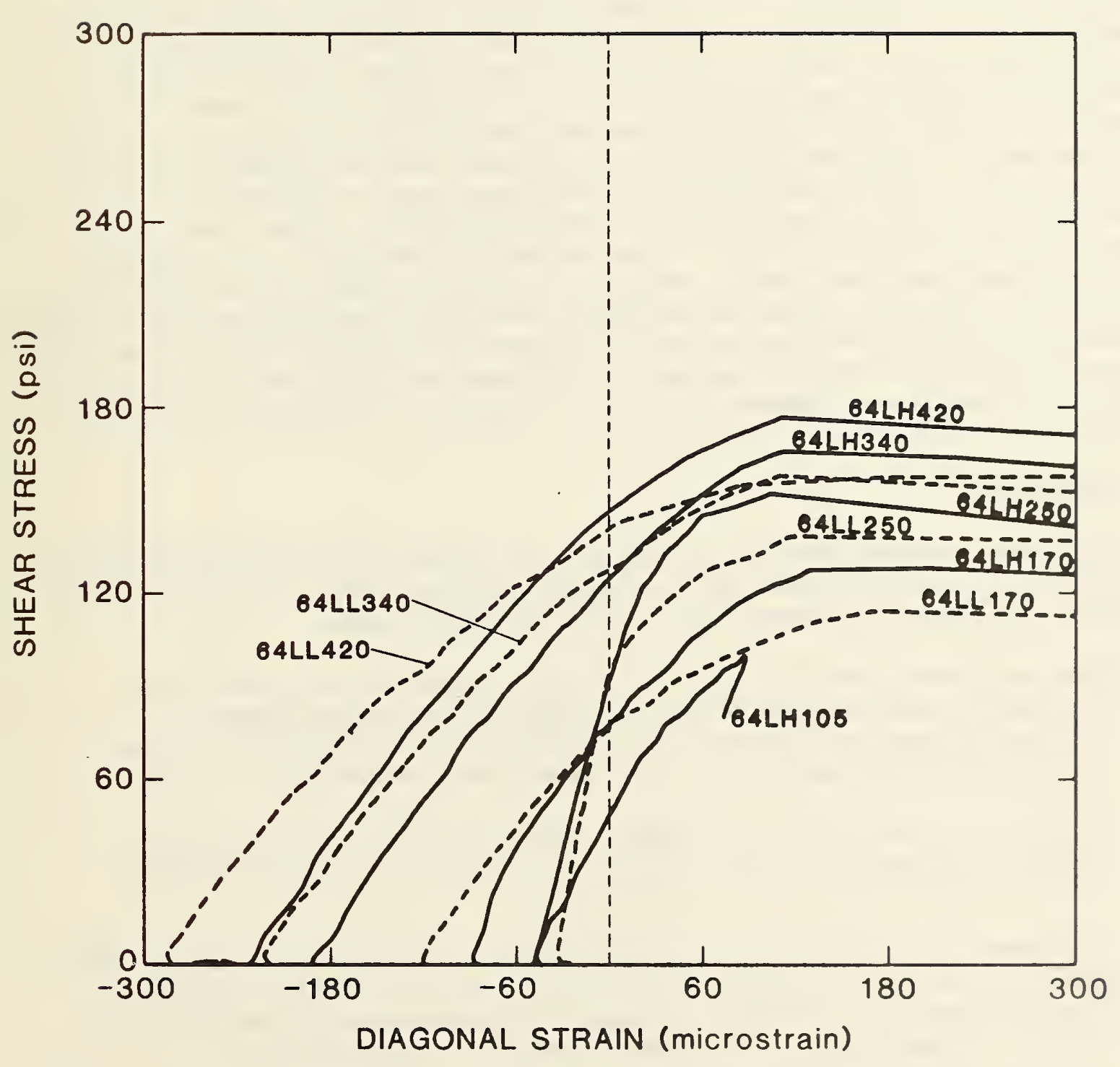

Figure 3.20 Shear stress-diagonal strain curves ( $64 \mathrm{LH} \& 64 \mathrm{LL}$ ) 


\section{SUMMARY AND CONCLUSIONS}

\subsection{SUMMARY}

Data from seventeen wall tests were presented. The walls were built using hollow concrete block having an approximate gross area unit strength of either 1800 psi or 1300 psi and mortar proportioned as either Type S or Type N. Al1 of the walls had a nominal height and thickness of $64 \mathrm{in}$. and 8 in., respectively. Thirteen of the walls had a length of $64 \mathrm{in}$., two of the walls were $48 \mathrm{in.}$ long, and the remaining two walls were $96 \mathrm{in}$. long. The applied vertical (axial) compressive stress was varied in the test series between the approximate limits of $100 \mathrm{psi}$ and $400 \mathrm{psi}$, based on the net cross-sectional area of the wall. The walls were subjected to in-plane lateral displacement in combination with a constant applied vertical compressive stress. The displacement was applied at the top of the wall while the bottom of the wall was held stationary. Rotation of the loading surface was restrained at the top and bottom of the wall, simulating a fixed-fixed boundary condition. The data indicated that for the lower levels of applied vertical stress used in the test series the influence of both block and mortar strength on the maximum shear resistance was negligible. However, as the vertical stress levels were increased the influence became significant with the expected result that higher strength block and/or mortar resulted in higher shear resistances. There also appeared to be an interaction between the effects of block and mortar strength on the shear resistance, suggesting that it may not be adequate to consider their effects independently.

\subsection{CONCLUSIONS}

The conclusions stated below are based solely on the data reported herein and data previously reported from this research program. The conclusions are only valid for the ranges of parameters included in these tests.

- For the lower levels of applied vertical compressive stress the influence of block and mortar strength on the maximum shear resistance was negligible. The influence of the strengths became more significant as the vertical stress was increased.

* Where block and mortar strengths influenced shear resistance, the influence appeared to be a function of their interactive effects and not solely due to one or the other.

- In general, the linear relationship between maximum shear resistance and applied vertical compressive stress was unaffected by block or mortar strength. The high strength block-low strength mortar walls were an exception and exhibited a quadratic relationship.

- The diagonal tension strain threshold at which diagonal cracking occurred was unaffected by the variation in block and mortar strength. 
5. ACKNOWLEDGEMETNS

The concrete block and the mason who fabricated the walls were provided by the National Concrete Masonry Association.

The authors wish to thank the reviewers, Dr. John Gross, Dr. Len Mordfin and Dr. Spencer Wu, for their comments and suggestions. 


\section{REFERENCES}

1. Woodward, Kyle and Rankin, Frank, "Influence of Vertical Compressive Stress on Shear Resistance of Concrete Block Masonry Walls," Report No. NBSIR 842929, National Bureau of Standards, Gaithersburg, MD, October 1984, 53 pp.

2. Woodward, Kyle and Rankin, Frank, "Influence of Aspect Ratio on Shear Resistance of Concrete Block Masonry Walls," Report No. NBSIR 84-2993, National Bureau of Standards, Gaithersburg, MD, January 1985, 56 pp.

3. Leyendecker, Edgar V. and Cattaneo, Louis E., "Review and Refinement of ATC3-06 Tentative Seismic Provisions - Report of Technical Committee 5: Masonry," Report No. NBSIR 80-211-5, National Bureau of Standards, Washington, D.C., October 1980,421 pp.

4. "Sampling and Testing Concrete Masonry Units," (ASTM Cl40-75), 1983 Annual Book of ASTM Standards, Vo1. 4.05, American Society for Testing and Materials, Philadelphia, PA, pp. 117-120.

5. "Standard Specification for Ground Iron Blast-Furnance Slag for Use in Concrete and Mortar," (ASTM C989-82), 1983 Annual Book of ASTM Standards, Vol. 4.02, American Society for Testing and Materials, Philadelphia, PA, pp. 629-633.

6. "Standard Specification for Blended Hydraulic Cements," (ASTM C595-83), 1983 Annual Book of ASTM Standards, Vol. 4.02, American Society for Testing and Materials, Philadelphia, PA, pp. 359-366.

7. "Standard Specification for Mortar for Units Masonry," (ASTM C270-82), 1983 Annual Book of ASTM Standards, Vol. 4.01, American Society for Testing and Materials, Philadelphia, PA, pp. 250-254.

8. "Standard Specification for Aggregrate for Masonry Mortar," (ASTM C144-81), 1983 Annual Book of ASTM Standards, Vol. 4.02, American Society for Testing and Materials, Philadelphia, PA, pp. 107-108.

9. "Standard Specification for Portland Cement," (ASTM C150-83), 1983 Annual Book of ASTM Standards, Vol. 4.01, American Society for Testing and Materials, Philadelphia, PA, pp. 156-162.

10. "Standard Specification for Hydrated Lime for Masonry Purposes," (ASTM C207-79), 1983 Annual Book of ASTM Standards, Vol. 4.01, American Society for Testing and Materials, Philadelphia, PA, pp. 221-224.

11. Woodward, Kyle and Rankin, Frank, "The NBS Tri-directional Test Facility," Report No. NBSIR 84-2879, National Bureau of Standards, Washington, D.C., May 1984,43 pp. 
The principal objective of the overall program of research is to define the shear capacity and behavior of shear-dominated masonry walls. The prediction of shear capacity and behavior of masonry has been identified as an area in which there is serious deficiency of supporting research. The NBS/BSSC review committee for the ATC3-06 masonry design provisions [3] suggested that research was needed to substantiate and improve the current design recommendations for shear capacity.

The main variables which are to be investigated in the NBS masonry research program are axial compressive stress, aspect ratio (wall length-to-height), masonry type, mortar type, grout, vertical and horizontal reinforcement, outof-plane loadings, and loading history. Analytical studies are coordinated with the experimental investigations so that a predictive model can be developed for defining the shear capacity and behavior of a masonry wall. The predictive model will lead to improved design standards, but in the interim the experimental test results will aid in substantiating and improving the current design provisions for shear in masonry walls. 

All materials used in the wall panel construction and associated prisms were commercially available and were representative of those commonly used in building construction.

\section{R.1 CONCRETE MASONRY UNITS}

Two concrete masonry unit shapes were used in the construction of the wall panels and prisms:

1. 8 in. $x 8$ in. $x 16$ in., 2 core hollow stretcher block.

2. 8 in. $x 8$ in. $x 16$ in., 2 core hollow kerfed corner block with a steel sash groove at one end.

The dimensions represent nominal sizes. Typical measured dimensions and physical characteristics of the units are presented in table B.1. The measurements were made in accordance with the procedures set forth in ASTM C140 [4]. The units are illustrated in fig. B.1. The half blocks at each end of alternating wall courses were made by sawing kerfed corner blocks in half through the kerf. Both halves produced by this procedure were used in the wall panels.

Al1 of the concrete masonry units used in the wall panels and prisms were manufactured on the same day by a commercial block manufacturer. The mixture proportions were set to produce units having ultimate gross area compressive strengths of either $1000 \mathrm{psi}$ or $2000 \mathrm{psi}$. The mixture proportions were:

\section{0 psi unit}

$19501 \mathrm{bs}$

$1250 \mathrm{lbs}$

$2001 \mathrm{bs}$

1901 bs

\section{0 psi unit}

$19501 \mathrm{bs}$

1250 lbs

$2601 \mathrm{bs}$

190 1bs lightweight expanded shale aggregate sand portland cement NEWCEM

NEWCEM is the proprietary name for a very finely ground water granulated blast furnance slag manufactured by Atlantic Cement Co., Inc. and is used as a partial replacement for portland cement. It meets the requirements of ASTM C 989 , grade 120 [5] and when blended within the range of 25 to 65 percent with portland cement, meets the requirements of ASTM C595 [6]. The preceeding description of NEWCEM is presented only for purposes of information and is not an endorsement of the proprietary product. The mixture used in producing the $1000 \mathrm{ps} 1$ and 2000 psi units made 118 units with 3.3 lbs of cementitious materials per unit and 115 units with 3.91 bs of cementitious materials per unit, respectively.

\section{R.2 MORTAR}

Two types of mortar were used in constructing the wall panels and prisms. One type of mortar was a portland cement-lime mortar that was proportioned within the limits of a Type S mortar according to the specifications of ASTM C270 171. 
The other type of mortar was also a portland cement-lime mortar, but proportioned within the limits of a Type $N$ mortar. The materials used in the mortar were:

1. Sand - A natural bank sand that was dug locally with its primary use being for masonry mortar. Sieve analyses were performed on the sand upon delivery. The analyses were done according to the specifications in ASTM $\mathrm{Cl} 44$ [8] and the results appear in table B.2. The fineness modulus was 1.57 .

2. Portland cement - A commercially available, bagged, 941 bs per bag, Type I portland cement identified as meeting the specifications of ASTM Cl50 [9].

3. Lime - A commercially available bagged, 50 lbs per bag, hydrated lime, Type S, identified as meeting the specifications of ASTM C207 [10].

The Type S mortar was proportioned 1:3/8:4 with 1 part by volume of cement, $3 / 8$ part by volume of lime, and 4 parts by volume of sand. The Type $N$ mortar was proportioned 1:1:5 with 1 part by volume of cement, 1 part by volume of lime, and 5 parts by volume of sand. The parts were mixed in a typical motorized mortar mixer (fixed horizontal drum with rotating blades) for a period of not less than 3 minutes after all cement, lime, sand, and most of the water were added. Finally, small amounts of water were added to produce mortar of a consistency acceptable to the mason. Retempering of the mortar, if required, was permitted only once per batch. 
Table B.1 Dimensions and Properties of Concrete Masonry Units

\begin{tabular}{|c|c|c|c|c|}
\hline & \multicolumn{2}{|c|}{1000 psi Unit * } & \multicolumn{2}{|c|}{2000 psi Unit $* *$} \\
\hline & $\begin{array}{c}\text { Hollow } \\
\text { Stretcher }\end{array}$ & $\begin{array}{c}\text { Hollow } \\
\text { Corner/Sash } \\
\text { Groove } \\
\end{array}$ & $\begin{array}{l}\text { Hollow } \\
\text { Stretcher }\end{array}$ & $\begin{array}{c}\text { Hollow } \\
\text { Corner/Sash } \\
\text { Groove }\end{array}$ \\
\hline Width (in.) & 7.65 & 7.64 & 7.63 & 7.63 \\
\hline Height (in.) & 7.56 & 7.56 & 7.59 & 7.57 \\
\hline Length (in.) & 15.66 & 15.66 & 15.62 & 15.64 \\
\hline $\begin{array}{l}\text { Minimum Face } \\
\text { Shell Thickness (in.) }\end{array}$ & 1.30 & 1.29 & 1.30 & 1.30 \\
\hline Gross Area (in. $\left.{ }^{2}\right)$ & 119.8 & 119.6 & 119.2 & 119.3 \\
\hline Net Solid Area (in. ${ }^{2}$ ) & 60.4 & 66.1 & 61.5 & 67.0 \\
\hline $\begin{array}{l}\text { Gross Ultimate Com- } \\
\text { pressive Strength (psi) }\end{array}$ & 1304 & 1398 & 1813 & 1795 \\
\hline Density $\left(1 \mathrm{~b} / \mathrm{ft}^{3}\right)$ & 98.1 & 96.8 & 102.4 & 104.5 \\
\hline Absorption $\left(1 \mathrm{~b} / \mathrm{ft}^{3}\right)$ & 14.0 & 13.7 & 10.8 & 10.2 \\
\hline
\end{tabular}

* Average of measurements from 9 units of each type.

** Average of measurements from 6 units of each type. 


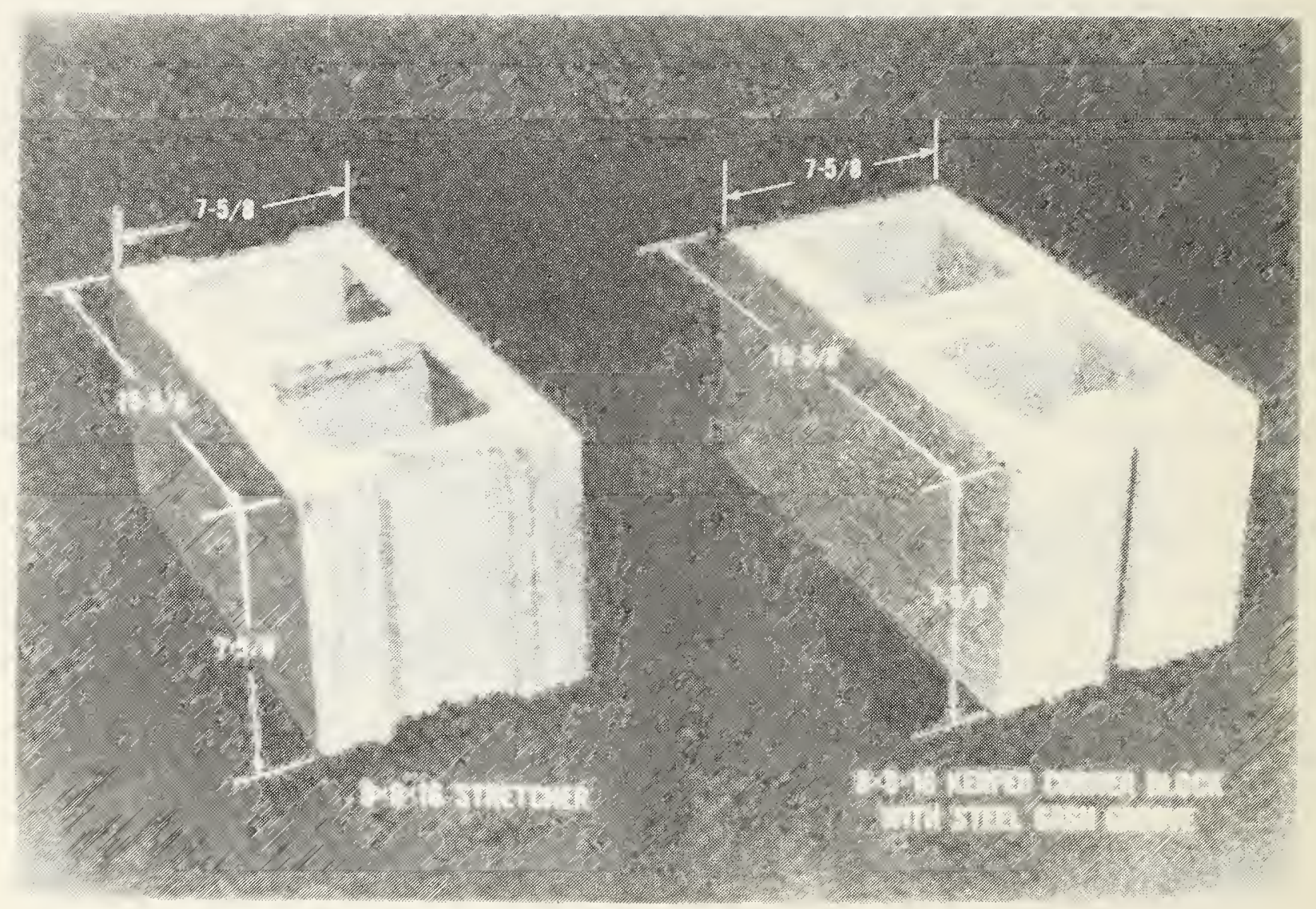

Figure B.1 Concrete Masonry Units 
Table B.2 Masonry Sand Sieve Analysis*

\begin{tabular}{c|c}
$\begin{array}{c}\text { Screen } \\
\text { Size } \\
\text { Number }\end{array}$ & $\begin{array}{c}\text { Cumulative } \\
\text { Percent } \\
\text { Retained }\end{array}$ \\
\hline 4 & 0.1 \\
8 & 0.6 \\
16 & 2.0 \\
30 & 11.0 \\
50 & 59.9 \\
100 & 86.6 \\
$100+$ & $\ldots \ldots$ \\
\hline
\end{tabular}

Total $157 \div 100=1.57$ Fineness Modulus

*Average of three samples taken upon delivery of sand. 

Appendix C. WALL PANEL DESCRIPTION

As companions to each wall, six mortar cubes ( 2 in. $x 2$ in. $x 2$ in.) were thade and three prisms were fabricated. The companion specimens were tested to provide information on mortar compressive strength and wall panel compressive strength.

\section{1 WALL PANEL FABRICATION}

The wall panels were constructed in running bond with 50 percent overlap of block in alternate wall courses. The wall panels had overall nominal dimensions of $64 \mathrm{in}$. in height, $8 \mathrm{in}$. in thickness, and either $96 \mathrm{in.,} 64 \mathrm{in.}$, or $48 \mathrm{in.} \mathrm{in} \mathrm{length.} \mathrm{The} \mathrm{wall} \mathrm{panels} \mathrm{(and} \mathrm{prisms)} \mathrm{were} \mathrm{constructed} \mathrm{by} \mathrm{an}$ experienced mason using techniques representative of good workmanship. The wall panels were fabricated in a controlled environment laboratory from materials stored in the same environment for a least 30 days. The temperture and relative humidity of the laboratory were maintained at approximately $73^{\circ} \mathrm{F}$ and 50 percent, respectively.

The bottom course of block was laid on a steel beam (channel) section without bedding mortar. The steel beam and first course were then leveled using shims as necessary. The first block laid in the bottom course was a whole kerf unit with no head joint mortar. Head joints were subsequently formed by buttering the end of the next block to be laid with mortar. The head joints were "shoved" joints with no closure units or backfilling of head joints. The mortar bed joints were formed by placing mortar along the face shells of the previously laid course of blocks. No mortar was placed on the cross-webs except for the end cross-webs. Each course was laid to maintain a course height of 8 in. The level of each course was fixed by a level string spanning between two vertically plumb posts. The end blocks were plumbed using a 4 foot level to maintain plumb end surfaces of the wall panel. All joints were struck flush with a trowel, but not tooled.

\section{C.2 PRISM FABRICATION}

Prisms were made along with most of the wall panels using mortar from the same batch as was used for the wall panel. Each prism was made by stack bonding three stretcher units. The mortar bedding between the blocks was either face shell only or full area bedding. Within each group of prisms the bedding was the same. The mason used a 4 foot level to maintain the level of each block and to plumb the prism. The ultimate compressive strength of the prisms was determined by testing the prisms in uniaxial testing machine having a total capacity of 400,000 pounds force. A spherically seated upper bearing block covered the entire bearing surface of the prisms. The load on the prism was applied at any convenient rate for the first 40,000 pounds force while the remaining load was applied at a rate of 40,000 pounds per minute until fallure occurred. The maximum load sustained by the prism was used in computing the ultimate compressive stress. 

Appendix D. WALL PANEL TESTS: SETUP AND PLACEMENT

\section{D.1 TEST SETUP}

The test setup ( $\mathrm{fig} .2 .2$ ) is the NBS Tri-directional Test Facility (NBS/TTF), a permanent loading apparatus designed to test building components using threedimensional loading histories. The NBS/TTF is described in a separate report [11], but for purposes of completeness a brief summary is presented in this section.

The NBS/TTF is a computer-controlled loading apparatus which can apply forces/ displacements in all six degrees of freedom at one end of a test specimen. The other end of the specimen is fixed. The six degrees of freedom are the translations and rotations in and about three orthogonal axes. The application of such actions is accomplished by seven closed-loop, servo-controlled hydraulic actuators which receive their instructions by means of computer generated commands. The major components of the NBS/TTF are shown in fig. 2.2. The reaction system is composed of the structural tie-down floor and two vertical buttresses. The load distribution system consists of the two $x$-shaped steel crossheads, one at the bottom and the other at the top of the test specimen. The load application system is made up of the seven hydraulic actuators. The control system is not visible in the figure, but includes the servo-control electronics, the data acquisition equipment, and a minicomputer.

\section{n.2 WALL PANEL PLACEMENT}

The wall panels were handled by attaching a carrying harness to the panel ( $f$ ig. D.1). The harness had attachment points for lifting the wall and a clamping arrangement which held the harness against the ends of the panel. The overhead crane was used to place the wall panel in the NBS/TTF and a special device was fabricated which permitted the wall to be placed under the upper crosshead. The special device was a large welded assembly in the shape of a " $C$ " which permitted the crane hook to be centered above the wall panel without interfering with the upper crosshead (fig. D.2).

The walls were set in place using mechanical stops which fixed the walls in their horizontal position. The walls were aligned vertically using small wedges set at four places under the face shells of the walls. The walls were fastened to the lower crosshead first, using an epoxy mortar along the bottom face shells and end cross-webs. The upper crosshead was then lowered onto the wall whose top face shell and end cross-webs were also mortared with the epoxy mortar. A small vertical compressive load ( 1,000 to 2,000 pounds) was applied to the wall to ensure contact between the wall and epoxy mortar. The upper crosshead was locked in position and the epoxy mortar was allowed to cure at least 16 hours before testing the wall. 


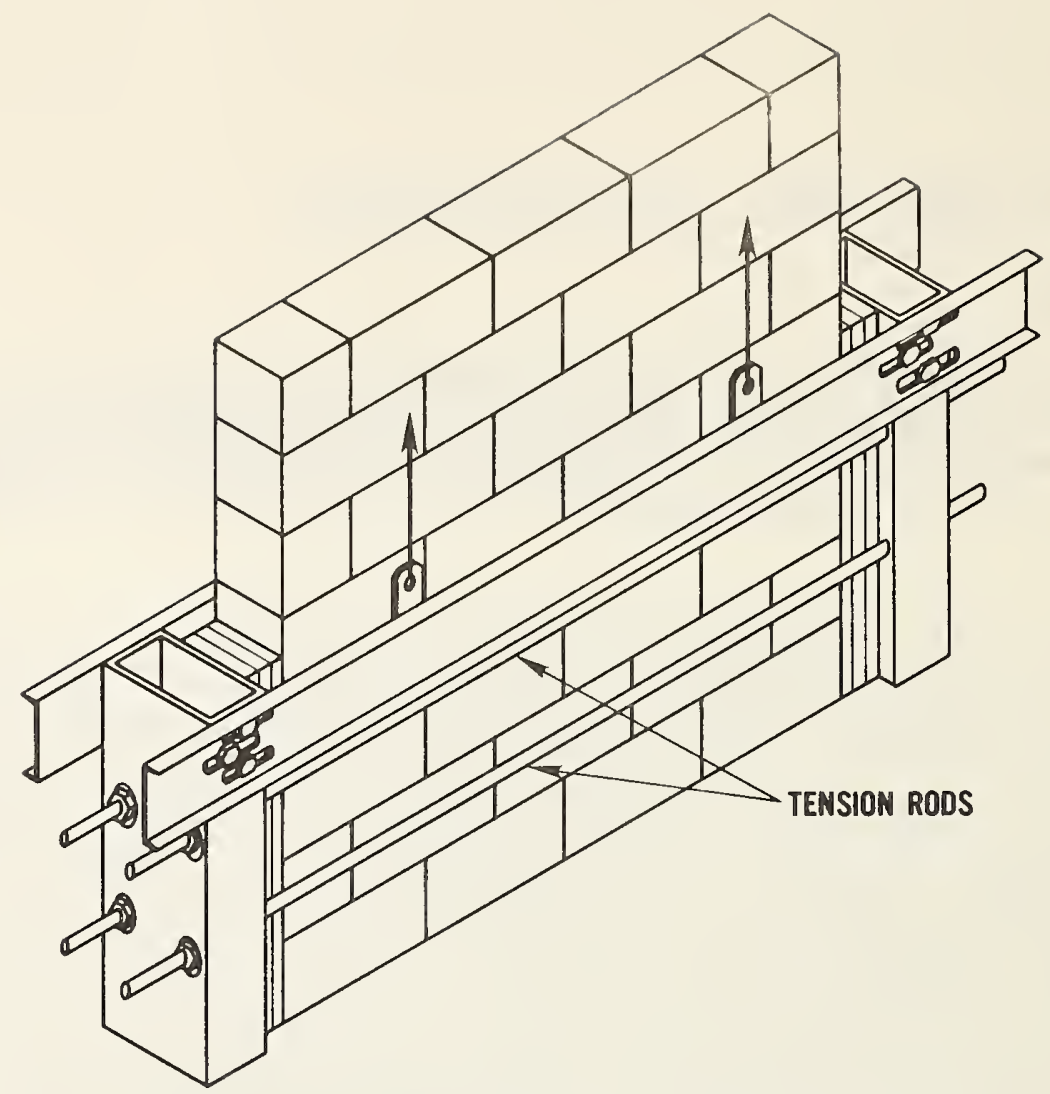

Figure D.1 Wall panel transport harness

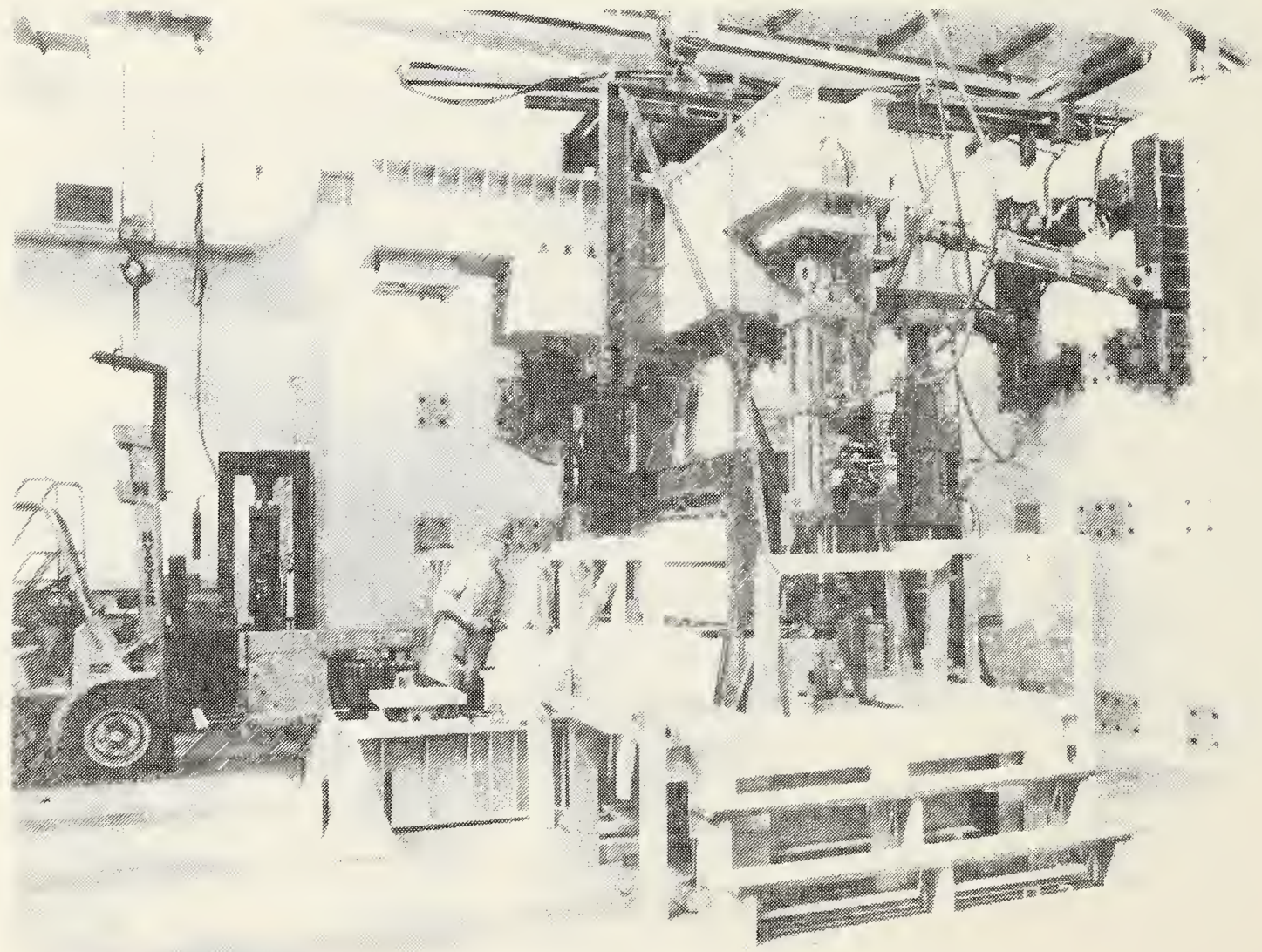

Figure D.2 Placement of a wall panel 
The load-displacement curves describe the complete loading (displacement) history for each wall test and provide a primary indicator of wall behavior. The load used in developing the curves is the horizontal load acting in the plane of the wall as measured by the hydraulic actuator load transducers. The load is referred to as the global in-plane load. The displacement used in the curve is the horizontal displacement of the upper crosshead in the plane of the wall (fig. 2.9). This displacement is referred to as the global in-plane displacement to differentiate it from the in-plane wall displacement measured by the horizontal LVDT's mounted to the wall (fig.2.3). The global in-plane displacment (GID) is determined by the displacement transducers in the hydraulic actuators. The GID and the wall displacement measured direct1y by LVDT's are not necessarily the same. The GID is affected by total apparatus displacement while the direct LVDT displacement more nearly measures an absolute inplane displacement of the wall. However, the direct LVDT displacment can be strongly affected by the breakup of a wall after cracking. Spalling and splitting in the region near a wall LVDT can produce large distortions in the apparent displacement. In general, the GID is a consistent measure of displacement which is unaffected by a local wall distortions and, as a result, is best for general comparisons between tests.

The crack pattern maps reflect the observations of wall cracking at selected points during the tests. The crack patterns provide useful information on the physical reponse of a wall to an imposed loading history. The patterns serve as a guide to identifying regions of high stress, general stress flow, and physical load resisting mechanisms. It is, of course, desirable that the points during a test at which crack patterns are recorded be identified on the load-displacment curves. This is accomplished by using an identifying symbol which marks a location on the load-displacement curve corresponding to an associated crack pattern on the map. The symbols are capital letters starting with the letter A. Thus, points on the load-displacement curve identified by the symbols are coincident with the crack pattern also associated with that symbo1. Symbol A does not refer to the same point on every load-displacement curve. 

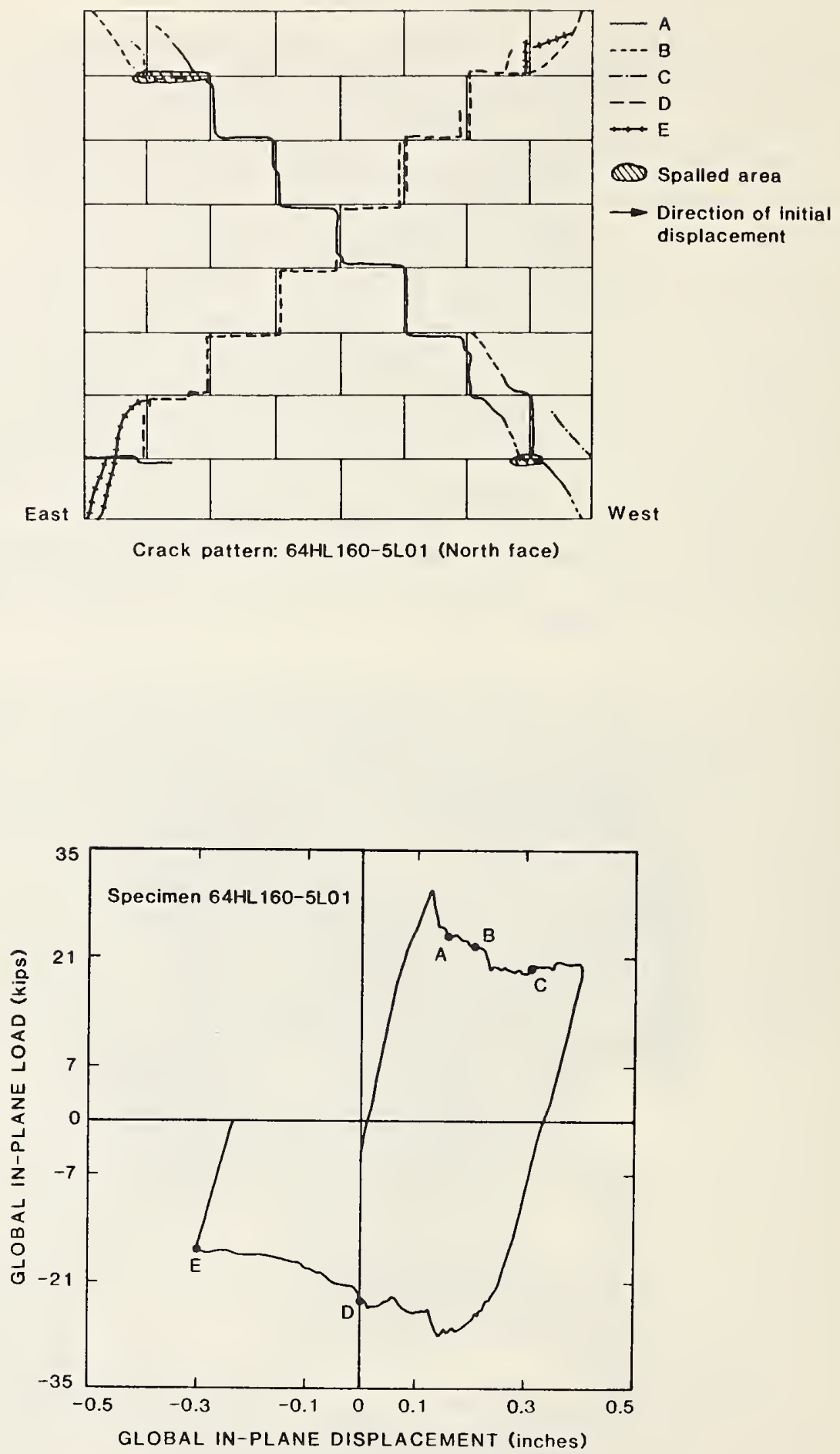

Figure E.1 Crack pattern and load-displacement curve for specimen $64 \mathrm{HL} 160$ 

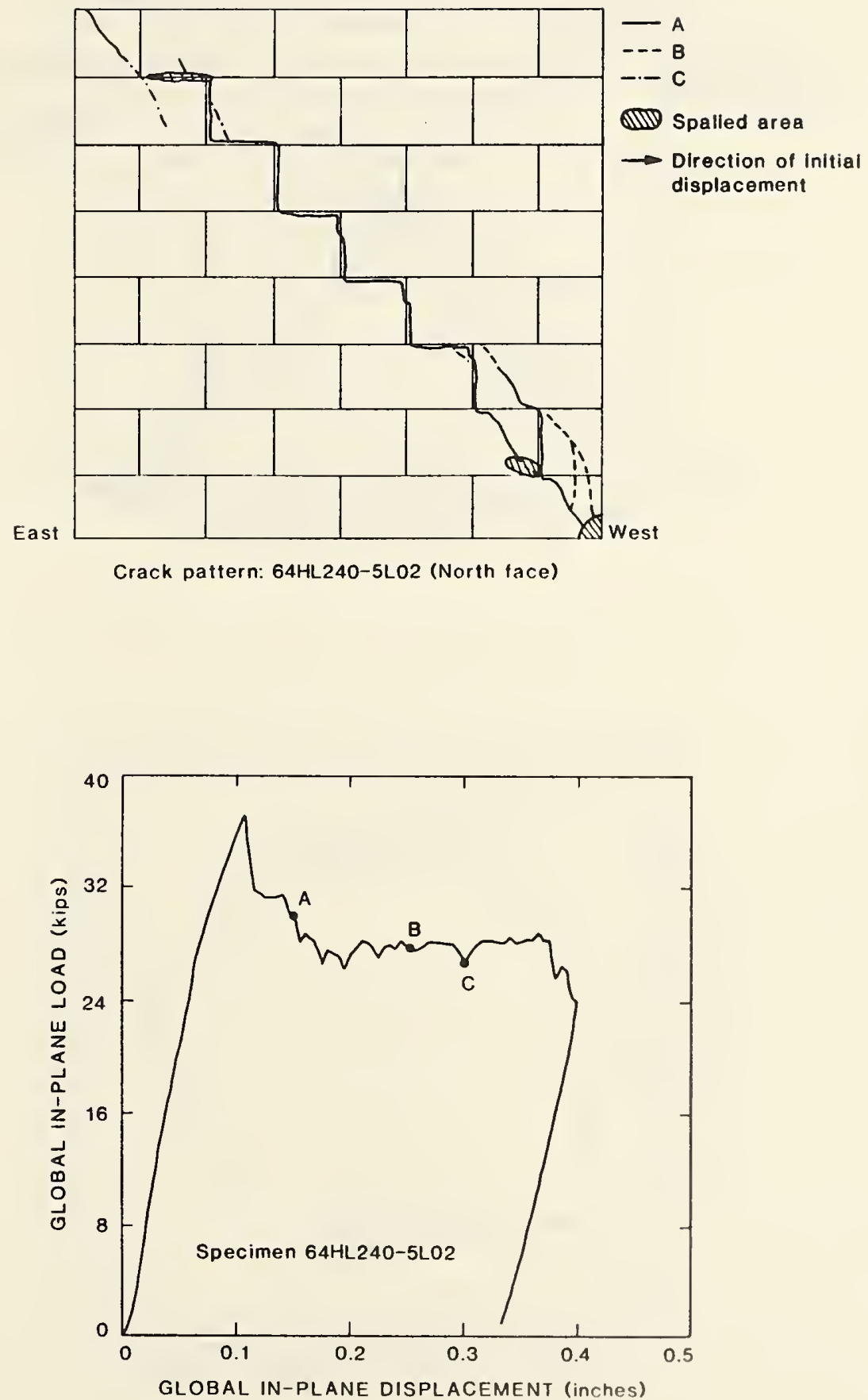

Figure E.2 Crack pattern and load-displacement curve for specimen $64 \mathrm{HL} 240$ 


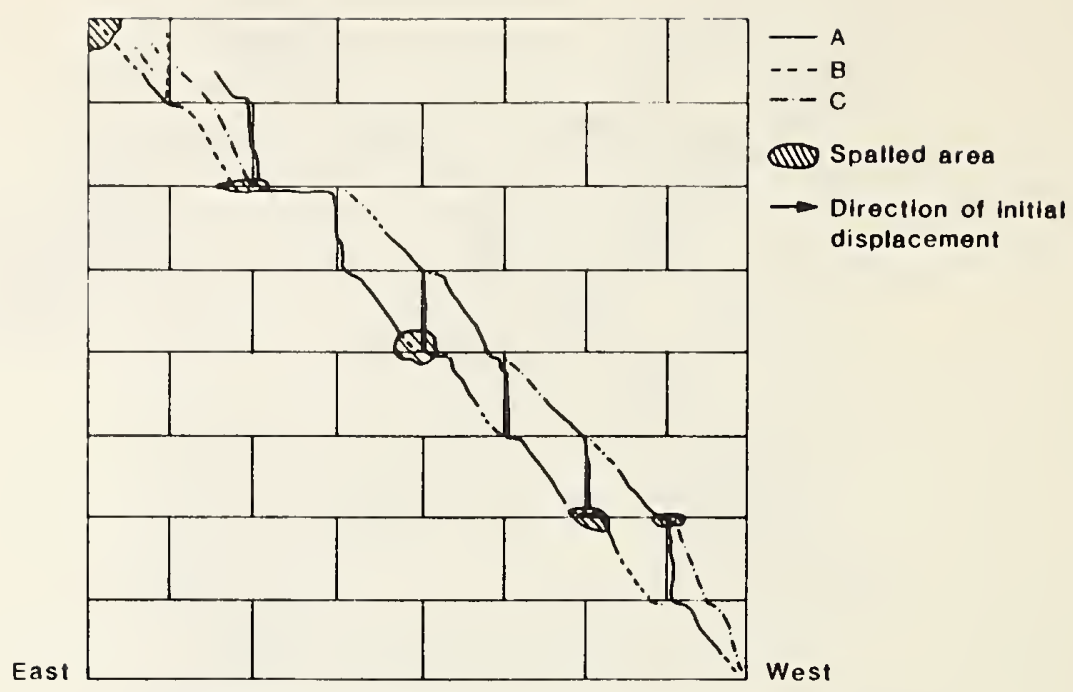

Crack pattern: 64HL320-5L03 (North face)

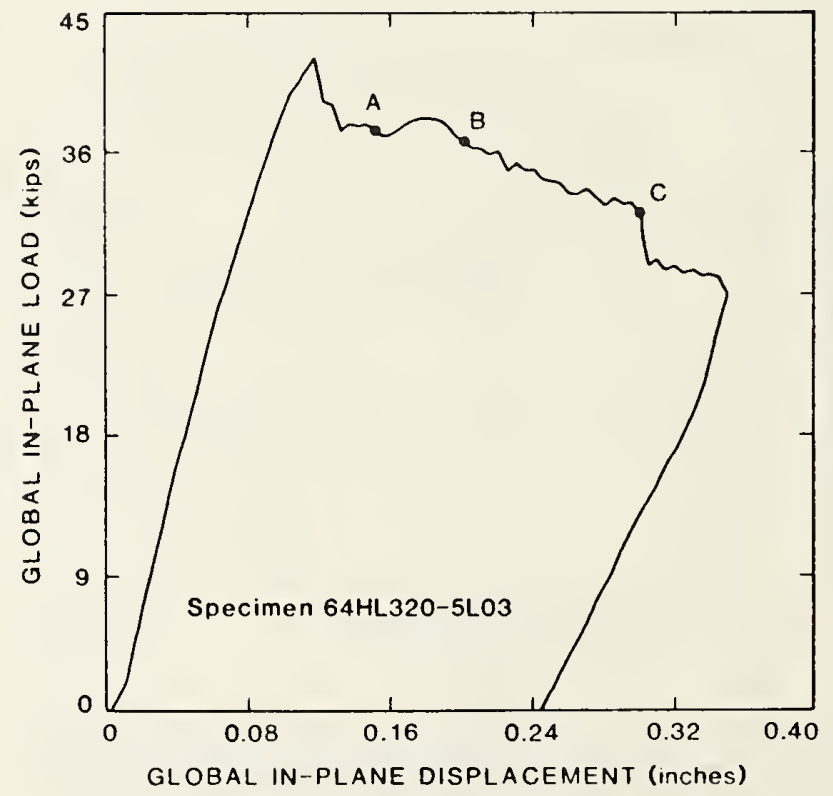

Figure E.3 Crack pattern and load-displacement curve for specimen $64 \mathrm{HL} 320$ 

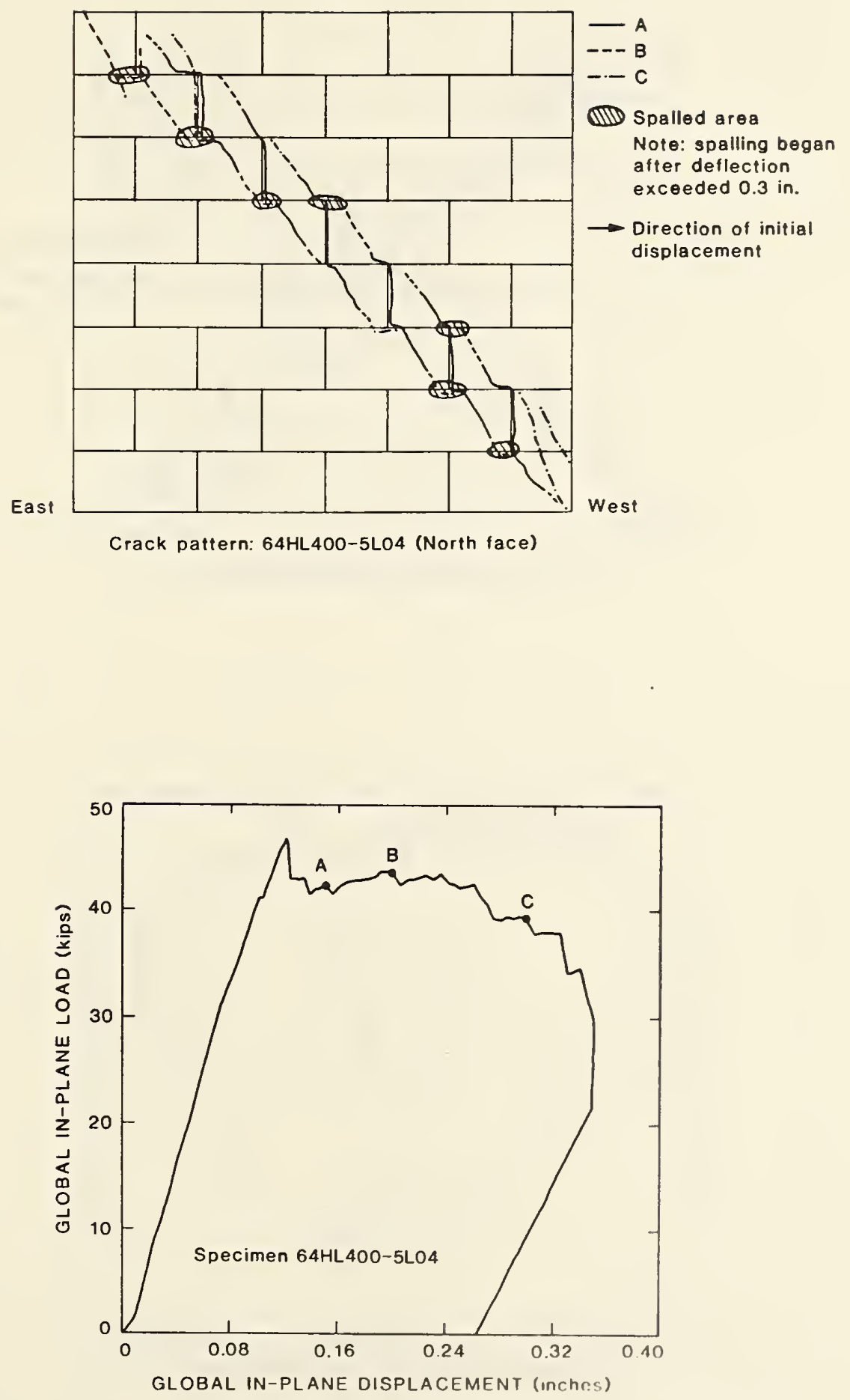

Figure E.4 Crack pattern and load-displacement curve for Specimen $64 \mathrm{HL} 400$

$$
E-5
$$



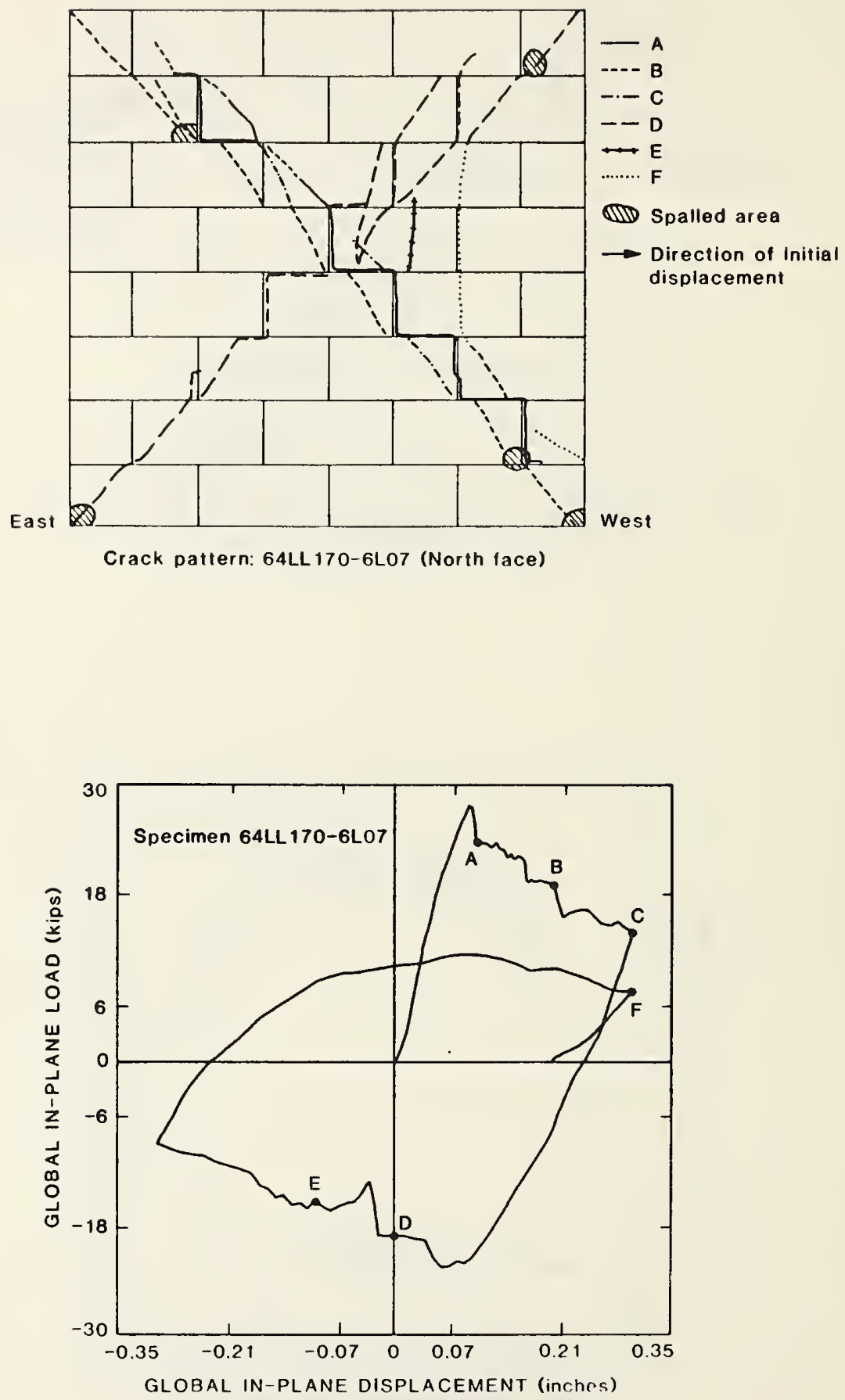

Figure E.5 Crack pattern and load-displacement curve for specimen $64 \mathrm{LL} 170$

$$
\text { E-6 }
$$



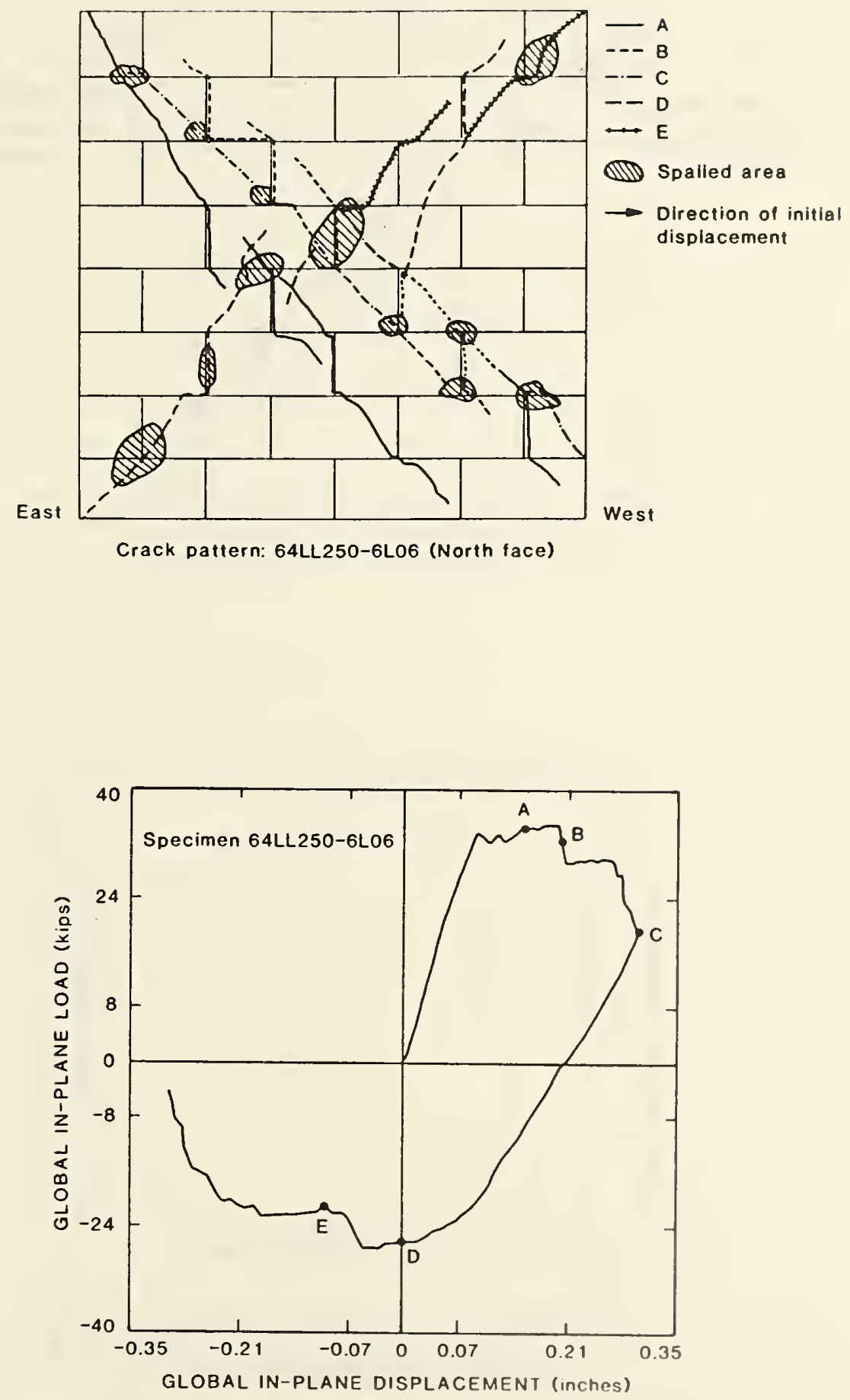

Figure E.6 Crack pattern and load-displacement curve for specimen 64 LL250

$$
E-7
$$



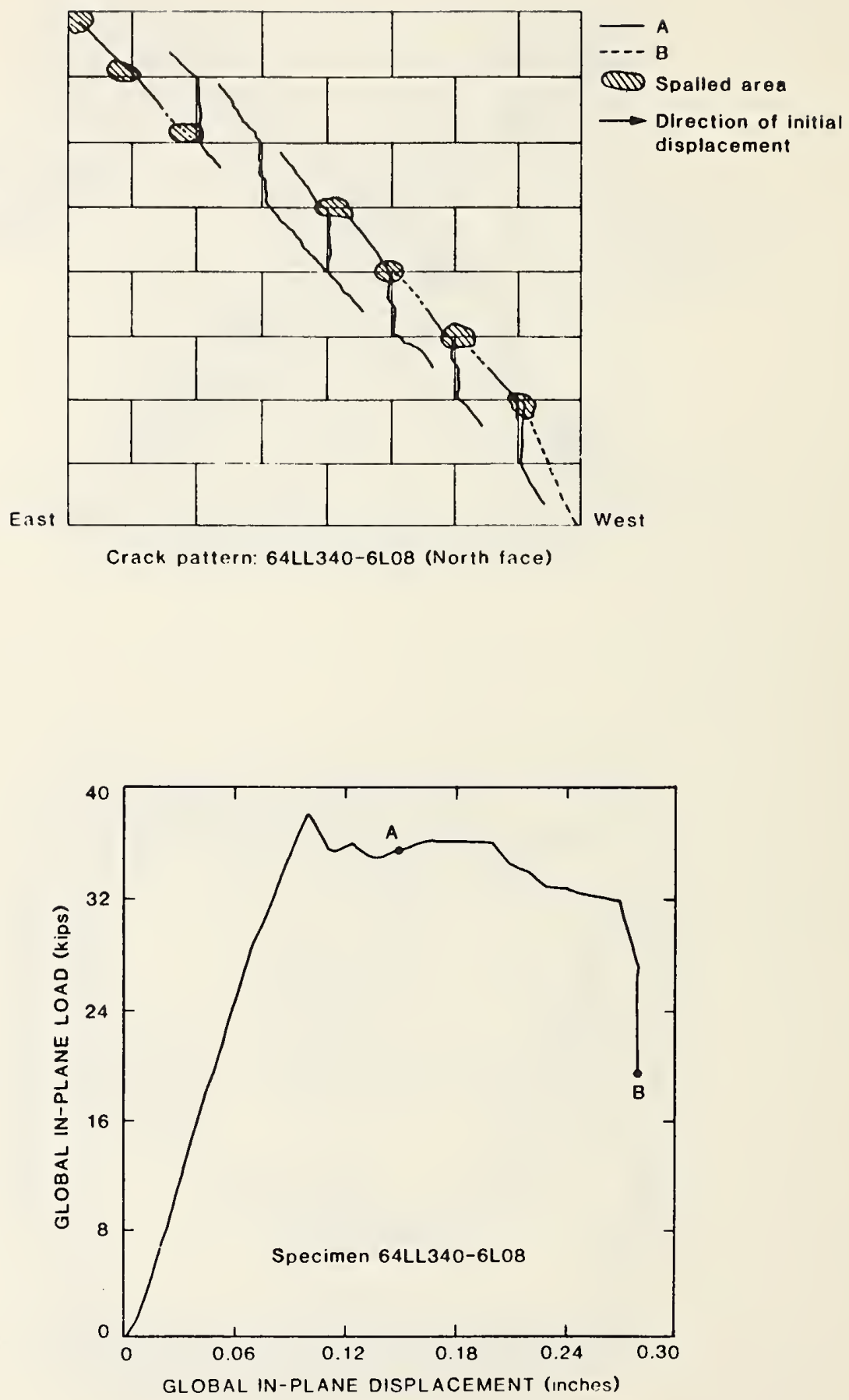

Figure E.7 Crack pattern and load-displacement curve for specimen 64 LL 340 

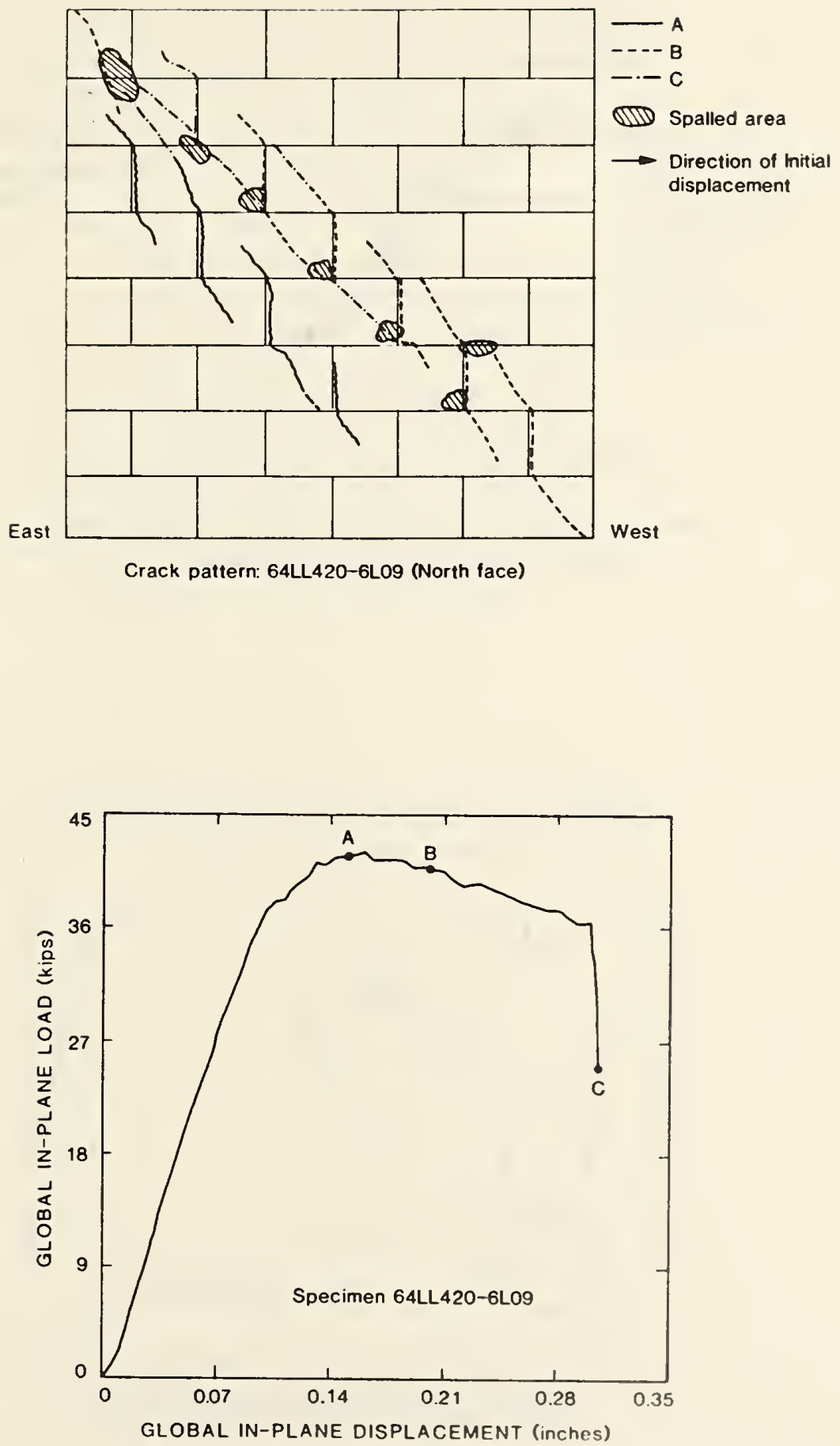

Figure E.8 ' Crack pattern and load-displacement curve for specimen 64LL420

$$
\text { E-9 }
$$



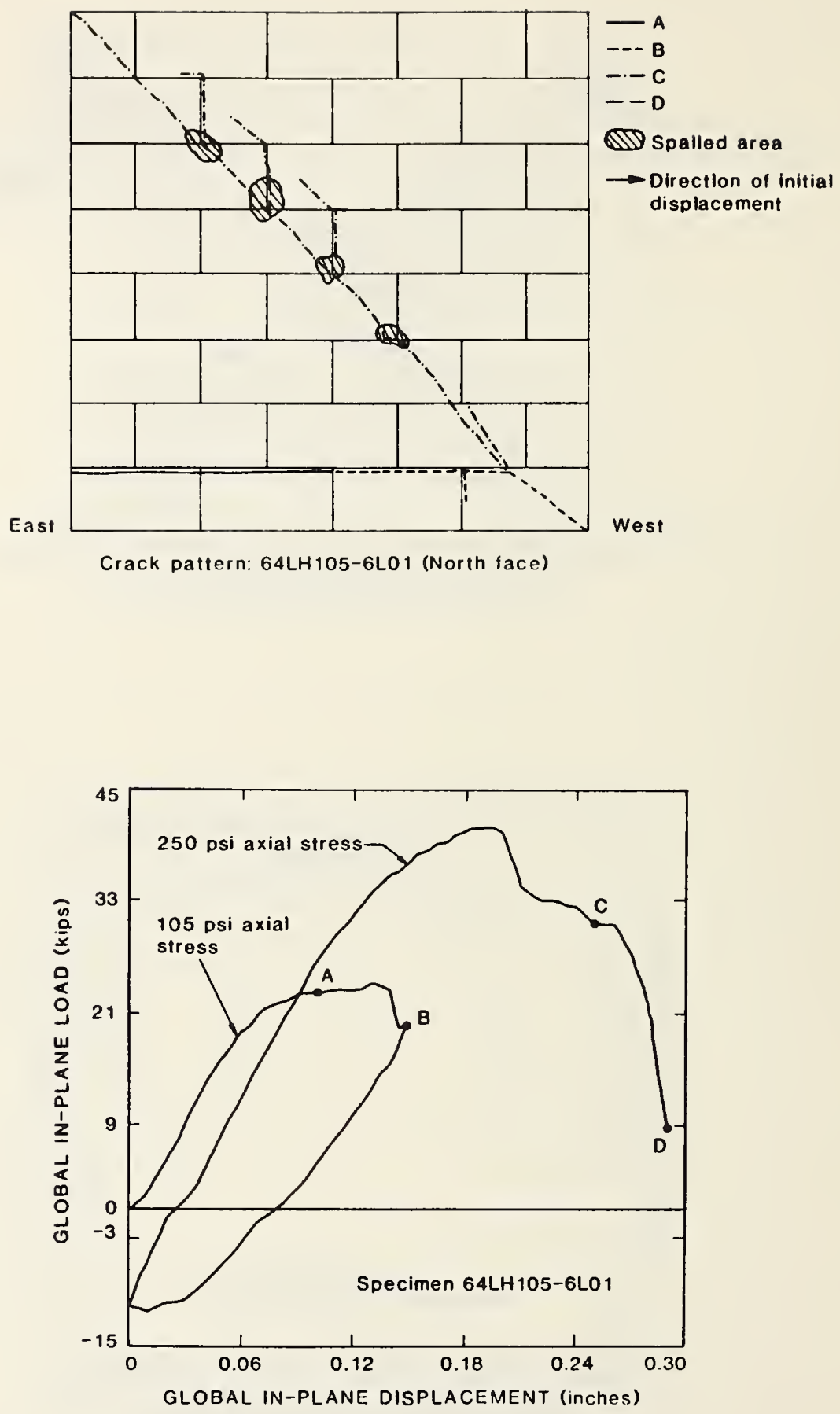

Figure E.9 Crack pattern and load-displacement curve for specimen $64 \mathrm{LH} 105$ 

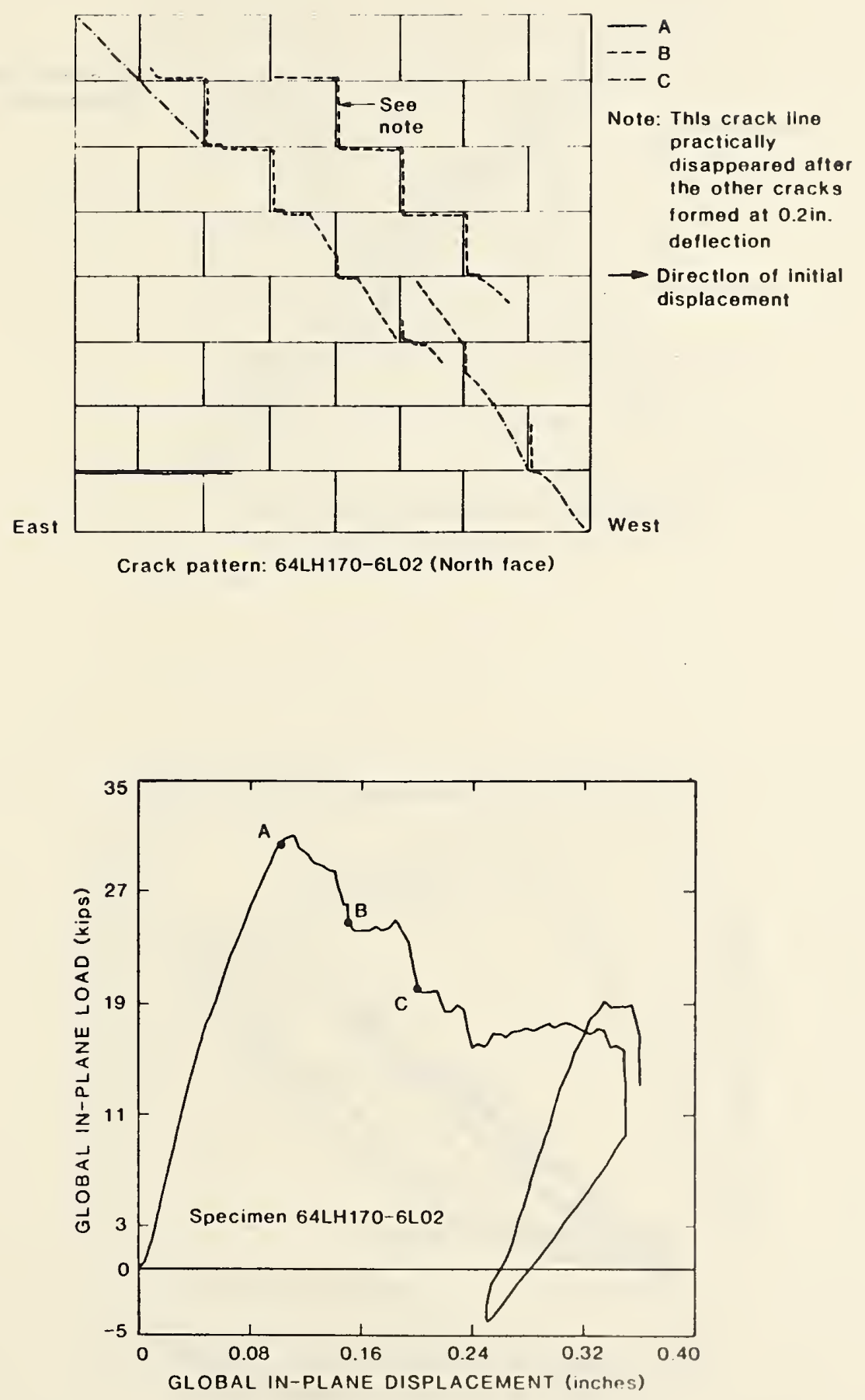

Figure E.10 Crack pattern and load-displacement curve for specimen $64 \mathrm{LH} 170$ 

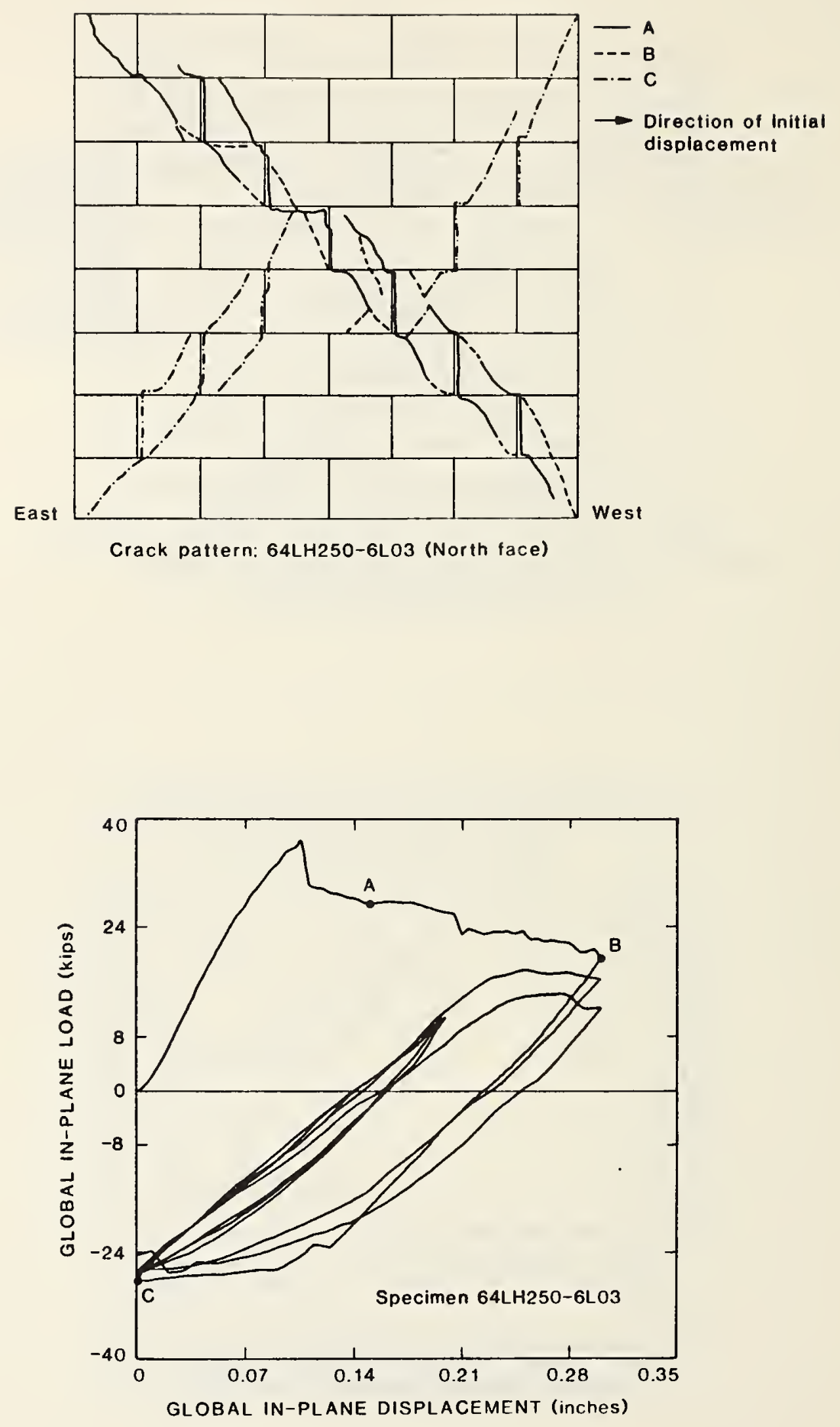

Figure E.11 Crack pattern and load-displacement curve for specimen $64 \mathrm{LH} 250$

$$
\mathrm{E}-12
$$



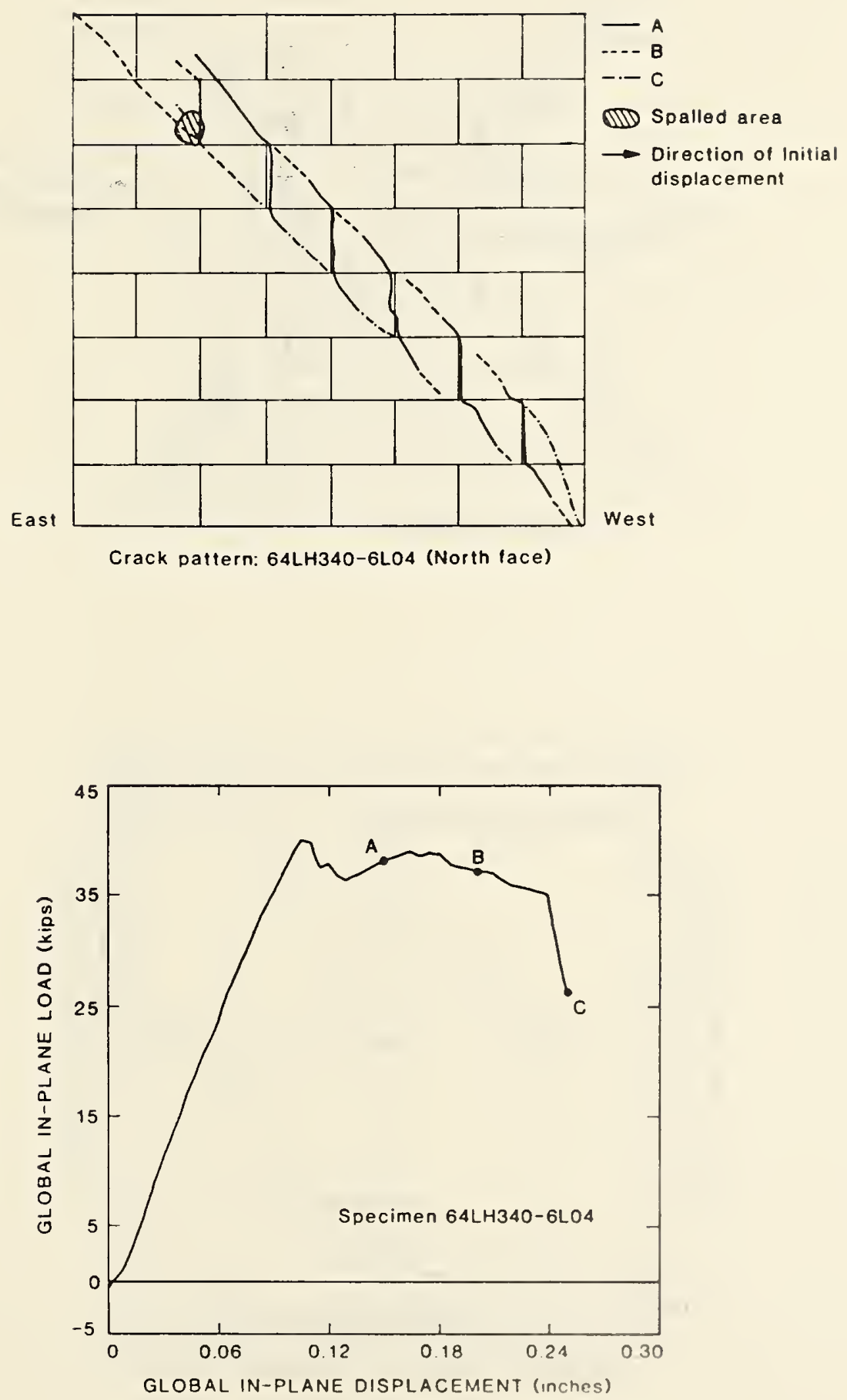

Figure E.12 Crack pattern and load-displacement curve for specimen 64 LH 340

$$
\text { E-13 }
$$



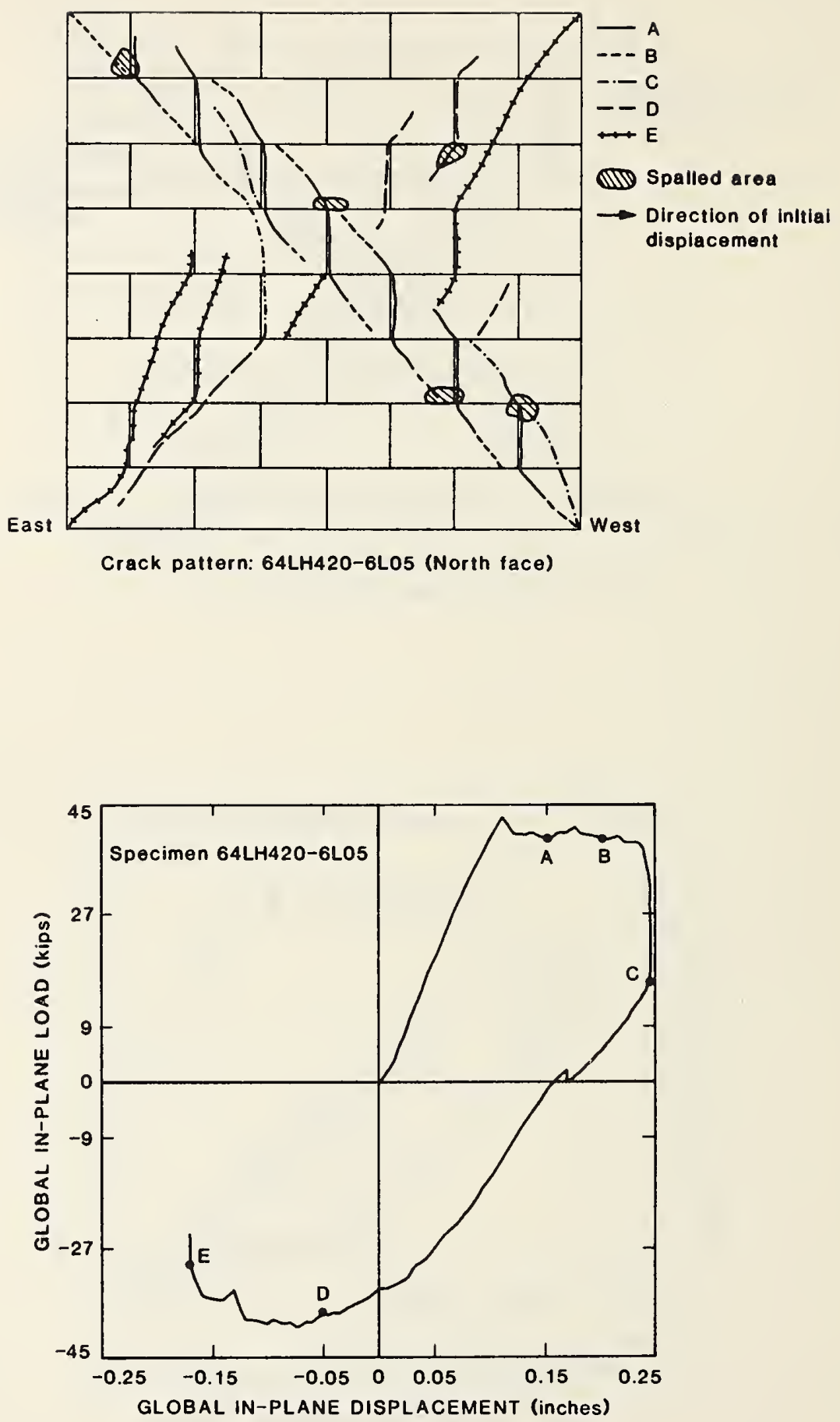

Figure E.13 Crack pattern and load-displacement curve for Specimen $64 \mathrm{LH} 420$

$$
\text { E-14 }
$$




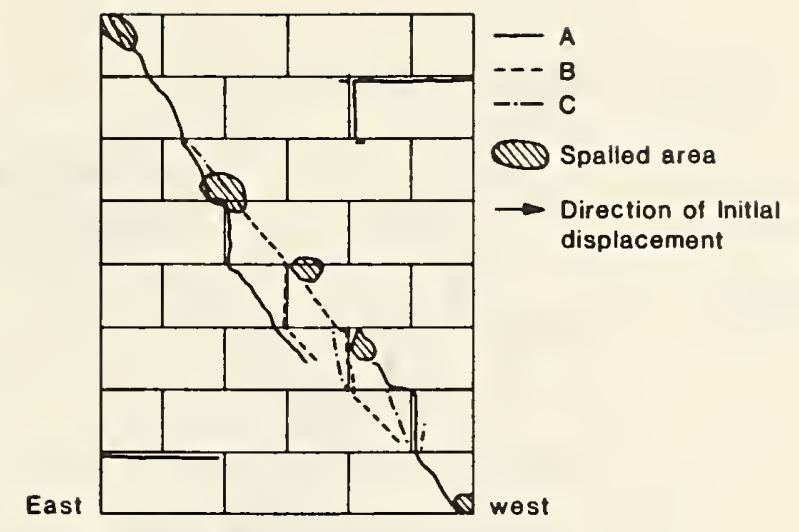

Crack pattern: 48LH170-6L10 (North face)

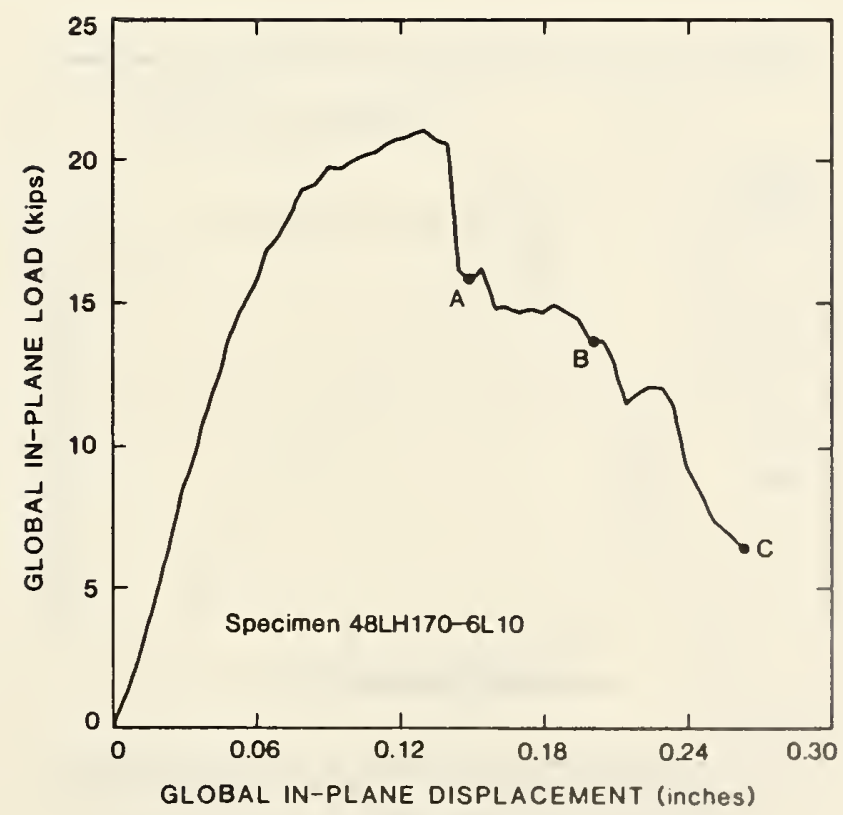

Figure E.14 Crack pattern and load-displacement curve for specimen 48LH170

$$
\text { E-15 }
$$



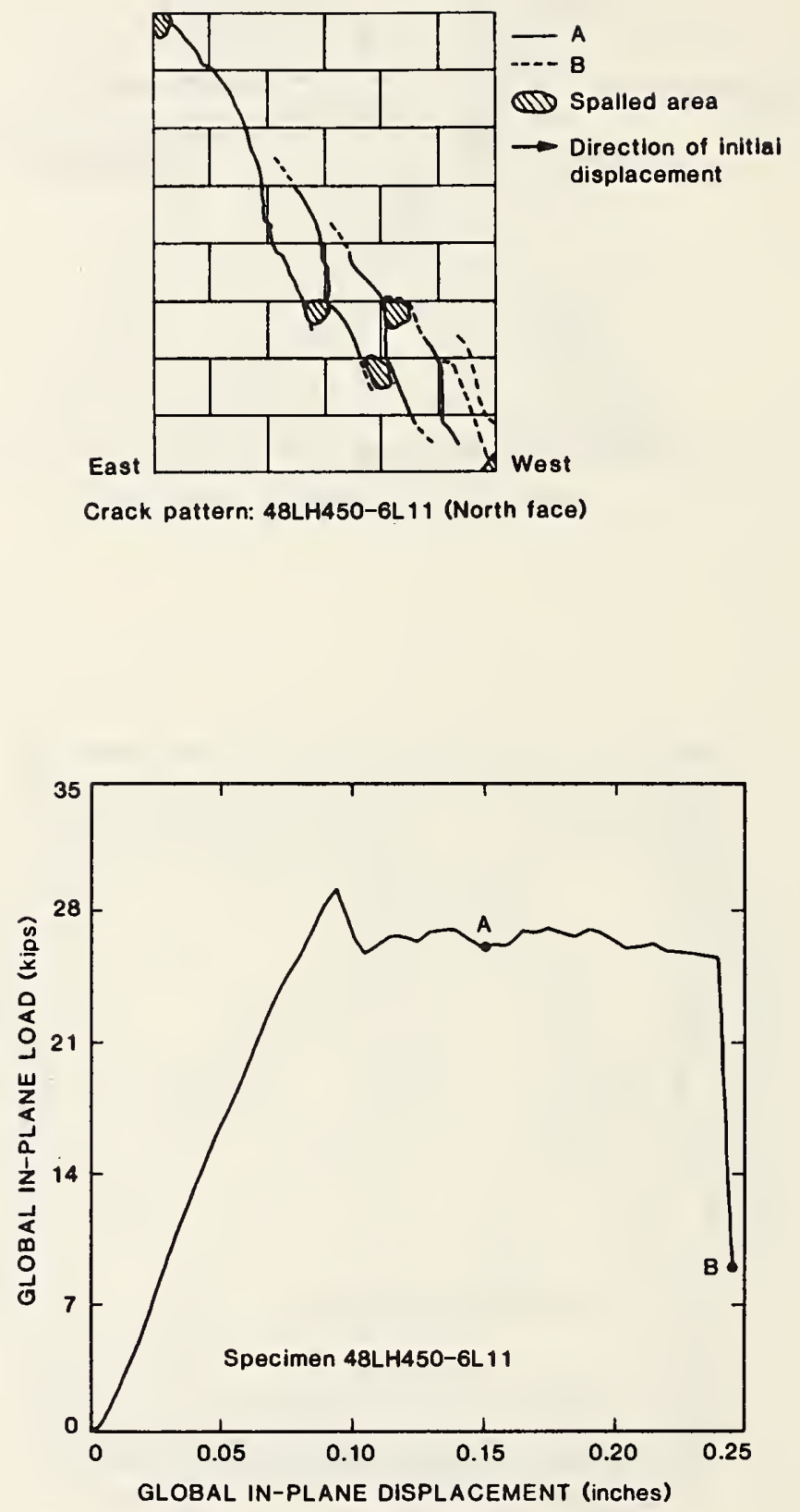

Figure E.15 Crack pattern and load-displacement curve for specimen $48 \mathrm{LH} 450$ 

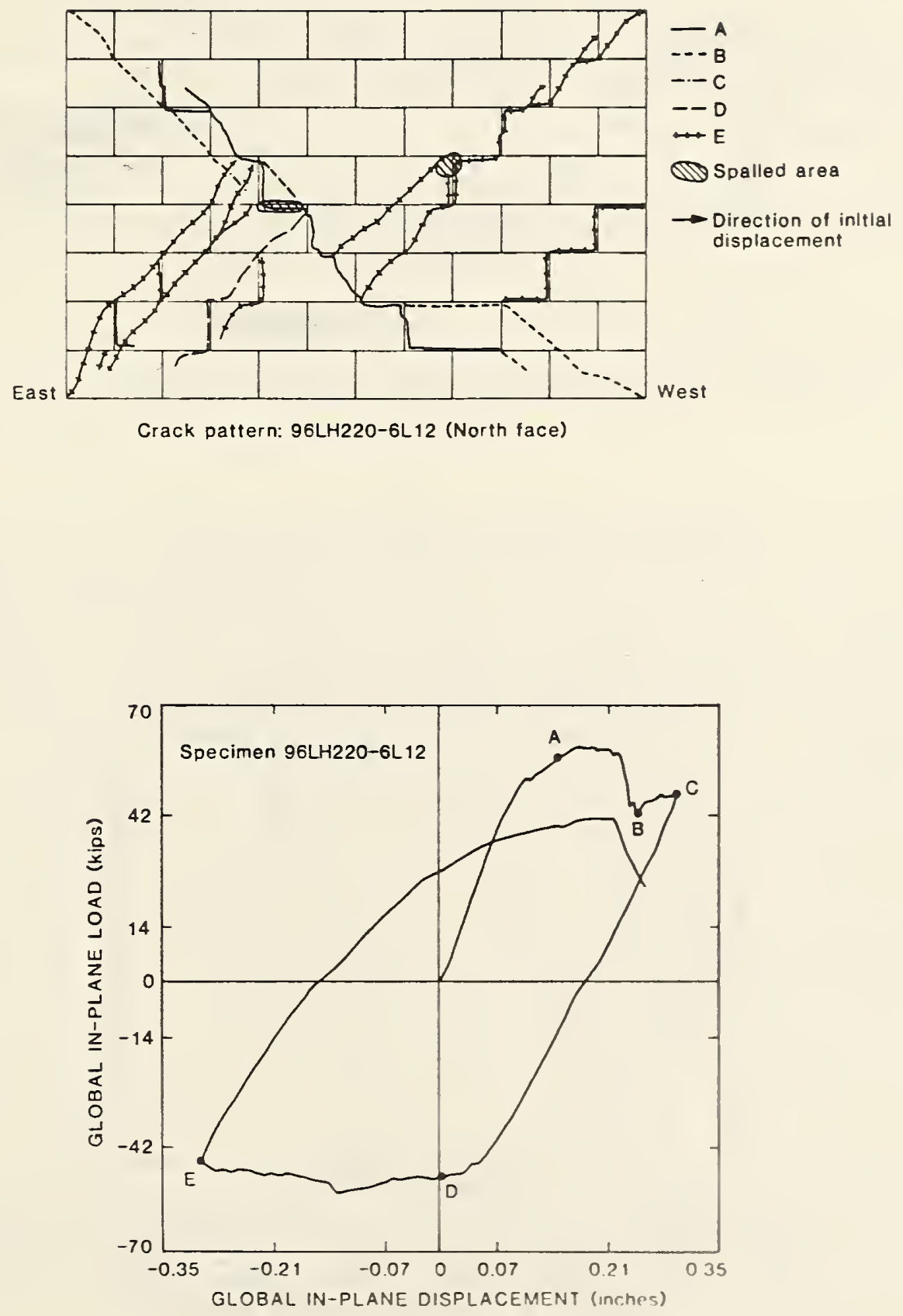

Figure E.16 Crack pattern and load-displacement curve for specimen 96LH220 

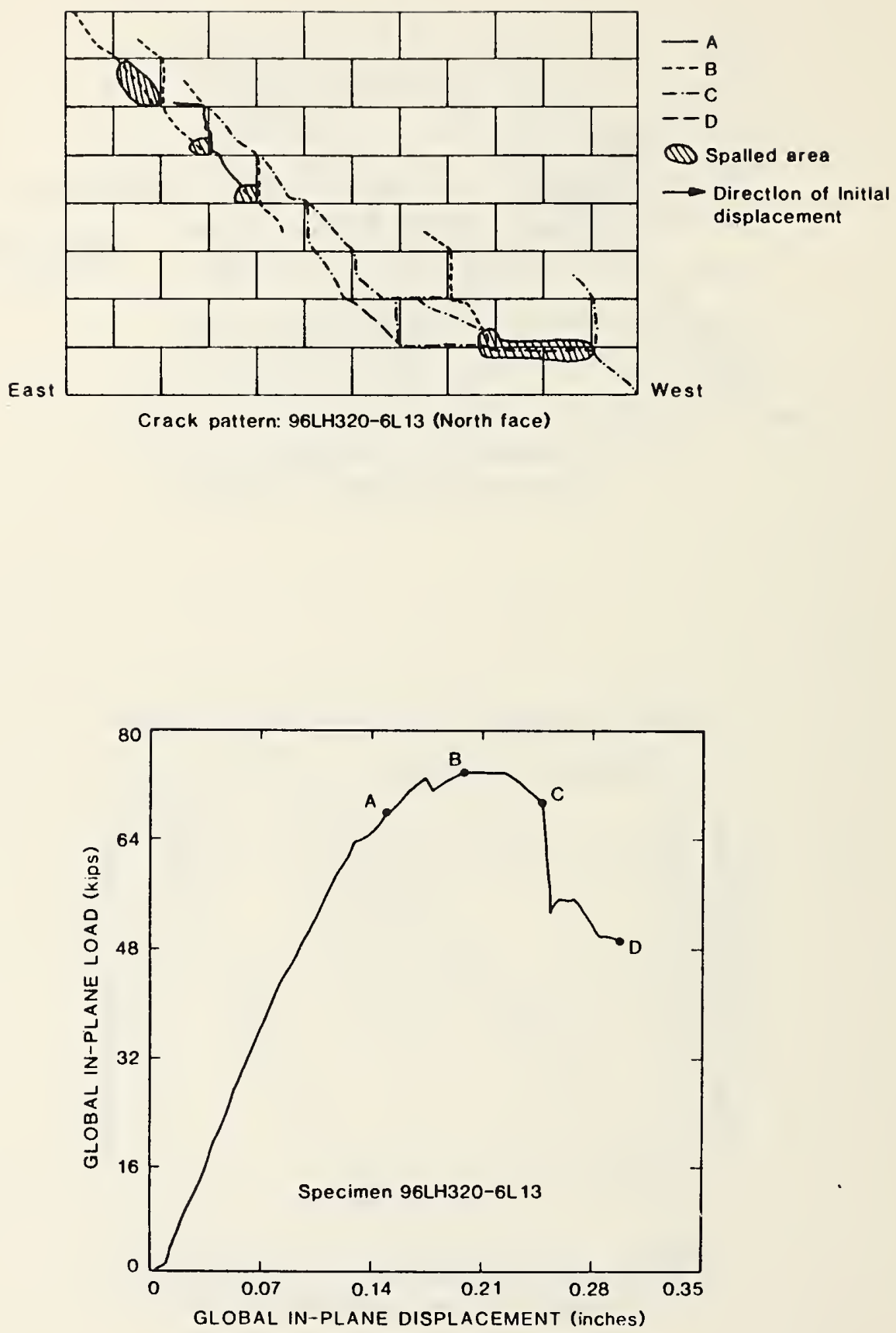

Figure E.17 Crack pattern and load-displacement curve for specimen 96 LH 320 


\begin{tabular}{|c|l|l|c|}
\hline $\begin{array}{c}\text { U.S. OEPT. OF COMM. } \\
\text { BIBLIOGRAPHIC DATA } \\
\text { SHEET (See instructions) }\end{array}$ & $\begin{array}{l}\text { 1. PUBLICATION OR } \\
\text { REPORT NO. }\end{array}$ & 2. Performing Organ. Report No. Publication Date & 3. \\
\hline
\end{tabular}

4. TITLE AND SUBTITLE

Influence of Block and Mortar Strength on Shear Resistance of Concrete Block Masonry Wa1ls

5. $A \cup T H O R(S)$

Kyle Woodward and Frank Rankin

6. PERFORMING ORGANIZATION (If joint or other than NBS, see instructions)

NATIONAL BUREAU OF STANDARDS

U.S. DEPARTMENT OF COMMERCE

GAITHERSBURG, MD 20899

9. SPONSORING ORGANIZATION WAME AND COHPLETE ADDRESS (Street, City, Stote, ZIP)

7. Contract Grant No.

8. Type of Report \& Period Covered

same as 6 above

10. SUPPLEMENTARY NOTES

[] Document describes a computer program; SF-185, FIPS Software Summary, is attached.

11. ABSTRACT (A 200-word or less factual summary of most significant information. If document includes a significant

Data from seventeen masonry wall panel tests are presented. All of the walls are ungrouted, unreinforced, and constructed with hollow concrete block. The primary variables in the test series are block and mortar strength, but the applied vertical compressive stress and wall aspect ratio are also varied. The walls are built with either a "high" strength block or a "low" strength block having gross area unit strengths of approximately $1800 \mathrm{psi}$ and $1300 \mathrm{psi}$, respectively. The mortar is either a Type S or Type N mortar and, for convenience, is identified as high and low strength mortar, respectively. Thirteen of the wall panels have nominal dimensions of 64 in. long $x 64$ in. high $x 8$ in. thick, but two of the walls are $96 \mathrm{in.}$ long and the remaining two walls are 48 in. 1 long. The applied net area vertical compressive stress is constant for a given test, but varies between $100 \mathrm{psi}$ and $400 \mathrm{psi}$ for tests in the series reported herein. The walls are tested in the NBS Tri-directional Test Facility using fixed-ended boundary conditions at the top and bottom of the walls. A vertical compressive stress is applied and maintained while in-plane lateral displacements are imposed at the top of the wall. The test results indicate that for the lower levels of vertical compressive stress the effect of block and mortar strength on maximum in-plane shear resistance is relatively small, while with increased vertical compressive stress the effect of increasing maceriat strength becomes significant and results in increased shear resistance. There is an interaction between the block and mortar strength such that the wall behavior may not be adequately predicted by considering the two strengths independently.

12. KEY WORDS (Six to twelve entries; alphabetical order; capitalize only proper names; and separate ker words ty semicolons: Axial stress; block; concrete block; failure; masonry; mortar; shear; strength.

13. AVAILABILITY

区즈 Unlimited

$\square$ For Official Distribution. Do Not Release to NTIS

[- Order From Superintendent of Documents, U.S. Government Printing Office, Washington, DC 20402.

[XX Order From National Technical Information Service (NTIS). Springfield, VA 22161

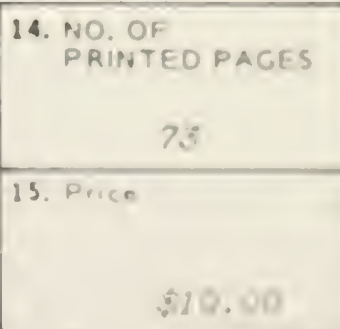





$\therefore \quad \therefore$ 